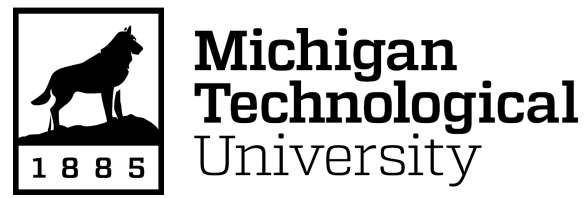

Michigan Technological University Digital Commons @ Michigan Tech

Dissertations, Master's Theses and Master's Reports

2019

\title{
A CRITICAL REVIEW OF CURRENT APPROACHES AND PRACTICES IN COMPUTING ETHICS EDUCATION
}

Sophia Farquhar

Michigan Technological University, sgfarquh@mtu.edu

Copyright 2019 Sophia Farquhar

\section{Recommended Citation}

Farquhar, Sophia, "A CRITICAL REVIEW OF CURRENT APPROACHES AND PRACTICES IN COMPUTING ETHICS EDUCATION", Open Access Master's Report, Michigan Technological University, 2019.

https://doi.org/10.37099/mtu.dc.etdr/793

Follow this and additional works at: https://digitalcommons.mtu.edu/etdr

Part of the Applied Ethics Commons, Graphics and Human Computer Interfaces Commons, Other Computer Sciences Commons, and the Quantitative, Qualitative, Comparative, and Historical Methodologies Commons 


\title{
A CRITICAL REVIEW OF CURRENT APPROACHES AND PRACTICES IN COMPUTING ETHICS EDUCATION
}

By

\author{
Sophia Farquhar
}

\begin{abstract}
A REPORT
Submitted in partial fulfillment of the requirements for the degree of MASTER OF SCIENCE

In Computer Science
\end{abstract}

\section{MICHIGAN TECHNOLOGICAL UNIVERSITY} 2019

(C) 2019 Sophia G. Farquhar 
This report has been approved in partial fulfillment of the requirements for the Degree of MASTER OF SCIENCE in Computer Science. Department of Computer Science

Report Advisor:

Committee Member:

Committee Member:

Department Chair:
Charles Wallace

Alexandra Morrison

Linda Ott

Zhenlin Wang 
To My Family. Thanks for Everything. 


\begin{abstract}
Recent scandals caused by the results of negligent, malicious, or shortsighted software development practices highlight the need for software developers to consider the ethical implications of their work. Computing ethics has historically been a marginalized area within computing disciplines, so educators in these disciplines do not have a common background for teaching the topic. Computing ethics education, although often a required part of coursework, can vary widely in the method of implementation from university to university.

In this report I summarize the insights I gained from interviewing four educators from three different institutions on their pedagogical approaches to computing ethics. I found there to be a few terms that had very different contextual meanings for the different educators. "Case study" and "group discussion" in particular are two terms with a diversity of purposes, methods of use, and literal meanings among the interviewees. I summarize three different methods of extending engineering ethics education beyond one ethics course. I review software tools designed to assist with ethical reflection or to encourage thoughtful discussion, and I make an argument for which elements of those tools seemed to assist in thoughtful consideration and discussion. Finally, I propose a sketch of an "ethically sensitive" software design, and consider the implications of applying software to ethical reflection. I conclude with some areas for future study that could benefit the development of a software intervention for ethics, as well as the field of ethics education in general.
\end{abstract}




\section{Table of Contents}

Introduction_- 7

Engineering Ethics Education 12

Ethics Education At MTU_12

My Interactions with Students in an Ethics Course. 17

Interviews with Educators. 19

Interview With Dr. Ott. 21

Interview with Dr. Morrison. 22

Interview with Dr. Wolf._.27

Interview with Dr. Kirkpatrick. 29

Analysis of the Interviews. 30

Class Discussion. 32

Case Study. 39

Suggestions for Future Research. 47

Distributed Ethics Education_. 48

Harvard-Embedded EthiCS. 50

JMU-Ethical Reasoning in Action. 54

MTU-Proposed Project._60

Curent Software Solutions. 62

Introducing Agora. 63

Learning From Agora. 66

Introducing ConsiderIt. 72 
Learning From ConsiderIt. 73

Future Considerations. 76

Future Research. 76

References. 80

Appendices.

Philosophy Background._ 88

Traditional Ethical Theories. 88

Philosophy of Technology. 91

The Ethical Cycle_ 95

Interview with Mike Kirkpatrick._98

Interview with Alexandra Morrison I._106

Interview with Alexandra Morrison II. 113

Interview with Linda Ott. 122

Interview with Marty Wolf._135 


\section{A Critical Review Of Current Approaches And Practices In Computing Ethics Education}

Software is used in everything from phone games to medical devices, and from social media to flight control software. As software uses expand, so too does the need for ethical consideration of the design and use of this software. The recent negative news coverage of Facebook, Google and Twitter, among many other large tech companies has made obvious to the public, and consequently to the companies themselves, that the need to take ethics into consideration is urgent $[42,23]$. Some companies are founding ethics councils and boards, or pushing for government regulation, but many companies are realizing that the change can't only come from an outside body. Anne Wojcicki of 23andMe, a DNA testing service, recognized this need "I think it has to be our management and leaders who have to add this to our skill set, rather than just hire one person to determine this" [41]. This idea by some of the tech companies, that the people who have the technical and business skills that an organization needs are now the people who should also have the ethical skills an organization needs did no go unnoticed by the universities that are educating the next generation of these technical leaders. The public and the companies' recent understanding of the importance of ethics is also helping to highlight to those same groups the importance of ethics education.

The universities are motivated extrinsically by this increasing sense societally that ethics is important for students, especially technical students. This is reflected in many university-wide goals which often include some form of ethical consideration in the list of student learning goals ${ }^{1}$

${ }^{1}$ Michigan Technological University has 8 University Learning Goals for students. Goal 8 is the Social Responsibility and Ethical Reasoning Goal stating that "Students will be able to identify and address conflicting ethical values and develop a sense of responsibility for the broad impacts of individual actions and social institutions. They will understand their role as citizens and their responsibility to work with others in promoting quality of life and a sustainable society." 
[26]. Universities, and specific colleges within universities, are also motivated intrinsically by accreditation standards from accreditation bodies like the Accreditation Board for Engineering and Technology (ABET), or from curriculum recommendations from professional organizations like the Association of Computing Machinery (ACM). Although ethics has been a required topic in the computing curriculum of most computing programs for many years, there is still a concern that graduates may be under equipped to apply the ethical skills they learn to a complex reality. There are some fundamental challenges to ethics education, especially in a computing ethics contexts. The first challenges is that ethics is complex, and often times very challenging, and some philosophers spend their entire careers studying ethics. So being able to teach ethics in a way students can understand more easily is a challenge. Additionally computing ethics has to be by nature interdisciplinary. Combining ethics pedagogy expertise with technical expertise of engineering faculty would help make computing ethics education current and continually improving. But interdisciplinary work is challenging. The nature of academic work is to spend years to build expertise in a particular field. The expectation is then to stay current in that particular field, and for many it includes conducting research. This specialization, along with teaching, is a full time job, literally, for university faculty members. Interdisciplinary work would then involve one expert taking time to learn about another academic area, which takes time away from their specialization. For computing ethics to become an interdisciplinary project it would mean that either the computer science faculty would have to take time to learn ethics and philosophy, or the philosophers would have to take time to learn computer science. Both of these options are challenging, and in the current university system there is not a lot of incentive 
to do this. ${ }^{2}$ Additionally, if this interdisciplinary work were to then be taught to students, it can come across as a confusing context switch for students who might not understand why information from another academic area applies. On top of the challenges all interdisciplinary work faces, interdisciplinary work between humanities and STEM departments, especially at a STEM specific institution faces additional barriers. The silo-ed department structure, requiring courses and faculty expertise to be classified as either humanities or computer science, and additional student resistance make this work even more challenging.

Seeking to better understand the challenges surrounding computing ethics education, and understand the context in which it is currently taught, I conducted four interviews with professors from 3 different universities. I analyze the transcripts of these interviews using qualitative methods, and use the results of the analysis to compare the instructors different approaches to their ethics courses. I then critique two current approaches to software assistance for ethics education and give suggestions for the design of future software tools. The critique and suggestions are informed by the analysis of the instructors interviews.

Originally this research project started to design a software to aid in ethics education, which was part of a larger project that considered engineering ethics education at Michigan Technological University (MTU) in a broader sense. One of the members of the larger project,

${ }^{2}$ To understand the challenges to interdisciplinary, we cannot look just at the faculty and whether they are willing to take the personal initiative to do it. We must also the university system that the faculty work in and the ways in which it discourages this work. In The challenges of The challenges of interdisciplinarity Brewer explains the importance of interdisciplinary work in environmental problems, and som of the challenges that surround this work. "Universities are arranged around scholarly disciplines. Environmental problems are not. Universities favor individual achievement. Environmental problems demand collaboration, often of a most unexpected kind. As urgent as environ- mental problems are, conventional institutional arrangements to understand and deal with them appear inadequate or lacking" 
Dr. Morrison, teaches an Engineering Ethics course at MTU and her course has included Computer Science and Software Engineering majors, as well as many other types of engineering majors. She wanted her students to practice thinking ethically throughout the design process, instead of focusing on the functionality of the product. This interest in students not "solving" ethical problems, but working on them overtime, interacting on them, led her to start teaching ethics using something called the ethical cycle. (For more information see Ethical Cycle in the Appendix). The same philosophers who came up with the ethical cycle, also designed a software program, Agora, to help teach ethics using the ethical cycle. Dr.Morrison was interested in using an ethics educational software as a way to be able to reach more students, possibly even students who are not in her Engineering Ethics course. She was also interested in software as a way to more quickly train the Enterprise students she was working with to integrate ethical reasoning and critical self-reflection into their design processes. Dr. Morrison was initially very interested in this Agora software, but found the reality of this program to be disappointing, and not something that would be useable for her course. So we started the design of phase of development for a new ethics education software by considering the currently available software solutions, which included Agora, thinking about what was done well and what needed improving. We soon realized to avoid falling into the same traps as previous software programs, we needed to consider the problem, the users, and the philosophy and ethics we wanted to teach in a deeper way, rather than consider this project as an update to the software this was intended to replace. We realized if we wanted any software intervention to be effective, we needed to thoughtfully consider ethics education pedagogy, consider how the courses are currently taught at MTU and more broadly. We would need to consider what we can learn from software that 
exists for thoughtful discussion and deliberation, thinking beyond software that exists for ethics education. Finally we needed to make sure that we practiced what we preached. We realized that we needed to thoughtfully consider the effects a software intervention could have on the students who would use it and on their education. We needed to make sure that the software we were proposing was itself ethical, because technologies shape users habits overtime, and therefore are not neutral. We realized that we needed to make sure that the software itself embodied the ethical scripts that we were encouraging the students who used it to consider. (For more information about embodiment and technological scripts, see Philosophy Background in the Appendix) In the end this report moved away from a focus on the UI of a new software as we realized that we were making assumptions about its use, and jumping ahead in the design process. The focus then moved to considering the educational situation this software would be situated within, and to question the ethical implication of some of the user interactions we had designed without this consideration.

My passion for and inclusion in a project of this nature stems from my situation as a STEM student with an interest in the humanities. I have a B.S. in Computer Science with a minor in Ethics and Philosophy. During my time as a student I have taken both the Computing Ethics Course and as the Engineering Ethics course, so I have some experience from a student perspective in both the courses. Additionally this is my second semester grading papers for the Computing Ethics course, giving me a wider experience with the student perspective in this course. It also allows me to see first hand what kind of misconceptions the educators I spoke to were talking about and also for me to notice for myself what types of misconceptions persist from semester to semester. 


\section{Engineering Ethics Education}

In order to understand how a software could be used in Engineering Ethics Education, a detailed understanding of the current state of Engineering Ethics Education is required. In this section I give background of the Engineering Ethics Courses at MTU. I follow this by interview with the instructor of the Computing Ethics course at MTU, Linda Ott, as well as an interview with the instructor for the Engineering Ethics course at MTU, Alexandra Morrison. This is followed by interviews with two faculty who teach a similar Computing Ethics course, similar to Ott's at institutions outside of MTU: Mike Kirkpatrick from James Madison University (JMU), and Marty Wolf from Bemidji State University. Then, finally, I consider three solutions that extend ethics education beyond one course. This consideration leads to a better understanding of the current engineering ethics education process. By better considering this background a more thoughtful approach can be taken to the design of a software solution that would lead to more realistic and less idealistic software design choices.

\section{Ethics Education At MTU}

MTU is the primary setting for this project though by considering other universities through interviews and literature it is our hope the the recommendations or ultimate software intervention will be usable beyond MTU. At MTU there are two ethics courses that focus on engineering ethics. There is the ethics course specifically for Computer Science and Software Engineering majors which is offered by the Computer Science department taught by a member of their faculty. There is also the Engineering Ethics Course which has a more general scope, so as 
to be applicable to all types of engineering, and is offered by the Humanities department, taught by a Humanities faculty member. ${ }^{3}$

MTU is primarily a STEM university and as such many of the academic departments have ethics education requirements for students which can be matched to ABET or similar accreditation requirements. ABET is an organization offering accreditation to programs in STEM disciplines as a way of guaranteeing the quality of the program, to prospective students, other institutions, and to employers. Both the Computer Science and the Software Engineering programs at MTU are seeking ABET accreditation, and so are abiding by ABET's standards and recommendations.

ABET does specifically mandate what kinds of courses should be offered, leaving the specifics up to the University, and instead defines "Student Outcomes" which are capabilities that graduates of these programs should have. ABET accreditation then focuses on the systems in place at the programs that are seeking accreditation. These systems are a way to measure and ensure that student progress is being made for students to meet the "Student Outcomes". So the ABET requirements do not say much about the details of the technical courses, or the ethics component. For the ABET engineering criteria, ethics education is mentioned in Student Outcome (f): students should have "an understanding of professional and ethical responsibility"[2]. So for MTU's Software Engineering program, the Computing Ethics Course

3 There are other ethics courses taught at MTU but they are not focused on engineering, either software or otherwise. Elements of this report will be applicable to these other ethics courses, but the focus and purpose of the Computing Ethics and Engineering Ethics courses differs from that of the other ethics courses. The other ethics courses focus more on the frameworks and theories, whereas these other two more technical ethics courses consider the theories but in the context of a larger purpose which is to help engineers bring ethics into their daily work. 
is designed to address this requirement. For many of the other engineering programs there is not an ethics course specific to their degree program, and instead they are taught ethics as a module set into another engineering course for example the Engineering 1101 course which is a requirement for most engineering programs is an introductory engineering course that covers many basic engineering skills and also has an ethics lesson. The ABET student outcomes for Computing Programs is similar, stating students must have "An understanding or professional, ethical, legal, security and social issues and responsibilities" [1]. The Computing Ethics course also helps address the ABET requirement for Computing Programs as well. Both the ABET Student Outcomes also lists another required outcome for students; they must be able to consider the local and global impact of computing or engineering on individuals, organizations and society $[1,2]$. Both the Computing Ethics and Engineering Ethics courses also help met this second ABET Student Outcome. An important part of ethical consideration of technology is a consideration of the impacts, both intended and unintended, that the technology will have on local and global society. And so through the ethics courses, students are also making progress toward this second student outcome.

In addition to ABET requirements, many programs are also designed around recommendations from the related professional organization, so for Computer Sciences and Software Engineering the related organizations would be the Institute for Electrical \& Electronics Engineers (IEEE) and the ACM. The two professional organizations publish documents for each computer related program, detailing specific recommendations for that program. These go into significantly greater depth than the ABET documents do. The document details how many course hours should be devoted to particular topics, both technical computing 
topics and ethical and professional responsibility topics. They also make specific recommendations of topics that students should be familiar with, for example detailing which ethical issues should be considered along with the technical aspects of computer security. Along with the specific details the document also starts with a broader description of what ethics and professional education component should look like in a broader sense. "The material in this familiarity area is best covered through a combination of one required course along with short modules in other courses. On the one hand, some units [...] (in particular, Social Context, Analytical Tools, Professional Ethics, and Intellectual Property) do not readily lend themselves to being covered in other traditional courses. Without a standalone course, it is difficult to cover these topics appropriately. On the other hand, if ethical and social considerations are covered only in the standalone course and not "in context," it will reinforce the false notion that technical processes are void of these other relevant issues. Because of this broad relevance, it is important that several traditional courses include modules with case studies that analyze the ethical, legal, social and professional considerations in the context of the technical subject matter of the course" [20]. These recommendations bring up several of the issues and recommendations that came out of the interviews with the professors.

Beyond ABET requirements, MTU also has a few University Learning goals which encourage ethics education. The first is the Global Literacy goal, which states students should be able to consider issues from multiple, diverse perspectives while also understanding the interconnected and complex nature of the issue. The Global Literacy goal also states students should be able to consider how their actions will affect the world, the people in it and also the environment. The second related goal is the Social Responsibility and Ethical Reasoning goal, 
which states students should develop a sense of responsibility, and the ability to deal with a situation containing conflicting ethical values. The third university goal fulfilled by the ethics courses is the communication goal, stating students have the ability to communicate effectively both written and orally. Oral communication is something Alexandra Morrison, the instructor of the Engineering Ethics course, mentions as being a challenge for her students: "For an ME [Mechanical Engineer] this would be a tough course, they're asked to think critically and then articulate their arguments in their own words in front of 79 other students. My brother, who is a mechanical engineer, would have been nervous in my class. He used to insist that since he was mechanical engineer he didn't have concern himself with oral argumentation. After being in the workforce over a decade he's changed his tune of course" [27, 28]. For a lot of students it is challenging to formulate an argument then express it verbally, and this skill is not emphasized in many classes other than the ethics courses.

MTU is a STEM focused university, and so in addition to the standard challenges of ethics education, there are some additional challenges faced by STEM universities. These challenges include the small number of ethics courses offered, the lack of formal ethics and philosophy background the STEM instructors have, and finally there is no structured system to bring humanities into the STEM courses. The heavy focus on STEM at universities like MTU tends to be paired with the assumption that the humanities is entirely separate from the technical STEM courses.

Despite the fact that the ABET accreditation standards require students to have an understanding of ethics, MTU offers a very limited number of ethics courses. The humanities department recently raised the caps on the classes, resulting in larger class sizes, but the overall 
number of seats in the courses is still only about 120 per year [30]. Allowing an increased number of students to take a formal ethics course solves one challenge, but it creates another for the faculty teaching these courses. They now have to teach the course in a way that provides the same level of instruction to a larger group. For students who don't take a formal ethics course their only exposure to ethics is through a course with an ethical module embedded within it. These ethical modules can vary greatly because they can be designed and taught by STEM faculty with vastly different backgrounds. The lack of formal training in ethics received by the STEM faculty means that the ethics modules that serve as the only required interaction with ethics that is required for engineers can be taught by someone with a varying degree of expertise in the area. The ABET requirements leave open the opportunity for some well implemented dispersed engineering ethics programs to count for accreditation requirements, by not requiring a particular course. Unfortunately, it also leaves open the possibility of a short module of coverage in a single course to be considered sufficient.

My Interactions with Students in an Ethics Course. As I mentioned in the introduction, I am a grader for the Computing Ethics course, and from my experiences as a grader and though interactions with colleagues in a professional setting, I have noticed mistakes that are similar to those mentioned by Morrison and Ott later on in this report.

One common misconception I've seen in student essays that students refer to a scientists' work and "world" in a professional sense, as separated from ethics, while leaving it to the consumer to bear the burden of responsibility for deciding how to implement the science. This is a concerning approach, because it removes their ultimate professional role from any ethical 
responsibility. It also echos Morrison's concern with the common misconception that technology is a neutral tool.

There is also often confusion about what it means for a business to have an ethical issue. It is a common belief, in the United States, that a business should be primarily focused on making money, because they have a responsibility to shareholders to do so. Many corporate decisions are made based on the belief by directors that corporate law requires them to make legal decisions that increase shareholder value [37]. Oftentimes the justification for making an ethical decision that doesn't immediately benefit profits is that the decision helps improve the corporate image, which increases profits for shareholders long term. Students can then get confused about a businesses ethical responsibility, and further confused when asked to consider a case study that involves a businesses' actions. They are confused about whether a business has an ethical responsibility beyond making money, if business' have a responsibility to shareholders, isn't it ethical to choose actions which fulfill this responsibility? This confusion is understandable, especially when directors of those business are making business decisions based on being able to legally justify it as necessary for shareholder value. This kind of thinking can limit the discussion to considering a business fiduciary responsibility, instead of considering a wider societal impact that a business decisions might have, and who the stakeholders are, beyond just the shareholders.

Additionally there is some confusion about what it means for something to be ethical and for something to be legal. The two are distinct and yet the terms tend to be used synonymously by students, using legality to justify ethicality. A concerning point to note here is that this confusion is not limited to students. It extends to software engineers in the workplace. Recently a 
colleague from one of my past software development roles noticed something that concerned him about a data collection process at work. He had a receptive and willing audience within the company to talk to him about his concerns, and there was never any negative fallout from the conversation. However, he found he was unable to gain any traction because the overwhelming response was along the lines of "you don't have to worry about it, the way we do it is legal". This was concerning to my colleague who tried talking to several different people, raising the concern as an ethical one and getting a response about the legality of the action instead. This seems to be indicative of a wider misunderstanding of the difference between the two. Compounding this problem was my colleagues' lack of experience in formulating an ethical argument, a method which would be necessary to voice his concern effectively. It might have helped this situation if my colleague had more practice and experience formulating oral arguments about complex moral ideas and therefore would have been better able to articulate his position as an ethical one rather than a legal one. The ability to orally argue a position is a distinct skill that must be practiced. This is experience is of the same type that a few of the educators mentioned as an important benefit of a formal ethics course, and I think this situation highlights how having that skill is an essential part of applying ethical skills learned to the workplace.

\section{Interviews with Educators}

In order to better understand what the day to day implementation of an ethics course looks like, I interviewed four professors from three different universities. By studying faculty from universities other than MTU I attempt to gain a wider understanding of what ethics education can look like beyond MTU's perspective as a STEM university. In the introduction to 
the MTU ethics educational structure I introduced Alexandra Morrison, the instructor of the Engineering Ethics course at MTU, and Linda Ott, the instructor of the Software Engineering Ethics course also at MTU. My next two interviewees were introduced to me by my advisor after they spoke at an ethics education panel he attended. The first is Marty Wolf, from Bemidji State University. I also interviewed Mike Kirkpatrick from James Madison University (JMU).

Although the four courses are distinctly different many of the challenges the instructors faced in student comprehension were the same. There were also some unique differences between the courses and instructors, for example although all instructors used case studies, they all used a distinctly different definition of a case study. And each had a justification for the reason they used the particular type of case study they did. Group discussions had more similarly in terms of definition between the educators but the purposes and methods of implementation also varied greatly from educator to educator.

These differences are important to consider for any criticism, recommendation, or possible software intervention to be applicable beyond MTU. 
Interview With Dr. Ott. The Computing Ethics course is taught by Linda Ott, a member of the computer science department. The course is specifically focused on ethical issues faced by software engineers. In this course the instructor has more freedom to be technical in the discussions around a particular situation because all the students have the same area of study and are expected to be in their 3rd year or beyond. According to a section from the interview with Ott, the biggest difference between the two courses is this course has an expectation that when students are engaged in ethical analysis they are basing their evaluations on their actual technical knowledge and a realistic understanding of what is and isn't possible instead of a more hypothetical understanding. Another point Ott highlighted is that this course has elements of ethical decision making but ultimately is about students understanding their impact on society as a software engineer and what that really means. "I want them to recognize that what they develop actually gets used and tell them that what they do may impact how it gets used. Really I want them to think" [32].

This semester long course is broken up into three sections, the first section covering the classical ethical theories, cultural relativism, Ethical Egoism, Kantianism, Utilitarianism, Social Contract Theory and Value Ethics. These theories are taught primarily from a lecture and then the class breaks up into small group discussion. The next section of the course covers case studies and students are asked to engage in-class, in small groups and and in homework assignments, with news articles about current events. The final section is made up of group presentations. A small group is assigned a computing ethics specific issue, so AI, corporations and privacy, government and privacy, backdoor access, etc. The group then presents to the class covering the 
technical details of the topics, some of the ethical issues that arise and the application of the learned ethical theories to their topic.

From her experience teaching this course, I asked Ott what she felt the biggest challenge she thought the software engineers would face, ethically, once in the professional world. She responded that her concern, and therefore the focus of the class, has actually shifted in recent years due to the changing societal views around computing ethics. "In my view until very recently my concern was that they [the students] really didn't take ethics seriously, and that they didn't think that there were ethical decisions to be made in their job, or that it was just going to be people asking them to do something illegal. But [considering] how software was used, and how the software was designed, and the impact of their software, I don't think it has hit most students. But with all the press around Facebook [...] I'm less concerned about them being completely oblivious that what they do has an ethical or social impact but still concerned that they are not prepared to make those decisions" [32]. So the challenge and purpose of the course has evolved from convincing students to view software as something that could be unethical, and the challenge has instead become preparing the students to make those ethical decisions.

Interview with Dr. Morrison. The other ethics course at MTU is the Engineering Ethics course taught by Alexandra Morrison, a philosopher from the humanities department. This course is focused on ethical issues faced by all types of engineers and gives students a background in the classical ethical theories as well as some of the newer ethical frameworks. One of her biggest goals of the course is to challenge student's assumptions that they are the active agents, and the technologies, the things they build, are passive and neutral. She hopes 
students challenge that assumption and to have them re-consider the role that technology plays in shaping who we are and what we value. The Philosophy of Technology lessons in this course highlight these issues in a way not usually stressed in other ethics courses. Traditional philosophical ethics courses consider ethics as a decision, isolating the the particular decision and then considers whether it was right or wrong ${ }^{4}$. Considering ethics this way misses the habitual nature of human engagement with objects and each other, the collective nature of the engineering design process, and the implicit decisions that the design and materiality of technologies make for us. An example of this is the way we treat a styrofoam cup as compared to the way we treat a china teacup. One is tossed out after only a single use, whereas the other is washed, displayed and often handed down to family members. The decision of the user of the cup to wash and reuse it, or throw it away is highly tied to the materials, washing a Styrofoam cup would be very strange. The difference in treatment of these two objects comes down to the materiality of each object. Those cups were designed with different materials for different purposes, and as users we follow those scripts embedded within the objects. When educating the creators of these future technological objects, the engineers, it is important ethics as more than the consideration of one particular decision. (For more information about Philosophy of Technology, see Philosophy Background in the Appendix).

${ }^{4}$ Considering ethics as one particular decision point, comes from the Cartesian way of thinking. Descartes defined the human being as a primary rational being, and like many of the other enlightenment thinkers he considered the mind to be distinct from the body. This Cartesian way of thinking keeps students from taking seriously the consideration of embodied and habituate practices, which then implicitly treats technologies as neutral tools, or as elements secondary to humans in ethical consideration. Philosophy of Technology came out of the rejection of the Cartesian way of thinking by Phenomenologists. This rejection allows Philosophers of Technology to consider embodied interactions with technologies. 
When asked her perspective on the difference between the two courses Morrison mentioned Computing Ethics puts the emphasis on case studies involving computers, whereas Engineering Ethics tries to introduce case studies that showcase many different engineering settings. When looking at the syllabus for both courses, and also the interviews with both Morrison and Ott, a major difference I noticed between the courses is that the Engineering Ethics course places more of an emphasis on the ethical frameworks, spending more time on each framework, and also emphasizes reading the original philosophers. Because more time is spent on the frameworks, and because of Morrison is a Philosopher, it comes more naturally that the Engineering Ethics course could provide an introduction to some of the non-traditional philosophies, like phenomenology and philosophy of technology. The Computing Ethics course places more of a focus on case studies, studying only the classic ethical frameworks and instead the focus is on applying those to a wider and more current and technical set of cases.

From Morrison's experience teaching the course her biggest concern around engineers in the field is that "It [ethics] is non-existent. Often when I hear students in the sciences or engineering talking about ethics I don't even recognize it as ethics. That's because there doesn't seem to be any critical component, it just seems like they are asserting cultural norms that are intuitively embraced" $[27,28]$. The separation between the humanities and STEM means the education of many STEM students does not include formal training in ethical analysis or a foundation in ethics and philosophy. Much of the STEM students understanding of philosophy and ethics comes from abbreviated modules in engineering courses. This results in a truncated notion of what constitutes ethical engagement in these STEM students. This understanding is significantly different than ethics as understood by someone with a formal education in ethics. A 
related concern here is that although an element Morrison deems critical to ethics is not present, the students she is talking about nevertheless believe they have an understanding of ethics. Thus there is a lack of recognition for what might be a critical knowledge gap. Morrison mentions a second misconception regarding the nature of ethical responsibility common among engineers and it is the singular concern with functionality. "There is the idea that if a technology is safe, if it doesn't malfunction that's it the 'ethical' work is taken care of. So there is no real critical element to to either of those positions [intuitive ethical judgments and ending analysis at whether it functions or mis-functions] and so for a philosopher it's not really ethical philosophy" [27, 28]. This fallacy that assumes a products' ethicality comes down to whether it functions as intended, is a concern echoed during some of my other interviews. Morrison hints at something bigger here when she brings up two ways the engineers in her course think they are engaging in ethics, albeit ways that do not engage in critical argumentation and thus ought not to be considered ethical engagement in any robust sense. In the context of the discussion about the separation between STEM and the Humanities this highlights an important issue. Morrison's view is that this approach to ethics is primarily opinion based lacks any sustained logical argumentation and overlooks the fact that one's moral opinions require evidence. They are not true or credible simply because they are passionately held beliefs. Ironically, these are the same types of complaints often heard about the Humanities from the STEM students, who think that Humanities disciplines are just concerned with personal opinions. So it is possible that some of the negative opinions of the Humanities, specifically ethics, by STEM students is likely founded in an incomplete understanding of what the Humanities and specifically ethics actually looks like. 
Interview with Dr. Wolf. The first outside interview was with Marty Wolf. Wolf is a Computer Science faculty member at Bemidji State University, and he teaches or has taught most of the courses in the department. The ethics course I interviewed him about, Social and Professional Issues in Computing (SPIC) was more similar to the MTU Computing Ethics course, and was also offered by the computer science department. Bemidji state is a smaller university, about 4,500, with arts as an important part of the university's mission. While I could not find information about whether they have or are pursing ABET accreditation, the Computer Science department has 7 learning goals similar to the University Learning goals of MTU and these include a reference to ethics. The $6^{\text {th }}$ learning goal is "Students will develop a basis for making professional and ethical decisions that pertain to the software they are developing“" [5]. So the SPIC course addresses this learning goal for the students of the Computer Science program. According to Wolf, the goal of the (SPIC) course is to develop in students the analytical abilities needed to consider the ethical situations that will come up in their professional lives. His biggest concern for a computer scientist in regards to ethics in a professional environment is students lack of empowerment. If they are just starting out as a junior employee he is worried about them being able to raise those ethical issues that they might have. Although not the primary goal of the course, The SPIC course is helping to address this issue by bringing it up as something to consider when looking for a job. Asking potential employers what types of systems are in place for employees to raise ethical concerns if they have them can help students make an informed career choice in that area.

Marty mentioned that students in his course tend to be really engaged in the small group discussions, staying after class to finish discussions. When asked about what factors he felt 
contributed to this high level of engagement, he listed the arts based mission, a university expectation of understanding of the humanities, and strong commitment to service and stewardship, as attracting a certain type of student to the school. He also cited his position as a CS faculty member to lend additionally legitimacy to the course. Having a technical instructor teach an ethics course as a way to give it more legitimacy in the eyes of students is something that was mentioned by multiple instructors and also by the authors of the Harvard Embedded EthiCS paper. His comments also seem to support the idea that STEM schools might experience challenges in ethics education in a way that STEM students at schools with a more even balance between STEM and the humanities may not. 
Interview with Dr. Kirkpatrick. My second outside interview subject, Mike Kirkpatrick is also a computers science faculty member who has taught a wide variety of courses, at JMU and is currently working on an instructor education project. James Madison University is not a STEM specific university. Additionally the Computer Science program goals also mention ethics, the College of Integrated Science and Engineering aims "To foster, among both faculty and students, life-long professional development, personal growth, and commitment to ethical behavior"'[15]. The course he taught, Societal and Ethical Issues in Computing, was also offered by the CS department and was a required course to graduate. The goal of this course is to meet the ACM curriculum recommendation for Ethics and Society. When asked about additional goals for the course Kirkpatrick wants to focus on educating the technologists "There is a place for philosophers and others, but it is important for technologists and computer scientists to have foundational knowledge [...] I am an advocate for technologists doing a better job of building that bridge [between technologists and philosophers] I want to improve those skills within technologist for us to work better with other people"[21]. By empowering the technologists with an understanding of ethics, the understanding could be applied to a highly technical problem, the types of problems that might not be considered by those who are not technologists.

According to Kirkpatrick, the biggest barrier to engineers making ethical decisions in the professional world is the difficulty in actually recognizing that they are in an ethical dilemma. From the perspective of someone involved in the situation, the beginning of an ethical dilemma may not be as clear as it looks from the outside. "Someone working on one component of a larger program doesn't have enough information to see all the details in a situation. Sometimes you don't even have enough to know to ask the questions. Then on top of that there is the 
problem of: do you have enough support to bring up the concern?'[21]. One way he works on this issue in his course is by using case studies designed to help the students get a view from the inside of the beginning of one of these ethical considerations.

Unique to JMU is a campus wide initiative called Ethical Reasoning in Action, which will be detailed in the next section. The result is a lot of top down administrative support for inserting ethics throughout the curriculum. Though his university has this program he still thinks there is more that could be done at JMU to bring ethical reasoning skills into more contexts. Although one service usually offered by distributed ethics programs includes support from the program to aid in developing ethical modules for a course. Kirkpatrick seems to advocate for an approach where the course instructors themselves write the curriculum. He suggests doing this instead of an outside organization helping, even in a way where the instructor is still involved. "Even if you are working with an outside group to develop the curriculum, one of my concerns is that when someone doesn't have the same level of technical depth they can be really good at ethics but they don't understand the implications of tech"[21].

\section{Analysis of the Interviews}

In analyzing the interview transcripts, I used qualitative research methods because as I was transcribing the interviews, I realized that there was more information to be gained from the interviews then was in the direct answers to the survey questions. Comments made throughout the interview on a related topic could be brought together, in order to see a richer picture, then just the answer to one question. 
In order to determine what topics to try to group the data by, and then find data from the interview related to that topic, I had to code the interview. Coding the interview is a way of pulling additional meaning out of an interview transcript. Categories and categorization are coding terms used to describe higher level "buckets", such as a overarching concept or theme that brings together multiple small elements from the data source, in this case an interview. Its a way of connecting related things. Codes are the way of finding those related things, they serve as the link between the interview transcript and the categories. "Codes serve as shorthand devices to label, separate, compile, and, organize data"[24]. Codes are the shorthand that get written on the transcript to start to distill the data down. Then when those codes are analyzed patterns can emerge and categories can be realized.

I used a version of coding called thematic coding ${ }^{5}$ when analyzing the interviews. I would read the interviews and write one or two word descriptions (codes) of what every few sentences of text meant. Then after working through all the transcripts, I was able to match those codes and themes between the different interviews.

Coding the interviews is helpful because gives a richer perspective by including all the related data points form an interview, not just the response to a related question. So for example, when I asked a question about case studies, I would get an answer related to case studies. This was an incomplete picture of how they used case studies. Oftentimes information about their use of case studies would come up in answers to other questions, such as inquiries around group discussions, this additional information might be coded as both case study and group discussion,

${ }^{5}$ A straightforward explanation of thematic coding is Theodore Zorn's "Conducting Thematic Analyses of Interviews and Field Notes". Zorn describes the process of coding in a concrete way, and his version of thematic coding is very similar to the process that I used to analyze the interviews for this report [44]. 
because it is useful to consider when thinking about either one. By including data from these answers into my analysis of how the instructors case studies allowed me to see a richer picture of how the instructors used case studies.

So the analysis of the terms Case Study, and Group Discussion come out of the analysis of the coded results of these interviews.

Class Discussion. Group discussion is an important piece of ethics education. All four of the professors implemented some type of small group discussion into their courses. Kirkpatrick, Ott and Wolf have students break into small groups during the class period as their main method for discussion, whereas the class discussions in Morrison's class are entire class discussions lead by her. Small group discussions do take place outside of class in her course in an online forum a number of times throughout the semester. .

Another element of the small group discussions is actually what takes place after the discussion, what method is used to let students share their results with each other, and to correct mistakes made in the groups. Both Wolf and Ott mentioned that an important piece to this in small group discussion was some type of classroom wide conversation afterwards to correct mistakes and share key takeaways. Wolf uses these lectures after the small groups to address mistakes or concerns that he found two or more of the groups made. For Ott the students write up the results of the small group discussion, for a submission and a grade. In Ott's course there are several small group discussions per class period, so she brings the class back together to share what they came up with and then allows the students to get back into those small groups so they can discuss again and come to new conclusions. Morrison's class discussions don't need a 'coming together' because they are led by her so problems and questions can be addressed as 
they come up in the discussion. Though Morrison does implement a similar class wide sharing and feedback system for her online discussions. While reading through the online discussions she takes notes of common mistakes and addresses them with the entire class during the next lecture. So although it is delayed by a class period these online small group discussions still have the classroom wide correcting and sharing. Another way corrections are made in Morrison's online discussion is through individualized feedback. She reads through the comments in the discussion groups online and gives feedback, either 'yes this is good' or 'its a bit more complicated here' allowing the students to receive individual feedback. She doesn't do this every time, but for more complex assignments she reads through and comments individually. This has an in person parallel in the course taught by Wolf. When using case studies to teach the ethical theories Wolf walks around the small groups discussing and listens for linguistic cues that they are using the right ethical system. For example, if he is teaching something like Kant, which as mentioned is not a consequentialist framework and the students start talking about the outcome then he will step-in and try to re-explain it to that particular group.

The types of activities done in small groups are unique in each class, but a common activity was to assign the groups different tasks in order to force a variety of viewpoints, which can then be shared out either by full class discussions, or in one case by mixing the groups and discussing again. For Kirkpatrick one small group activity is assigning different stakeholders to the different groups, having each group do a stakeholder analysis, and then coming together as a class to share it, using the different groups to be able to get different perspectives from the different stakeholders. In Ott's class the focus was on using the groups to become 'experts' in a slightly different ethical theory, so she might have the entire class read the same article and 
makes a big list of ethical questions. Then she assigns different groups to different ethical theories and the group picks an ethical question. After considering it they come together as a class this way there are several different points to discuss in the full group discussion. Wolf had a unique method. "Sometimes I'll actually plan it so that individual students will be assigned different areas of expertise for example 'think like a manager' or 'think like a developer' and then I'll arrange the groups, and put all the kids who were supposed to think like developers together, and have them start out and say, "what can we do as developers and then I'll rearrange the groups so that now there is a developer, a manager, and a salesperson in the same group and they now have to take on the different roles"[43]. This method uses the same start as the other activities, starting in a small group where the small group becomes "experts" in a given perspective, in Wolf's case, a certain stakeholder's position. But then instead of sharing out the diverse perspectives to the entire class the groups are rearranged and each small group now has a member of each perspective. So this "sharing out" also takes place in a small group, but one that is guaranteed a particular composition. Another important point to note is that the value of assigning the small groups to talk to each other first. This improves the quality of the second small group discussion because by talking with people who had the same assigned viewpoint the students likely gained more confidence and understood better the position they were assigned. This could be related to the echo chamber effect: if an opinion is discussed with others of the same opinion, that opinion can become stronger. Whether or not this effect applies to assigned opinions instead of actual opinions is a valid question. Regardless, being able to share arguments with those arguing for the same position would be helpful. 
There were a few recurring purposes for the discussions that came out of the interviews. One purpose was to create a variety of different perspectives and to have students realize this diversity. The instructors phrased this purpose in a variety of ways. Ott stated this goal as "helping students realize that they see different factors than the ones other groups raised, so that they can see the complexity of the questions"[32]. which broadens their perspectives. Wolf hoped students would be better able to consider "a diversity of ideas. Students bring different perspectives either through who they are as individuals or they bring different perspectives because they've been assigned a different role to play for that particular exercise"[43]. Without explicitly stating it, Kirkpatrick's emphasis on splitting the class into two and having them take different sides to lead groups of stakeholder analysis shows he too uses group discussion to showcase a diversity of perspectives.

Another key purpose was increasing students analytic skills. Ott uses group discussions to help students "get a sense to actually reason through things, instead of just going with your gut'[32]. Wolf uses discussion to provide students a way to practice course skills. Morrison uses discussion to give students a chance to engage with philosophy and ethics in a critical way. Similar to Wolf, she highlights that these discussions provide students with an opportunity to practice these skills that they don't get practice elsewhere in the university.

Discussions also serve as a way to help students practice oral communication, and articulation of complex moral ideas and formulation of arguments about ethics. This is important because if a professional wants to bring up an ethical issue with a manager or colleague they would need to be able to articulate it, usually orally, to another person in a way that is concise and persuasive enough that the person will pay attention. Wolf brings up this benefit, citing that 
group discussions help students to "gain some confidence in the ability to talk about things, the social and ethical concerns that the individual might have. They learn to talk about these things and they learn the vocabulary that they know, and that their colleagues know"[43]. Practicing the skill of verbally making an argument to explain a position the students gain the confidence required to do it in other situations. Morrison brings up this purpose as well. Through discussion she hopes to "to get them [students] thinking about ethics and talking about it in a philosophical and critical way. They're not going to have a lot of opportunities, from what I can see, to do that at this institution. [...] It's only when they can articulate it for themselves and interpret it for themselves and put it in their own words that they can actually own it and they feel like they have a command of it. It's a different way of thinking and its different way of engaging with engineering artifacts and technological systems so they need to be able to articulate for themselves"[27,28]. These class discussions provide students one of the only chances to practice a necessary communication skill during their education.

Because Morrison hosted part of her class discussions online the discussions serve and additionally purpose for her course: engagement of otherwise quiet students. There are often students who perform well in the online forums, but might not be initially willing to talk in front of people, especially in a larger class. She writes down the names of these students and during the next class discussion mentions that what a particular student said in their online post that was correct or insightful, and asks if they would be willing to explain it to the class. She explains this tends to have the lasting benefit of giving those students the confidence to continue speaking up in class in the future, without prompting. 
On a related note, the instructors viewed class discussions, or certain aspect of class discussions, as a way to combat some of the challenges associated with increasing class sizes. All three of the currently teaching instructors mentioned that class sizes were increasing and were larger this semester. Additionally these instructors also mentioned that holding a larger class discussion can be extremely challenging due to the difficulty of moderating such a sizable discussion, and secondly the problem of students' anxieties about articulating their ideas in front of a large class[27,28,32,43]. Other challenges include groups getting stuck on a particular point [43]. and students not coming up with their own thoughts and instead saying what they think the instructor wants to hear, or what they read in the textbook. The concern is that many engineering students get used to learning by rote and so are unprepared to think on their feet when the context is altered or they don't have all of the facts at their disposal. It is frustrating when they are "not really taking up the ideas for themselves and they're not really exploring the ethical issues. Ethics isn't about getting the single right answer, ethics is inherently ambiguous and so it needs to be explored. It is not about memorizing the ethical theories to give you the "key" to being ethically responsible" [27,28].

Although small group discussion is mentioned above as a possible partial solution to the problem of student engagement in large classes, small group discussions come with their own challenges to student engagement. Both Morrison and Ott mentioned thoughtful engagement as being a challenge of the discussion groups, Morrison's being online and Ott's being in class, and that the groups need a critical mass of engaged students to be successful. Both Ott and Wolf used homework assignments to help get students to engage and to talk. They found by having something to bring to class students have a starting point for discussion. Morrison does this as 
well by requiring her students to read a particular text before each class and to complete an assignment for the online discussions. She cites this as one of the reasons that she is able to get engagement online. Engagement in online discussions can pose a special challenge, so much so that Ott mentioned this as her reasoning when making the choice to keep discussions offline $[27,28,32]$. Ott also mentioned that in her personal experience using online discussions during educator training she found the asynchronous nature of online communication made quality conversation challenging. "Someone might not respond for so long and by which time I have already gone off on something else. I am no longer in that context and don't remember to even check it"[32]. Morrison uses a few methods to mitigate the engagement issue. One way is by assigning pre-discussion work, as mentioned above, meaning the only way students get credit for the assignment they did is by participating in the online discussion. Secondly, there is an optimal size for the window of discussion. Morrison purposely makes her window small enough that people are engaged and can be engaged consistently, but not too small that students have trouble or feel rushed. This way the communication is still asynchronous but now is not unbounded. According to Morrison the change of the bounds on discussion is correlated directly with the quality of the discussion. This closely bounded time window addresses the context issue brought forth by Ott. By having the discussion asynchronously but in a short enough time allows users to stay in the same context long enough to actually re-engage with the discussion after making their initial remarks. Finally, Morrison cited making the assignment worth a bit more, and doing fewer discussions overall, as another reason that she was able to promote better engagement online. 
Case Study. Understanding the use of case studies by the different educators was significantly more complex than understanding the use of discussions in part because the definition of a case study is not entirely clear. Analyzing the way the word itself was implicitly defined by the four instructors brought up questions like: Is there a difference between a case and a case study? Ott made a distinction, saying that she uses cases instead of case studies. From context based on how she used the term, I would define a case as being a new article without any additional analysis, and when the context is added it becomes a case study. Additionally the word scenario was used by Ott to define a simple situation she made up without too much complexity. A tool with a similar purpose and description was used by Wolf, but was defined by him as a case study. It is possible that there is still a distinction between the two. Maybe Ott's were in fact more contrived and simple whereas the "simple" version of a case study that Wolf describes was in fact more complex than a scenario but simple by case study standards. To neatly categorize the way case studies were used for analysis was challenging because it was hard to actually define the criteria for a case study. For the purposes of my analysis I included Ott's cases and scenarios as case studies. I further sorted case studies into four categories: news articles, simple cases, complex cases, and hands-on (experiential) cases. Many of the educators used case studies from more than one category.

News articles were defined as a case study that did not include any more detail or context then an article published in a magazine, or online newspaper. These were used by Ott, she selected articles representing current events, including a few of the software engineering disaster cases, for example many of the events surrounding Facebook. 
Simple cases were defined as a case study where the defining feature mentioned by the educator was simplicity, and the case was not designed to deceive, mislead, or confuse students. These were used by Wolf, as his primary form of case study. For his simple cases the details are added slowly and at points where the students need more information. The overall level of detail is lighter in these simple cases. Ott also uses simple cases to use when teaching the ethical theories to highlight the differences between the theories. Hers are likely a bit simpler than Wolf's because she makes hers up in an ad hoc way during the lectures.

Complex cases were primarily used by Morrison and Kirkpatrick. For Morrison the complexity comes from a detailed context surrounding the moral issue. Kirkpatrick uses a few different types of complex cases. He uses dystopian scenarios from Black Mirror, to highlight how good technology can be used for evil. He also tends to use complex cases to highlight the multiple perspectives in a given situation. Wolf's primary use of complex cases is for professionals and academics. For him, these two groups are further along in their ethics education and therefore can appreciate and apply skills to a more detailed and nuanced case.

The last type is a hands-on case. This type was used by Kirkpatrick when teaching students about the complexity of identifying a moral situation. He uses them to help the students understand what a confusing moral situation looks like from the inside. He used this exercise when he was teaching a more technical CS course. He assigned students a gene sequencing and pattern matching assignment earlier in the semester. Later in the semester during a discussion about ethics he started talking about the VW bug case with his students. His students responded with something along the lines, "Why would they write bad code to bypass the testing?"Kirkpatrick then replied, "you guys did 6 weeks ago". And his students were really 
surprised. He explained, "I had you write this code weeks ago and you never asked questions about why you were writing it, or what it was going to be used for." He went on to explain that, "In the VW case, it's really writing a program that given certain inputs returns T or returns F. So a manager could have just said to write that. In a larger software program no one has all the details. Someone working on one component doesn't have enough information to see all the details in a situation. Sometimes you don't even see enough to know to ask the questions" [21]. This gave his students a really clear idea of how confusing a moral situation was from the inside, and how power dynamics and work culture might play a role. I included this as a case study because it serves the same purpose of demonstrating to students an example of a moral situation. In this activity Kirkpatrick actually turned his classroom into a case study, using a students own thoughts and experiences as the facts of the case study. Though I can see the argument being made that this is an activity and not a case study, I think it should be included as a case study.

The qualities of a good case study varied for each instructor, based on the purpose of the study and also the type of study they used. Both Kirkpatrick and Morrison used complex case studies, and so one trait of a good case study for them was was a high quality of writing and good use of rhetoric. In a good case study the language conveys meaning along with the facts. Morrison uses case studies where the story builds slowly "you get this feeling of moral righteousness like 'I wouldn't do something stupid like that'. And this case study kind of pulls you into thinking that and giving you that feeling and then pulls the rug from under them"[27,28]. In describing a good case study she highlights the elements of the writing. The style and delivery of the facts in the case purposely plays with the readers beliefs and opinions, changing them as the case unfolds to help teach the students. How the facts are delivered is just 
as important in a good case study as the facts themselves. Kirkpatrick's complex case studies also use thoughtful and creative writing to convey additional meaning in a case study. Kirkpatrick uses purposely coded language to imply a certain party's innocence or guilt. He writes multiple versions of the same case, keeping the facts the same but changing the language used to describe the subject's actions. By subtly pushing his students towards a particular opinion in a case he helps his students see the story from various perspectives. He often pairs this type of case study with a small group activity where he splits the class. He then gives half of the class one perspective and half the other. Both Kirkpatrick and Morrison consider an element of creative and persuasive writing to be a trait of a good case study.

For Ott, who primarily uses news cases, a bit quality of a good case for her is that it is timely. One of her justifications for seeking out timely case studies is that timely case studies help with student engagement, and can help provide more evidence of the real world applications of the ethics course. Morrison also mentioned the timeliness of case studies in a few different contexts throughout her interview, but in a slightly different way then Ott. Morrison is much less concerned with the timelyness of a case study, she instead prioritizes how it is written, instead of the age of the study. However, she also mentioned making an effort to include current updates to a case study. For example, one case study she used in her class is a relatively old case, but there was recent work done by journalist and new information was discovered, so she included these new updates when using the case study.

Another quality of a good study is details being added slowly, building up the case study as the reader works through it. An interesting thing about this quality is the adding of details serves two distinct purposes. Morrison cites the slow addition of details to the complex cases as a 
way to continue to add complexity the case. Sometimes this slow addition is used to add a "gotcha" moment, where the reader is unsure of who to sympathize with. Wolf also values cases where details are added slowly in his simple case studies. He uses them to add details as students need them while working through the case, so that the cases aren't overwhelming at the beginning. So the same trait in a case study is valued for two very different reasons by different instructors.

The purposes for using case studies are diverse, as the purpose is usually related to the type of case study, and sometimes the specific instructor. One purpose of using certain case studies is actually to demonstrate to students what a bad case study looks like. For Ott this looks like using news articles with notably limited context to show students the importance of context in an article. These are also used to help students better understand how people without a technical background might misunderstand certain articles [32]. Bad case studies can also be used to demonstrate how framing of the facts matters. Kirkpatrick also demonstrates how framing of a case matters in a roundabout way in his case studies that use language to imply innocence and guilt. Framing isn't the primary focus of these case studies though, as he does it primarily to highlight stakeholders positions. Morrison gives her students a purposely poorly designed case study to demonstrate how framing can impact how people in the future will interpret the facts. "I purposely gave them crappy ones because case studies are so often presented like 'here's the bare unadorned facts' but how you frame it is really important to how people will interpret them and I think they [the students] understood how important this is from doing this exercise" [27,28]. 
Case studies are also used by instructors to provide students a way to practice analytical skills. Wolf uses simple case studies to do this because it allows his students to practice the skills they are learning in the course in a more straightforward way. Ott has a similar approach, using simple case studies while introducing the ethical theories. She has the students apply the ethical theories as they learn them to the simple cases. This lets them understand the differences between the ethical frameworks and also gives them a chance to immediately practice what they learned. Morrison also uses case studies to give her students practice with analytical skills. She uses complex case studies to provide this practice. For a student who does not have experience with ethics or philosophy Morrison finds that case study is an approachable way of starting. Providing an initial way into ethics is similar to the reasons for using case studies mentioned by both Ott and Wolf.

Case studies are also a big part of small group discussions for all the instructors. Case Studies serve as a way to practice newly acquired analytical skills with other people (Wolf), demonstrate a diversity of viewpoints (Ott), or serve as a starting point for discussion (Kirkpatrick).

Case studies also provide a way for students to better understand what types of contexts might surround a moral problem. These can be issues of understanding what corporate culture might look like and how that impacts the moral problem, and the situation that led up to it. This context can also include highlighting the fact that in many cases there are several key moral decisions that get made before the big moral decision that lead to the disaster. Case studies can highlight what types of shared responsibility exist and how a communal working situation effects this $[27,28]$. 
Case studies can also give users the ability to see themselves and relate to moral problems. A typical argument made against disaster studies is that they are not relatable. So it might seem counterintuitive but Ott uses disaster news cases as a way to help students see themselves impacting society in a bigger way. One such disaster case she talked about in our interview was the Facebook hearing in congress, and Mark Zuckerberg's testimony given there. “They [students] didn't foresee themselves being in a position where they had any impact on the decisions that would become congressional hearing worthy but in some sense that's the whole point of what I was trying to make them aware of. You know you never know how your software ends up getting used or a flaw in your software that ends up getting you into sort of trouble"[32]. She uses other articles to highlight how software made for one purpose could be used for another, to help dispel students belief that they wouldn't be in a big moral situation because they will choose not to develop software that does morally fraught things. For this she uses case studies like the recent press around the military application of the HaloLens. The HaloLens being used in military applications is upsetting to developers at Microsoft who did not consider the military application of their code. Her students are able to see themselves developing that kind of software, because its true purpose was hidden from developers. As a result her students can see themselves in this moral situation. Students ability to relate to the subjects of the case studies is also the reason Kirkpatrick uses many of his case studies. He uses the Black Mirror case studies, to showcase how legitimate technology can be used for malicious purposes. This is similar to Ott's purpose when using disaster studies when she aims to show how the implications of technology they build could ultimately be more serious then they imagined. Kirkpatrick aims to highlight a more hopeful message when using the Black Mirror cases. He uses these cases to 
show students that they have the power to influence the ultimate use of the technology in the small design decisions they make through the entire development process. When case studies portray legitimate technology being misused as still being a moral issue, it helps demonstrate that moral consideration does not end at considering the intended use of the product. These kinds of case studies help show the product itself as being worthy of moral consideration, and that the design of the product needs to be considered as more that achieving its intended goal. Although not explicitly mentioned, these cases serve an important purpose: they help break down the technological utopian belief in many students, as well as the instrumentalist belief that technology is simply a tool to achieve a particular purpose, because in this case, the technology is serving a different purpose and is portrayed at the center of a moral dilemma. Repeated exposure to cases where the "neutral" technology itself becomes the center of moral issues might be able to challenge the default beliefs in students about technological neutrality.

Another interesting result of the interviews was the educator response to the criticism that case studies do not parallel the real world. All four of the professors agreed that case studies often do not accurately portray the real word, and that the real world was much murkier and complex. Importantly though they all mentioned that although it doesn't parallel the real world, that isn't the goal of the case studies. Case studies serve their own purposes and don't need to parallel the real world in order to be effective at achieving those purposes.

Some instructors also mentioned the type of case studies that students prefer, or their reaction to particular types of cases. , and their reactions to them. One educator's responded that "people seem to gravitate towards case studies with a protagonist of some sort that sort of can be taken to task"[43]. Case studies formulated this way might be easier to apply the classical ethical 
frameworks to because there is one critical decision point, and one active subject to consider. However this type of case study wouldn't be effective for the purposes of case studies for Ott, Morrison and Kirkpatrick, because it presents an uncomplicated situation where only one party is to blame and ignores the context and any other actors. This could also be problematic because when the case study presents one person as being completely blameworthy it considers them to be the only active agent in the case. By doing the case isn't presenting the technology as having agency and being worthy of consideration of the values within that technology.

Suggestions for Future Research. In the future this work could be built upon in several ways. Firstly, by including an additional interview with an instructor in a role similar to Alexandra Morrison's. I have only one voice from the humanities faculty and also only one voice from an engineering ethics course instead of a computing ethics course so I think it would be beneficial to have another interview here.

Secondly, in future interviews a line of questioning could be pursued asking about the textbook used for the course. During my interviews I noted some interesting relationships between the textbook the instructor chose, the justification for choosing that textbook, and the particular instructor's course focus was interesting. Although because this was not a focus of my interviews, I did not feel like I had enough detail or a long enough conversion to actually support an in-depth analysis on this topic. The interesting question would not be whether the educators use a textbook or which one, but why or why not they choose to use one. I think there might be some additional insight to be gained into the instructor's particular course focus, timelines, organization, connection to CS, or a certain ethical and philosophical framework through questioning about the textbook. 
Lastly, these interviews provided a groundwork for what could become a taxonomy of “case study". In my interviews I found there to be a variety of different uses for the word case study, but my work in this area was quite limited. More extensive work in this area could provide some useful insights that could help conversations between ethics educators be more productive and lead to more collaboration.

\section{Distributed Ethics Education}

The computing programs at MTU, JMU and Bemidji state, the three I have looked at during this report, all have standalone courses in computing ethics. For many other engineering programs at MTU a standalone ethics course is not require, they consider an ethics module in an introductory engineering course to be sufficient to meet the ABET ethics student outcome. Program's meeting this minimum requirement should not take away the need for thoughtful consideration about whether this is the best way to legitimately meet the goal of empowering and educating students to make ethical decisions in an engineering setting. According to the ACM curricula recommendations one course in either isn't sufficient, but neither is relying on ethics lessons distributed into technical courses. The ACM recommends a hybrid approach combining the two. A concern about depending on one ethics course was echoed in the interviews with the various educators of ethics courses. According to Marty J. Wolf, a Computer Science department professor at Bemidji State University,

"We need to have ethical considerations built into the curriculum really throughout it and not having this one off course at the end, especially having the one-off piece at the end not taught 
by a computer scientist sends a message that ethics is something you do at the end or something that you get someone else to do, and so I think that is a problematic message"[43].

Not only is this important to do because it shows that ethics is something that you do throughout the process of learning and developing technical skills and programs, but it is also important to do because it provides a second but also very important part of ethical reasoning, which is learning when to ask the question. One of the challenges that students face when learning how to apply the academic lessons about ethics to the professional world of engineering is the challenge of understanding when to ask the questions and realizing that there is something ethical to be considered. The fast pace of industry or academic pressure to produce can overshadow the quieter more reflective need to ask ethical questions. This is in contrast to an ethics course or some rare scenarios in the working environment, where there is an obvious ethical problem that needs to be dealt with. One way this problem is expressed is by Professor Mike Kirkpatrick, "One of my pet peeves is the overused words "ethical reasoning" and "critical thinking", these are context specific skills. To use critical thinking you need to be aware of the uses that need to be analyzed first. And that skill of when to be aware or when to be asking the questions is a context specific skill, and that is really hard to generalize"[21]. One ethics class is such a finite period of time that it is a real challenge to try to show students and practice with students a wide variety of contexts for ethical reasoning. One solution to this problem is to teach ethics in the same way the technical computer science courses are taught, one course at a time, building on each other as a student progresses, in this way teaching ethics not just at the end, but instead all the way through the student's education. 
There are a few programs working on this issue currently, at a few different universities. One is Embedded EthiCS, implemented in the Computer Science program at Harvard; another is the Ethical Reasoning in Action project at James Madison University. MTU currently does not have this type of program, though there has been some work, and an NEH grant proposal to try to push towards a more distributed approach to ethics.

Harvard-Embedded EthiCS. Embedded EthiCS is a program started at Harvard, and is one new approach to working ethics into the CS coursework. Embedded EthiCS adds ethics modules to computer science courses. Each of the ethics modules has a philosopher, either a Ph.D. Student or a postdoctoral fellow who has a background in both ethics and teaching, who will work with the course instructor to develop an ethical education module that fits with the course material, which they will then lead for one or two class periods. This project is an attempted solution to address the complaint cited in the Embedded Ethics paper, as well as the educators I interviewed. "In teaching these courses, we repeatedly notice how easy it was for students to forget about ethical concerns when focus on technical systems issues"[13]. Embedded EthiCS is trying to make it a habit to consider ethics at the same time as technical problem solving. It also helps the problem mentioned about about ethical reasoning being a context based skill. By learning ethical reasoning in a variety of contexts, Embedded EthiCS helps students to practice that context based skill, and to show that ethical consideration is part of the job of a Computer Scientist.

This program was piloted at Harvard, and feedback was taken at the end of the modules. According to faculty the modules "contributed to class with only a mild burden"[13] and the 
students responses to the program were overwhelmingly positive, with $80 \%$ saying they would be interested in learning more about ethics in a future class. Another important thing to note is that the program worked best with closer faculty partnership, so even though the module is taught by someone else, the program tends to work best when the faculty includes some ethics assignment that contributes to the course grade, and also when they mention ethics, however briefly at other points in the semester, either as a precursor to the module, or as a reference back to the module. Both the faculty teaching the course itself and teaching the ethics module expressed concerns that they did not know enough about the other department to effectively partner. But after the pilot both indicated that they were able to gain the skills and benefited enormously from the exposure to the other expertise. The Embedded EthiCS program was not immune to many of the common issues mentioned above, with Computer Science students struggling to grasp a problem without a clear answer, and a general inexperience with this type of reasoning skill. They found that this can be somewhat mitigated due to the multidisciplinary nature of the program, and having both parties work together during the module designing process. One other problem the authors mentioned was the supply of the Philosophy department representatives available to design and present those modules. They mentioned this as the purpose of including postdoctorate fellows. I think this could be a much larger problem at other universities, and it would not be able to be mitigated by adding in postdoctoral fellows. In a smaller university than Harvard, or one where there was more of a focus on STEM, such as MTU, the program would have to be reworked to be able to still involve the philosophy faculty but more effectively use what would be a much more limited resource. Another challenge that was not addressed was if this were to be scaled out to other departments. If this proves to be a 
successful model, then other engineering departments may want to adopt it. Due to the similarities in the teaching of engineering ethics and computer science ethics, if a program like this improves the teaching of one, it would likely be a strong candidate to implement in the other. However, this would put an even larger strain on the philosophy faculty to be able to support many different departments. These modules are being creating and are online for reuse, which would allow other courses in the future to adopt the modules without requiring an embedded philosophy, meaning the workload for the philosophers could be reduced over time. It is important to consider what might be lost here when the module is no longer taught by a philosopher, it may impact the benefit of the module to students. Though this might be a tradeoff that would be acceptable so that many different courses and programs would have access to high quality modules. If the program were to expand to a point that started to stress the module design resources the pressure might be to reuse similar modules, which would take away a core value of the project which is to provide detailed modules specific to the course, which is another point to be conscious of if elements of this program were to be replicated.

Though this solution still has some scalability issues, the program itself highlights some important elements for teaching computer scientists ethics, even if they were to be taken back to a non-embedded program. Firstly, the solution is put forth as a way to habituate students to consider ethics at the time of the design of the software, this habituation is a solution to a complaint that ethics are forgotten during the solving of a technical problem. In a more subtle way, this habituation can be a solution to the problem mentioned by Mike Kirkpatrick, that one of the biggest concerns he has concerns software engineers not knowing that they are in an ethical situation. Having a habit of doing ethics while doing development would eliminate the 
need for determining whether or not ethical questions need to be asked. If asking ethical questions were as much part of the initial development habits for engineers as was reading the documentation for the codebase, then ethical questions would be considered automatically and the problem of determining when to ask the ethical questions would be resolved. Another takeaway from the success of the embedded ethics project is the importance of a partnership between computer science and philosophy faculty. The greatest success from the program came when there was buy in from the professor of the course, when they indicated the importance of ethics by grading the ethics assignment, and also by referencing ethics several times during the course. This sends the important message that ethics is something that is to be done by computer scientists, and is an important part of doing data structures or algorithms. One last takeaway is that the ethical modules were closely tied to the course material, so it was easy for students to see how it could be applied. Attempting to include some of these elements previously mentioned into a software program might mean making the software support a large library or case studies, maybe sorted by topic so it would be easy for students and educators to find case studies relating to a particular course. Another element might be to try to make the software stand on its own in a way that would allow it to be used by professors of many different subjects to help students consider ethics in the context of those other subjects. 
JMU-Ethical Reasoning in Action. While Embedded EthiCS addressed what was lacking in an ethics education for computer science majors at Harvard, Ethical Reasoning in Action at James Madison University (JMU) aims to distribute ethics education in slightly different way, reaching all the students at the university instead of just one particular department. I heard about Ethical Reasoning in Action from one of my interview subjects, Mike Kirkpatrick when he was describing to me why he thought that students at his university in his software engineering ethics course might be unique in their understanding of ethics because of James Madison's campus wide initiative. Ethical Reasoning in Action has 3 stated goals, as taken from their website,

"1 Elevate the campus-wide understanding and discourse on ethical reasoning as a teachable, evaluative process.

2 Provide a unifying framework that aligns campus efforts to teach and assess ethical reasoning.

3 Encourage multiple avenues of intentional connection among personal, professional, and civic application of ethical reasoning skills in the classroom, co-curricular activities, and student life"[18].

Ethical Reasoning in Action uses a tool called the 8KQ, which stands for 8 Key Questions, as that unifying framework to help make ethical consideration more standard across multiple disciplines. The 8 Key values are Rights, Fairness, Outcomes, Responsibilities, Character, Liberty, Empathy, and Authority, with 8 key questions to ask while trying to think through an ethical situation. In the 8 Key Questions handbook each of those values has a page in the handbook which lists questions, a short philosophy and ethics background lesson, and then a 
section for "How to Proceed". Additionally on the front page of the handbook, an important reminder is given to "Attempt to ask all eight in an exploratory rather than confirmatory way" [16]. Diving into the handbook the level written at a level that a student with no formal philosophy or ethics training could understand the philosophy lessons, and the 'How to Proceed' section is easily utilized as a concrete step forward for people who are unsure. For example for 'Fairness' section the handbook instructs the students to ask themselves, 'What is the fair or just thing to do' and 'How can I act equitably and treat others equally'. Underneath these questions is a philosophy and ethics lesson, on a few related background theories, providing a level of detail which is enough to understand the theory and how it relates but not so much that it is confusing to a new student. The first paragraph of this lesson portion is a discussion of intuition, of knowing that something is intuitively not fair. Next a paragraph with an example and an explanation of procedural fairness, defining it as treating equal cases equally. Next an example from the U.S. Declaration paired with the topic of distributed justice, and finally an introduction to Rawl's Theory of Justice. Lastly there is a sidebar "How to Proceed?" offering some concrete advice for using the ethical lessons introduced on the page, this specific page citing Rawls 'Veil of Ignorance" as a way for someone to try to remove themselves and their biases from the consideration.

The 8 Key questions are used across campus, in all the disciplines, so the students become familiar with the framework as their education progresses. Another important element of the Ethical Reasoning in Action is a series of events held throughout the year, where students have a chance to practice and use these skills in both their professional and their personal lives, this is probably best represented by goal 3, one such event was the Ethics Slam, which gave 
students a way to practice the 8 Key Questions outside of the classroom. Beyond these activities, every student is introduced to the 8 Key Questions as a first year student, attending a workshop during the orientation week before classes, with other workshops throughout their education. The program also has opportunities for faculty education, offering workshops in the $8 \mathrm{KQ}$, and also offering customized ethical units for a particular academic area or student group, helping individuals implement an ethical unit into their course. This is similar to the philosophers in embedded ethics, but here it is not limited to the CS courses and is instead offered to the entire university. Though the program website does not discuss the issue of too great a demand for this type of help, it is possible they are also experiencing this and do not mention it, or it is possible that they are not are not experiencing a problem in this area because of a larger headcount to the program, or to low faculty request rate, due to either disinterest or faculty could be encouraged to attend the workshops and so are able to develop their own ethical units.

Part of the 8 Key Questions program at JMU is measuring student achievement. Built into the framework is a set of Student Learning Outcomes, and also published to the website is the result of the universities progress towards these outcomes. As previously mentioned, the ABET requirements focus heavily on measuring student progress. In a FSU Character Clearinghouse review of $8 \mathrm{KQ}$ they found that the success of the $8 \mathrm{KQ}$ "demonstrates how an aspirational, ambitious approach to an accreditation process can make immense strides in shaping the student experience"[25].

One valuable element from this project is the short, concise summaries of the ethical theories, available in a one page format. While, this one page tour through several different ethical theories is not enough to have the students become an expert in any of them, or replace a 
formal ethics course, the summary is nevertheless a good way to provide information about the different ways to consider the ethical principles in an easily digestible format, right when the student needs it. (For example, just as they are considering the value of fairness surrounding whatever it is they are considering). Having several different but related concepts available as the student considers fairness helps students consider points and interpretations of fairness that they may not have thought of otherwise. The short lessons provide value to students who might not otherwise be motivated to Also having the short and accessible lessons I think aids in the introduction of ethics into many courses, because it removes the need for the instructor to be an expert, though it would definitely help if the instructor understood these topics well, and could help if students had questions. By having a nice summary it removes a fear from instructors that they may not be knowledgeable in ethics. Though faculty apprehension with regard to this particular project was not discussion in the literature form the Ethical Reasoning in Action website, it was something that was brought up as a concern in the Embedded EthiCS pilot discussed above and so I think is something that likely extends beyond Harvard.

Another valuable element of the 8KQ handbook was having a list of straightforward questions to ask yourself and the "How to Proceed" section. These elements add an element of concreteness that helps it be accessible and easy to consider in a variety of situations. The How To Proceed provides a good way to begin to apply the theories to answer the two big questions at the top. A concrete hint like that helps students to have a way to start if they are feeling lost. One potential drawback to this system it is important to give students concrete hints if needed, but without pushing them into a certain method of considering a situation. A balance must be struck 
between a concrete set of questions and allowing for the flexibility that must come with considering ethics.

A third takeaway, is that this way of teaching ethics not only considers ethics in a variety of educational contexts, but also in a variety of personal contexts. Although this is a bit outside of the scope of the project, I have been focused on Software Engineers and how they are able to understand and apply ethics, in their lives as a student and also as a professional, but I do not often consider a student or professional's life outside of work actives. Though it is likely that this additional consideration of extending ethics beyond just work, or study but also to their personal lives could have additional value, in the same way that Embedded EthiCS did, as a way of habituating students to think ethically. Beyond habituation, working through ethics in a wide variety of situations help students experience a variety of contexts, which was stressed by Mike Kirkpatrick as being an important element to ethical reasoning, since it is a context based skill, it is hard to learn to do it without practicing in a wide variety of contexts. So another takeaway is that ethics and ethical decision making should be practiced in a wide variety of contexts, whether that be a variety of professional or personal contexts.

Finally the $8 \mathrm{KQ}$ system is simple and self contained, as well as being open ended enough to be applied to a variety or situations and by a variety of abilities. Being self contained, by having within the handbook enough of a background to start an ethical analysis, it removes some of the barrier to entry for student groups, or non-philosophy faculty to implement the system without help or frustration. The types of questions also allow for students who are trying it for the first time to use it in one way, with more simplistic answers to the questions, while students who have philosophy and ethics experience are able to answer in a more complex way, this 
allows the same framework to be used throughout the college education, having the framework be able to grow with the academic understanding of the student. In implementing a similarly modular ethical system, an important consideration will be to avoid setting up the feeling that going through this checklist of question will suffice and once they are considered once the process of ethics is over. Again a balance must be struck, the concrete, checklist of questions, does help students who are not familiar with the ongoing and non-concrete nature of ethical reasoning, but at the same time care must be taken to ensure that it is still clear that ethics is not a checklist that can be completed but instead is something that must be considered repeatedly. In essence, a balance between showing students that ethics is ongoing, yet still concrete enough that they will not feel hopeless and frustrated at the start.

Although the system would require a significant buy in from the university and faculty in many different departments, certain elements are still valuable to study to use in a situation that might not have that level of buy in. 
MTU-Proposed Project. Michigan Tech does not have a widely implemented ethics project like the ones mentioned above. Though for completeness I wanted to mention a proposed solution in the same vein as the first two, proposed for implementation in at Michigan Tech. The grant writers, Alexandra Morrison, Charles Wallace and Scott Marratto, propose the project 'Building Ethics into Technology Design' aimed to solve some of the challenges faced by Michigan Tech, but also by other STEM schools. For reference the other two distributed ethics programs discussed before were by Harvard and James Madison University, neither of which has the primarily STEM focus that MTU has. This program was designed to work on STEM university challenges of a small number of ethics courses, the lack of formal ethical training of engineering faculty, and the lack of integration between STEM and the humanities.

The project is designed to create a team of faculty to help try to combat the problem of ethics education falling to faculty who do not have formal training, are not aware of the current developments in the field, and who may not be interested or incentivized to learn more.

Additionally by creating a more formal process for ethics education across disciplines, it could help ethics education be less sporadic and more continuous throughout a student's education, no matter which department they are a part of. From the grant proposal directly "Our transdisciplinary team at Michigan Tech, with faculty from the humanities, engineering, and computer science, will explore new venues and modalities for integrating the Ethical Cycle into the engineering design process in a manner accessible to non-philosophers but without forsaking the critical philosophical content" [30].

The goal of this team would be to create interventions, workshops and seminars to better share with students and faculty what the current field of philosophy and ethics looks like. The 
team would also work with STEM faculty to update their current ethical units that are being taught in engineering courses to include topics from STS, Philosophy of Technology and the Ethical Cycle. Specifically the initial project focuses on a updating the curriculum in courses that are already teaching ethics to a large number of students. Similar to the Ethical Reasoning in Action the team will also hold events outside of the classroom, but distinctly the events by this team would showcase ethics and STEM instead of personal and group activities. These events would primarily initially include speakers in engineering ethics and philosophy of technology. Also similar to Ethical Reasoning in Action is this project's focus on educating the faculty members, empowering to better the quality of their own ethics instruction, as well as attempting to break down the distinction between STEM and humanities.

Though this is taken from a grant proposal and therefore not actually implemented at this time at MTU and there is not yet feedback some of the elements are similar to those that worked well in the Ethical Reasoning in Action program. Both projects have a focus on a wholistic approach with attention paid to both the material that the students are being taught and working with, but also on educating the faculty. In terms of the material that is taught, it would probably be considered more similar to the Embedded EthiCS, because the proposed project was going to create a unique curriculum for each of the courses it proposed to update. The one element that could be similar to the $8 \mathrm{KQ}$ is the use of the ethical cycle. From the proposal it sounds as though many of the updates to the courses would involve updating the courses to use the Ethical Cycle, meaning that although much of the material would probably be unique for each of those courses, like the $8 \mathrm{KQ}$, the Ethical Cycle would likely remain consistent as a framework throughout a student's different interactions with ethics. Another unique element of this project is the focus on 
helping the faculty in other departments understand the recent developments to the Philosophy of Technology, Ethics Education, and STS. Neither of the other distributed ethics projects mentioned any of these, and only one out of the four educators that I interviewed mentioned this area, so this is a unique area of study and something that makes this project stand out. By showing students the most current methods for considering ethics in regards to technology and engineering, it can increase overall respect for the discipline.

\section{Curent Software Solutions}

There have been software solutions proposed and implemented to attempt to address some of the challenges in engineering ethics education, or other similar deliberative problems. The main software for engineering ethics education is AGORA, but there are some fundamental issues with the instrumentality of its design, as well as some issues with its ultimate implementation. Although AGORA is the only current ethics software, there is value to be gained from considering elements of software that exists to solve similar problems, such as the need for thoughtful online consideration. Additionally a consideration of some of the current research into the effect of online deliberation, and online discussion on the discussion itself and those using the software can provide some insight into what elements a software intervention should contain.

It is important to consider carefully these beginning design questions of the software intervention because it is these early decisions that will ultimately shape the final product. Any software intervention that moves some part of ethics education online will create an experience that is mediated by that software technology. It is critical that the software scripts in a proposed intervention be thoughtfully considered, because they will impact the users actions. Considering which elements of software with similar goals helped to push users toward those goals and can 
help me better understand which elements to include in my recommendation. Similarly by considering which elements of a software might contain scripts which discourage the type of logical, thoughtful and polite discussions online can help us to consciously avoid those those elements. Deciding to use software in ethics education in itself is an ethical decision, as it changes the way the students experience the course. In this way, in order to best be able to design a software which can help students learn to question design decisions of technology as ethical issues, it is essential to consider ethically the design of that software itself.

\section{Introducing Agora}

The current version of AGORA that is up and accessible online lacks much of the proposed functionality written about the in the paper on the software, by two of the creators of the software.

Because the paper seems to be more true of the creators vision for the software, the primary focus on the software will be about that version.

AGORA was created in an attempt to solve three major issues in ethics education. The first issue is students tended to jump to conclusions when analyzing case studies, instead of considering fully the relevant facts or moral considerations. They also found that when analyzing a case study the students would often fail to consider and use the ethical systems that were taught. And lastly they found that some students considered ethical dilemmas to be a problem of opinions and not a problem for rational arguments, supported with facts [7].

Agora was designed by several professors from Dutch engineering ethics programs. Agora was designed with the aim of correcting student beliefs that are not rational, but instead the opinion of the speaker. In this way Agora, the technology is designed to purposely mediate 
students perception of ethics. Additionally Agora is an effort to address the misconception that technology is neutral, meaning that the moral burden around technology doesn't rest on its engineers. Additionally AGORA attempts to call into the question for students the enormous amount of trust they place in the ability of an engineer to make an ethical decision without formal training $[34,35]$.

AGORA's goal, as stated by the authors, is to emulate the self-reflective process a student experiences when talking with an instructor, as the instructor encourages self-reflection. "To this end, a program was developed that does not only offer the possibility to analyze cases with the help of a systematic and rational method that is based on a specific kind of theory, but which also (1) offers the possibility to distinguish different lines of thought that belong to different ethical theories, in order to allow students to reflect on the differences between these theories, and (2) asks students to give their own view and think critically about the possible discrepancies between their view and the result of the application of a rational method, or to think about the differences between the results that the application of different rational methods provide" [7]. The Agora software aims to encourage the students to continually revise their thoughts, in order to discover previous errors. Agora aims to demonstrate how well designed software could allow for and encourage self-reflection without requiring the aid of a third-party observer.

The Agora software encourages students to consider evaluating a case study using several different ethical systems. Using different ethical systems highlights different relevant facts of the case, which helps students to remember aspects of the case that they had previously ignored or forgotten. 
The purpose of the Agora software is to provide a solution to two problems. First, the problem of how to teach ethics concepts to engineers in a way they will be receptive to. This is a problem Agora solves by using the ethical cycle. The second problem is the scalability issue of using teacher/student discussions to promote self-correction as class sizes increase. The idea that this would be a software reduces some of this scalability issue.

In their paper the development team of Agora referenced two existing softwares designed to aid in teaching ethics in order to highlight the ways Agora was different. First, the Agora software is not a series of fixed steps and instead a "choose your own adventure" which gives flexibility to students and teachers. The second way the Agora software differs is it encourages the students to analyze and reflect before the end. In previous software interventions the student was asked about his or her opinions and analysis only at the end, which reduced the amount of self reflection and revision that was performed overall.

The AGORA software also has tools built in to allow instructors to give students quick automated feedback while also allowing the course instructor to provide individualized feedback as needed. Additionally AGORA allows students to learn more about the different ethical theories from within the tool itself by visiting the theory chamber. AGORA also provides a forum for discussion, with certain bounds in place in order to keep the conversation productive. As I mentioned previously, this version of AGORA is not currently online and accessible and so most of my information about this feature comes from a photo and a description in the paper published about the software. This description doesn't go into detail about what elements of this discussion forum encourage this productive conversation. 
The version of this software that is accessible online currently is very different from the software described in the paper. The online version allows the creation of cases and functions as a library for these case studies. The tool encourages users to fill out a form about their case study, and then the case study becomes part of the library. Additionally there seems to be a way for an instructor to build out the specifics of ethical cycle that they want their class to use. Ultimately a lot of the functionality talked about in the paper is not implemented, or at least was not visible to the account that I was given to view the system.

\section{Learning From Agora}

Although the current implementation of AGORA online is fairly sparse, there are still elements of it that are useful to consider. One feature that would be useful to consider for a future software intervention is the library of cases. The AGORA platform is set up to allow educators who use it to submit their case studies to a larger library so they can be used by other educators. This library and sharing of case studies is something Morrison mentioned during her interview as something that would be useful. Kirkpatrick is working on creating a library of case studies for ACM, to be used to demonstrate codes. I think having a wider variety of cases to use and adapt from would be beneficial to Kirkpatrick as he works on this project, and then the results of the project would be useful for others to adapt as well. There are some implementation issues with the case study library. The interviews showed when educators are searching for a case study to use in their ethics course they often have different expectations of what a case study looks like, and very different use cases for that study. By failing to separate the case studies into some type of category the case study library will not be very useful for educators as they search for a particular style of case study. If categories seem too restrictive for what ultimately is a sliding 
scale of attributes a tagging system might be considered as an alternative to hard categories. A case study in the library could be tagged as both "news" and "complex" for example, eliminating the need to choose one category. Additionally the method of entering the case study into the Agora library currently encourages one type of case study. The case study can be entered through a relatively small text box. This decision to input using a text box instead of a file upload or multiple text boxes is one that discourages more complex case studies. For example consider the case studies used by Kirkpatrick that involve the multiple written perspectives of the same facts. This type of case study is too complicated to fit into the text boxes that are provided to submit to the case library. Additionally consider the types of case studies used by Morrison, they tend to involve longer blocks of text, articles and other resources that are challenging to submit via this form. The case study entry method seems to both assume and encourage instructors to use the simple case type of case study. In a future software intervention the method of entering a case study should allow for submission of a wide variation of case study types. The result would be a diversity of case studies in the library, instead of a library dominated by one type of case study. An additional benefit of a diverse library of studies means that educators might be encouraged to try different methods of teaching case studies, inspired by those other types of studies that are now available to them. With a strict category system, the software intervention might risk encouraging users to stay within their often used type of case study, by eliminating the serendipity of a user finding a different type of case study then they were looking for. A tagging system might help this because it would encourage cross over between categories, encouraging educators to branch beyond one category. Additionally having the tagging go beyond category to also include topic could encourage users to search by topic instead of by type encouraging the 
discovery of new types of case studies. The image shows a suggestion for a possible UI that considers these suggestions.

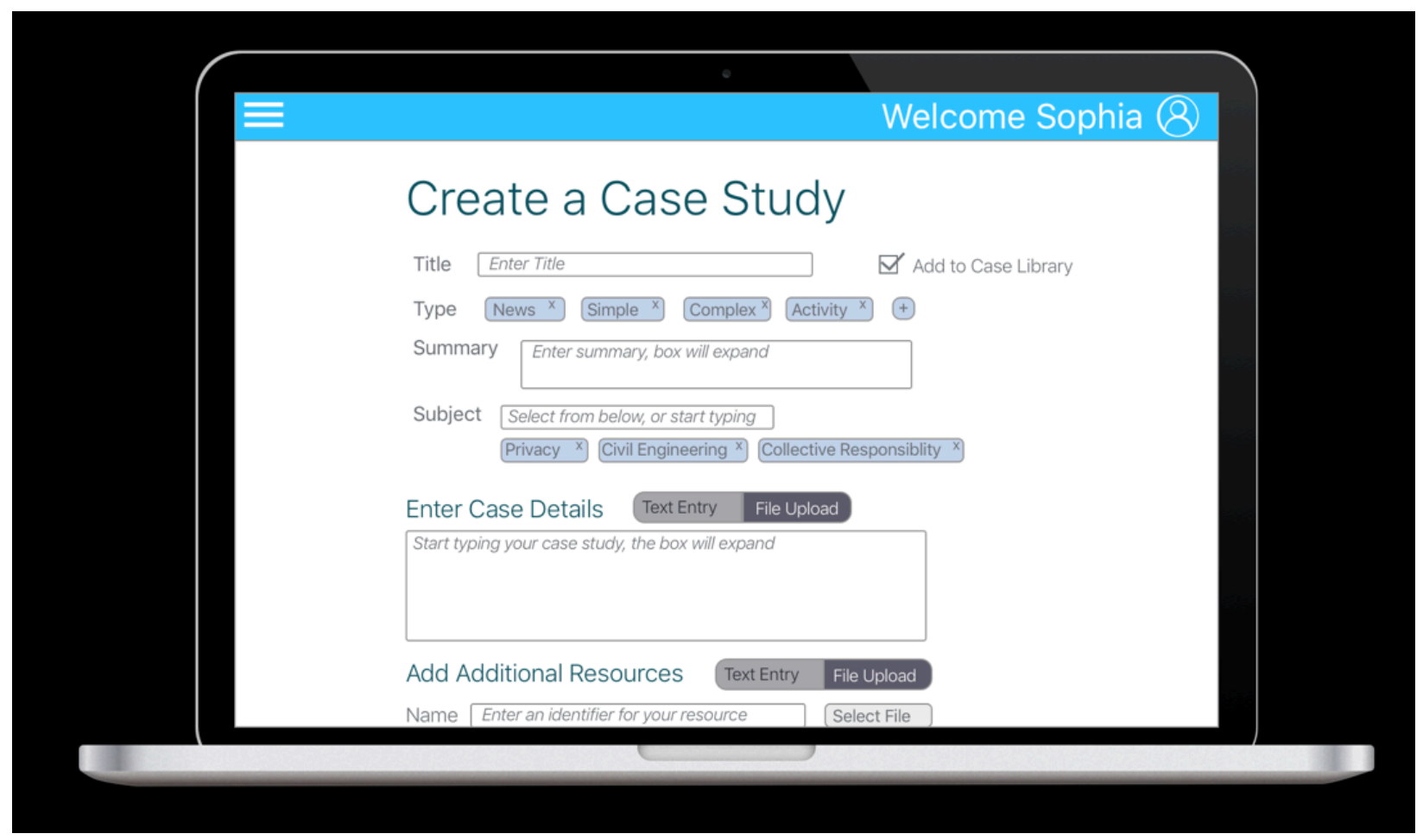

A Sample UI for Case Study Creation

The planned implementation of AGORA contains additional elements worthy of consideration, even if they didn't make it into the current implementation. The systematic user flow of the ethical cycle is something that could be useful to implement in future software interventions. The planned implementation gives educators a lot of freedom to modify the ethical cycle for their own class. This flexibility is an element that should be included in a software going forward. By encouraging educators to pick from a list and then also add additional frameworks if they wish allows educators the flexibility to tailor the ethics course to their own 
style. Additionally the elements of a pre-populated list can spark inspiration in an educator who might not otherwise include a certain ethical framework but because there is support in the tool for including it, might be more apt to try it out. In a software intervention this flexibility will help ensure the software is useful by many educators instead of only certain types. This flexibility should be extended to the students too. Letting students add their own ethical frameworks if they wish allows the software to help students feel empowered to own it for themselves instead of the feeling that they are working through someone else's system. Having software which encourages individuals to own ethics sends the message that ethics needs to be owned by everyone, even those who are not controlling the process, like students in a classroom setting or junior engineers in a workplace setting. Additionally this flexibility and ownership of ethics might make students more likely to see this as a useful framework to think through moral problems that come up in other areas, outside of the ethics course.

Agora also contains a way for students to receive feedback from instructors either personalized feedback or a more generic, automatic feedback. The ability to receive feedback for thought processes either written during the ethical cycle or during discussions done afterwards is an important part of the process. This is something all the educators implemented in their physical classroom and that Morrison implemented in her online discussion. The implementation of the automatic feedback is something that is not detailed in the paper and not available in the current version, so it is hard to tell exactly how it works. All the instructors have methods of providing immediate in-class feedback to students. It becomes more challenging if the discussion moves online though. Automatic feedback for online discussions is something that could be really useful for educators in a large class setting, allowing educators to give feedback in 
situations that would otherwise be too hard to do. Morrison mentions the she doesn't give feedback to the discussion groups online every time but chose to do it because this situation was more complex. Perhaps those other discussions could have benefitted from feedback, but it is not feasible to give feedback to every student for every post especially in a large class. Here is a case where some type of automatic feedback would be useful. Great care must be taken to avoid having the software send the wrong message to students. Having the software respond unambiguously 'yes' or 'no' would counteract the message the content of the software is trying to deliver: that ethics and moral problems are hard, ambiguous and options for action are not simply 'right' or 'wrong'. A better form for this feedback might be in the form of helpful tips. Possibly phrasing it more as a "learn more about X topic here" instead of a "Your interpretation of X was wrong, here is a correct one". The first phrasing frames the feedback a chance to continually improve, to learn more and then to go back and rework previous responses, taking into account this new information. This aligns with the process that the ethical cycle is trying to encourage, continual rethinking and continual improvement. These "suggestions for more information" can possibly be displayed to students based on certain keywords in the students responses that might indicate a misunderstanding. This could be built up overtime with a similar tagging system. So at first an educator might be able to use some automatic responses given by the system with their preset tags. The educator could improve the system by working through the student responses and tagging certain sentences or phrases as indicating certain feedback was needed, and then craft that feedback with links to the applicable part of the framework from some sort of internal philosophy resource, or a comment written by the instructor. Then they could use this response at other points in the future, tagging which new phrase suggested the 
need for this type of feedback. As the educator kept doing this, the program could learn and in the future would be able to automatically recommend these same types of responses based on the same and similar keywords used in other students work. There is no reason that these have to be negative either. Certain words or phrases might be used simply to provide a way for the student to continue to expand and improve, even if their interpretations were correct, possibly this time asking additional questions for a student or consider or linking to possibly more complex additional resources. Additionally the responses could continue to grow for a particular instructor every time they teach the course, meaning that they would be able to use responses from the previous years, and then use their time to continue to reach out to students who need help individually instead of rewriting the same suggestions to many students. It is easy to imagine how a system that tries to nudge student to rethink things and push them towards more resources can quickly turn into a system that tells students they were right or wrong. Ultimately this system is not intended to replace instructors, but to be able to amplify their ability to respond to individual students. I think how exactly the wording and the UI elements end up in this case are important to keep the system on the nudging side. The displayed UI shows what a design that took into consideration these suggestions might look like. 


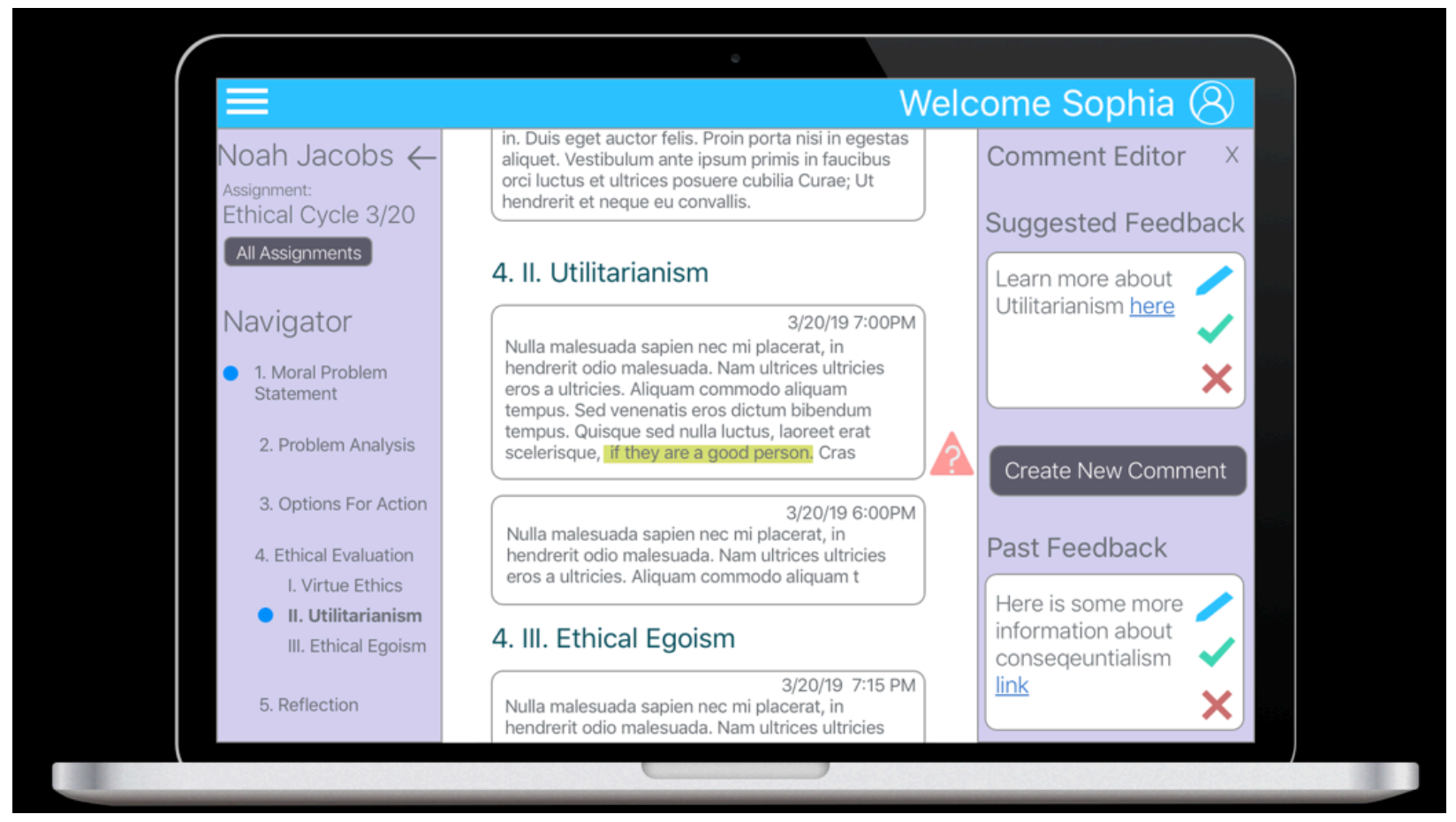

A Sample UI for Feedback

\section{Introducing ConsiderIt}

Another software that could be useful to draw inspiration and lessons from is the ConsiderIt platform. ConsiderIt is proposed as a solution to help increase thoughtful deliberation for contentious issues. It is a variation on a pro-con list and therefore works best for problems with a clear yes or no answer. In its current form it is not well suited for ill-structured moral problems. Initial tests of the ConsiderIt platform have been positive. Giving thought how elements of the user experience help mediate the type of interactions the users have with one another could be productive in carrying those elements over to a software intervention for ethics.

ConsiderIt aims to solve the problems evident in public debates and public conversations about divisive issues. During these discussions the issues tend to be framed as zero-sum games with supporters of each side talking out loud but not necessarily to the other person. This is a 
critical opportunity that gets missed for both sides to better understanding the other's thoughts and perspectives.

ConsiderIt aims to solve this problem using a publicly constructed pro-con list.

ConsiderIt encourages users to create their own pro-con list by pulling in points from the lists on the side of the screen. These lists were generated by aggregating all the pros and all the cons from previous users' lists. These elements from others' lists are displayed in sidebars on either side of the screen and can be dragged to a user's own lists. The user can also write their own point, if the point is not in either list. Users of the platform are encouraged to interact with ideas from both sides, without knowing who authored the points, or included those ideas in their lists. Any ideas that the users add to their list that is not in the bank of public points gets added after the user is finished, allowing the bank to continue to grow and improve for future users $[22,40]$.

\section{Learning From ConsiderIt}

The ConsiderIt platform depends on the quality of the user generated bullet points as a critical part of the platform's functionality, and because of this the issue of the points being low quality is a significant one. The quality of the points could be low because the point is known to be false, but more worryingly because the point is a common misconception.

The concern of false information, or bad points heading to the top of the lists is addressed by the creators of ConsiderIt. Their solution is an algorithm for determining the order of the points on either side. Points are given a score that changes based on how often the point is included in users' lists. So a point that is strong for either side will likely be included in many lists either as a pro or a con, and therefore will be given a high strength score. A point not used often will be given a low strength score and be ordered near the bottom. This helps to filter out 
some of the bad points so that the good points get more visibility. A concern is that a new point will have trouble reaching the top of the list and so would be unable to gain enough visibility to have a high strength score. The algorithm addresses this as well, all the points actually start with a high strength score and that score is reduced as the points go unused, so new ideas have an advantage. If this type of platform was used in the long term, this algorithm would help keep the facts and discussion relevant to the current time. For example, if this platform was used when discussing a certain case, and in the past year a new and highly relevant piece of information has come to light, comments or points that do not consider this information would start to drop in the rankings whereas comments that consider this new information or are still relevant in light of the information are higher up in the list [22].

When talking about the ConsiderIt platform with Morrison, she expressed concern although the algorithm dealt with untrue information, it allowed common misconceptions to persist. Although a common misconception is factually wrong, because it is common it might be a popularly used point, and therefore be given a high strength score. If this type of deliberation were to be applied to a computing ethics tool, there are a couple of ways of dealing with this issue. Because the system would likely be used in a classroom setting an educator could serve as a moderator and simply pull those types of points down. However I think what might be more valuable is having users be able to tag those posts as a "common misconception" and maybe give a sources to back up their claim. Then the system could have the moderator review it, and if it is deemed to be untrue it be removed. This has the benefit of encouraging students to read critically and consider the factual truth to even widely believed claims. A drawback to the removal of the point is that other users are likely to think this point has not been made in which case they would 
simply add it themselves and it would continue to propagate as its removed. An option to mitigate this, and allow for learning is to have a separate box, maybe at the bottom where these common (and now debunked) misconception points could go, along with sources and an explanation of why this point isn't true, so the students could see this as they consider the other points in the list. If this software were applied to teaching ethics this would be a good way of allowing students to learn from one another's mistakes.

Another element I think could be added to the ConsiderIt system is the ability to cite a source when generating a point, or to add a source to an existing point. By adding the option to do it, even if that option were not required, it could encourage users to think about the source of their information, and also to encourage users to think about a point as being both the information and a source instead of just the information.

Another element of this software that I think is worth considering for potential applications in ethics education software is the way ConsiderIt managed to make asynchronous communication work for deliberation. With the exception of the first couple users, anyone who uses the platform has ideas to interact with, and those ideas are available at the time that the user needs them. I think this could address some of the problems that Ott found with online discussions: that the ideas are not available to interact with until the user is no longer in the context to interact with them. Maybe there is a way to use a strategy similar to ConsiderIt so that students in a current class are able to interact with ideas put forth by students in a previous class. In a way this could lead to higher quality discussions because if the "best points" continued to rise improving the quality of the ideas that the user sees with each iteration of the software. This solution would also help solve for timelines. There are some differences here because this is a 
learning environment instead of a public one ConsiderIt was designed for. One challenge is that points might be valid but not appreciated by students, because they are still gaining understanding in the topic. This might cause good points, or those written by the instructor to sink lower. A possible solution might be to allow instructors to "pin" points to the top of the list, and "unpin" them if they are no longer needed to be at the top of the list. This would prevent the algorithm from filtering out points the instructor deems as highly important. Another change that would need to be made is that timing could be an issue here because it is a classroom setting. It might not be appropriate for other individuals thoughts to be given to the students right away because that might discourage them from thinking for themselves, or struggling with it themselves. A possible software solution to this might be to only release the interaction or idea page once the students have written down their own thoughts on the issue, a copy of which would be saved to encourage prior reflection before interacting with others ideas.

\section{Future Considerations}

\section{Learnings From This Report}

As I mentioned after the interviews, one area that future investigation to create a taxonomy of how "case study" is used by educators. In the limited interviews that I conducted, I found significant variety, and also was able to categorize some of the variants of the usage, but this is certainly an area where additional study would be valuable. A taxonomy would provide some clarification and standardization in the use of ethics education terms. Right now the word "case study" is used by instructors as though it is clearly defined, when in reality this may not be the case. Though there is a risk from standardization of terms to lose some of the diversity in the case studies that are being used. Another risk being that instructors might have less conversations 
about it because the terms are already clearly defined. I think if standardization of terms was done properly, perhaps it could result in more appreciation and publicity for the different types and purposes of case studies, allowing instructors to better communicate and share resources with each other. I think additionally it could showcase the legitimacy of other types of case studies to educators who do not use them, because it could make clear that they are made to serve a unique purpose. I think this taxonomy could include other words in ethics education as well, I only focused on the word "case study" in my interview transcripts, but I think further research could show other similarly complex words. Making clear what people actually mean when they use certain terms is important for communications from one educator to another, and being able to better share compatible resources. Some additional clarity in definitions is also important when reporting the results of studies in ethics education, and then when readers attempt to apply their findings. Research in this area could consider using resources from the National Initiative on Cybersecurity Education (NICE) ${ }^{6}$, from New America, as they are trying to work towards a standardization of other term in computer science, cyber security, and ethics education, in order to learn more about what the process of doing a taxonomy and working towards a standardization might look like from someone also working in the computing field [31].

${ }^{6}$ NICE is situated within the National Institute of Standards and Technology. While they work on several different projects, on in particular that they have taken on is the task of standardizing the language and taxonomy used to describe work in cybersecurity. The NICE Cybersecurity Workforce Framework19-a self-described "non-prescriptive cybersecurity workforce dictionary" - was first posted for public comment in 2012, and since has been informed by extensive outreach to the cybersecurity community [31]. The Framework standardizes and makes clear the relationship between different terms without forcing the definitions onto anyone. The motivation is primarily for the Cybersecurity job market, to make sure that job responsibilities were be accurately communicated from job post to applicant. 
Another area that should be considered in future research, especially in computing ethics specifically is something called the Ethical OS. It is similar to the ethical cycle but focuses specifically on what its creators feel are the needs specific to software companies. Ethical OS includes 8 risk zones ${ }^{7}$, and an associated risk assessment checklist to consider specific software risks. The Ethical OS toolkit includes an in-depth discussion of those risk zones with their checklist questions, example scenarios and questions to ask when considering a scenario and then a What To Do section offering advice on how teams can start working on future proofing against some of the potential problems of their technology [10]. Ethical OS is used by Techstars, a startup accelerator, to decide which companies to invest in. If the company seeking funding isn't able to think about some of the issues presented in the Ethical OS Toolkit, then Techstars is hesitant to invest. Beyond Techstars the Ethical OS system has been piloted by 20 companies, startups and schools. [33]. Ethical OS is designed to look and function like the playbooks that are used by product developers to launch their products. The Ethical OS is something that should be considered alongside the ethical cycle when thinking about how to teach ethics to software engineers, because it seems to be resonating with many in that industry. Especially if this framework continues to expand in startups and then the broader Silicon Valley area as a whole, it could be useful to introduce to students. Additionally it provides an way of implementing ethics education that is focused on industry instead of academia. Many elements parallel the programs that this report has covered and many elements to ethics education that have been discussed are also mentioned in the Toolkit. Some differences include wider industry support for this particular way of thinking about ethics, including investing firms exerting influence to support this 
framework. Additionally it is a concrete and modular way of thinking about ethics is designed specifically for computing ethics, which is another unique element of Ethical OS. Considering a computing ethics specific framework could provide some important suggestions in the design of a framework or larger software project to aid in computing ethics education. 


\section{References}

[1] ABET. Criteria for Accrediting Computing Programs 2018-2019. 2018. Retrieved from https://www.abet.org/accreditation/accreditation-criteria/criteria-for-accreditingcomputing-programs-2018-2019/\#GC4

[2] ABET. Criteria for Accrediting Engineering Programs 2018-2019. 2018. Retrieved from https://www.abet.org/accreditation/accreditation-criteria/criteria-for-accreditingengineering-programs-2018-2019/

[3] Madeleine Akrich and Bruno Latour. 1992. A summary of Convenient vocabulary for the semiotics of human and nonhuman assemblies. Shaping Technology/Building Society: Studies in Sociotechnical Change. MIT Press.

[4] Maria Baghramian and Adam J. Carter. 2018. The Stanford Encyclopedia of Philosophy: Relativism. Retrieved from https://plato.stanford.edu/archives/win2018/entries/ relativism/.

[5] Bemidji State University. Computer Science: Our Mission and Vision. Retrieved from https:// www.bemidjistate.edu/academics/departments/mathematics-computer-science/computerscience/our-mission-and-vision/ 
[6] Garry D. Brewer. 1999. The challenges of interdisciplinarity. Policy Sciences, 32. 327-337.

[7] Simone van der Burg, and Ibo van de Poel. 2005. SCI ENG ETHICS, 11 (Jun. 2005), 277-297. DOI: https://doi.org/10.1007/s11948-005-0046-8

[8] Julia Driver. 2014. The Stanford Encyclopedia of Philosophy: History of Utilitarianism. Retrieved from https://plato.stanford.edu/archives/win2014/entries/utilitarianism-history/

[9] Ethical OS. 2018. Ethical Operating System. Retrieved April 20 $0^{\text {th }}, 2019$ from https:// ethicalos.org/

[10] Ethical OS. 2018. A guide to anticipating the future impact of today's technology. Retrieved April 20 ${ }^{\text {th }}, 2019$ from https://ethicalos.org/wp-content/uploads/2018/08/Ethical-OS$\underline{\text { Toolkit.pdf }}$

[11] Ethical OS. 2018. Ethical OS: Risk Mitigation Checklist. Retrieved April 20 ${ }^{\text {th }}, 2019$ from $\underline{\text { https://ethicalos.org/wp-content/uploads/2018/08/EthicalOS Check-List 080618.pdf }}$

[12] Maarten Franssen, Gert-Jan Lokhorst, and Ibo van de Poel. 2018. The Stanford Encyclopedia of Philosophy: Philosophy of Technology. Retrieved from https:// plato.stanford.edu/archives/fall2018/entries/technology/ 
[13] Barbara Grosz, David Gray Grant, Kate Vredenburgh, Jeff Behrends, et all. 2018.

Embedded Ethics: Integrating Ethics Broadly Across Computer Science Education.

Forthcoming - to be published in Communications of the ACM.

[14] IMDB. 2011. IMDB: Black Mirror. Retrieved from https://www.imdb.com/title/tt2085059/

[15] James Madison University. College of Integrated Science and Engineering Mission. 2019.

Retrieved from https://www.jmu.edu/cise/about/mission.shtml

[16] James Madison University. Ethical Reasoning in Action: Eight Key Questions Handbook. 2018. Retrieved from https://www.jmu.edu/ethicalreasoning/Docs/8KQ-Handbook$\underline{\text { Web.pdf }}$

[17] James Madison University. Ethical Reasoning in Action: Student Learning Outcomes. 2019. Retrieved from https://www.jmu.edu/ethicalreasoning/slos/index.shtml

[18] James Madison University. About Ethical Reasoning in Action. 2019. Retrieved from http:// www.jmu.edu/ethicalreasoning/about/index.shtml

[19] Rober Johnson and Adam Cureton. 2019. The Stanford Encyclopedia of Philosophy: Kant's Moral Philosophy. Retrieved from https://plato.stanford.edu/archives/spr2019/entries/ $\underline{\text { kant-moral/. }}$ 
[20] The Joint Task Force on Computing Curricula Association for Computing Machinery (ACM) IEEE Computer Society. 2013. Curriculum Guidelines for Undergraduate Degree Programs in Computer Science. DOI:http://dx.doi.org/10.1145/2534860

[21] Mike Kirkpatrick. Ethics Education Interview with Dr. Kirkpatrick. Interview.

[22] Travis Kriplean, Jonathan Morgan, Deen Freelon, Alan Borning, and Lance Bennet. 2012. Supporting Reflective Public Thought with ConsiderIt. In $C S C W$ '12. ACM Press, Seattle Washington, USA.

[23] Paige Leskin and Nick Bastone. 2018. Business Insider: The 18 Biggest Tech Scandals of 2018. (Dec 2018). Retrieved April 20, 2019 from https://www.businessinsider.com/ biggest-tech-scandals-2018-11

[24] Thomas R. Lindlof and Bryan C. Tayor. 2019. Qualitative communication research methods. ( $4^{\text {th }}$. ed.). SAGE, Los Angelos, CA

[25] Jessica Mestre. 2018. The Madison Collaborative, James Madison University. Retrieved April 20 $0^{\text {th }}, 2019$ from https://characterclearinghouse.fsu.edu/article/madisoncollaborative-james-madison-university 
[26] Michigan Technological University. Undergraduate Goals and Rubrics. Retrieved from www.mtu.edu/assessment/undergrad/resources/goals.

[27] Alexandra Morrison. 2019. Ethics Education Interview with Dr. Morrison I. Interview.

[28] Alexandra Morrison. 2019. Ethics Education Interview with Dr. Morrison II. Interview.

[29] Alexandra Morrison. 2019. Situating Moral Agency: Addressing the Blind Spots of Engineering Ethics with Phenomenology, Philosophy of Technology and STS. Accepted Journal Article. Michigan Technological University, Houghton, MI.

[30] Alexandra Morrison, Charles Wallace, Scott Marratto. 2019. Building Ethics into Technology Design. Grant Application. Michigan Technological University, Houghton, MI.

[31] New America. 2018. Section One: What are Cybersecurity Jobs? Retrieved April 20 ${ }^{\text {th }}, 2019$ from https://www.newamerica.org/cybersecurity-initiative/reports/cybersecurity_workforce-development/section-one-what-are-cybersecurity_jobs/

[32] Linda Ott. 2019. Ethics Education Interview with Dr. Ott. Interview. 
[33] Arielle Pardes. 2018. Silicon Valley Writes a Playbook to Help Avert Ethical Disasters. (Aug. 2018). Retrieved April 20 th 2019 from https://www.wired.com/story/ethical-os/

[34] Ibo van de Poel and Lamber Royakkers. 2007. The Ethical Cycle. Journal of Business Ethics, 71, 1 (Mar. 2007), 1-13. DOI: $\underline{\text { https://doi.org/10.1007/s10551-006-9121-6 }}$

[35] Ibo van de Poel and Lamber Royakkers. 2011. Ethics, Technology, and Engineering. WileyBlackwell.

[36] John D, Ranney and Wendy Troop-Gordon. 2015. Problem-focused discussions in digital contexts: The impact of information and communication technologies on conversational processes and experiences. Computers in Human Behavior 51, (2015), 64-74. DOI: https://doi.org/10.1016/j..chb.2015.04.038

[37] Jacob M. Rose. 2007. Corporate Directors and Social Responsibility: Ethics versus Shareholder Value. J Bus Ethics 73, 3 (Jul. 2007), 319-331. DOI: https://doi.org/10.1007/ s10551-006-9209-Z

[38] Robert Shaver. 2019. The Stanford Encyclopedia of Philosophy: Egoism. Retrieved from https://plato.stanford.edu/archives/spr2019/entries/egoism/. 
[39] David Woodruff Smith. 2018. The Stanford Encyclopedia of Philosophy: Phenomenology. Retrieved from https://plato.stanford.edu/archives/sum2018/entries/phenomenology.

[40] Hans Stiegler and Menno D.T. de Jong. Facilitating personal deliberations online: immediate effects of two ConsiderIt variations. Computers in Human Behavior 51 (2015) 461-469.

[41] Kara Swisher. 2018. The New York Times Opinion: Who Will Teach Silicon Valley to Be Ethical? (Oct. 2018). Retrieved April 20"th 2019 from https://www.nytimes.com/ 2018/10/21/opinion/who-will-teach-silicon-valley-to-be-ethical.html

[42] Nicholas Thompson and Fred Vogelstein. 2019. Wired: 15 Months of Fresh Hell Inside Facebook. (April 2019). Retrieved April 20"th 2019 from https://www.wired.com/story/ facebook-mark-zuckerberg-15-months-of-fresh-hell/

[43] Marty Wolf. 2019. Ethics Education Interview with Dr. Wolf. Interview.

[44] Theodore Zorn. Conducting Thematic Analyses of Interviews and Field Notes. Handout. University of Waikato. 


\section{Philosophy Background}

\section{Traditional Ethical Theories}

These are the traditional ethical theories, these are ones typically referenced in ethical modules, the $8 \mathrm{KQ}$, and also were covered in both ethics courses at MTU, as well as the other two courses taught by the professors I interviewed. These theories are for the most part much older than their contemporary counterparts. Virtue ethics, for example, can be traced back to Ancient Greek philosophy and utilitarianism was first championed in the 18th century by British philosopher Jeremy Bentham.

\section{Ethical Egoism}

Ethical egoism puts the individual at the center of the ethical consideration. An action is ethical if and only if it creates the maximum good for that one individual [38]. It is difficult to take this ethical position seriously because an individual's actions do not only impact that individual, and ethical egoism does not consider the impacts of an act on any others who might be impacted.

\section{Cultural Relativism}

Cultural relativism means that something is ethical depending on the context it is within, the idea that something might be ethical under one culture but by another cultural standard it might be considered unethical [4].

\section{Utilitarianism}


According to most utilitarian approaches to action an act is ethical when it produces the most good. Such consequentialist theories focus then on outcomes, and attempt to measure or calculate how much 'good' is generated by the consequences that are assumed to follow the action. Utilitarianism aims to be egalitarian, thus the ethically right action is the one that produces the most good, regardless of who that good is being created for, so the individual taking the action may not benefit from the action [8]. However, much depends on how the theorist defines 'good' which is why many utilitarian thinkers have to utilize other ethical theories to justify their consideration of a consequence as good.

\section{Kant}

Kantian ethics, unlike Utilitarian ethics, is non-consequentialist. Kantian ethics is most well known for the categorical imperative. The first formulation of the categorical imperative is to act only in accordance with that maxim through which you can at the same time will that it become a universal law. When considering whether an action should be considered moral the agent should not consider the consequences of the action at all, instead considering only whether the action being universalized would lead to a logical contradiction. For example, one cannot rationally justify their desire to lie for personal gain since in order to do so one would need to first ask whether it is possible to make lying into a universal law. Once one tries to do this, one discovers that universalizing lying would make it impossible for their own lie to deliver the intended personal gain since this could only happen if the lie was taken for true. A lie only works when everyone trusts that people can be taken on their word, that is, that most of the time people actually mean what they say. Kant understood that very few actions could be deemed "morally pure" by applying the first formulation of the categorical imperative and thus we ought to be 
very wary when we assume the rightness of our own moral positions. Kant's Categorical Imperative echoes his aims in his magnum opus The Critique of Pure Reason, in which he tries to point out the limits of human reason. The categorical imperative is actually a very pointed criticism of ethical consequentialism, which portrays morality as capable of being calculated. The second formulation of the categorical imperative also highlights this criticism, it states that people must be treated as ends in themselves, and not as means to an end. People, as rational beings capable of employing their own powers of reason logic, must be respected as autonomous moral agents. Thus, in light of Kant's criticism of utilitarian ethical theories, the second formulation is a direct criticism of utilitarian calculus, considering people harmed or benefited as purely numbers to be calculated when considering which action brings about the "the greatest good." Often times when Kant is taught as an ethical theory in a list of ethical theories, the larger meaning of Kant's philosophy as a critique of the utilitarianism can get lost. This is because today people often assume that utility is synonymous with reason. However, in the age of the Enlightenment and the Scientific Revolution this was certainly not the case. As with the meanings of many words, especially abstract ideas such as "reason", "justice", "democracy" and even "objectivity" meaning changes, sometimes quite dramatically, over time. ${ }^{8}$ Only people with historical knowledge then recognize the contingency of their interpretative frameworks and this is something that Kant's philosophy meant to rationally and systematically uncover. [19]

\section{Deontological Ethics}

\footnotetext{
${ }^{8}$ For more on this see Lorraine Daston and Peter Galison's "Objectivity" (2007), which traces historical and cultural changes as the word "objective" acquired different meanings and associated scientific practices. Daston and Galison also consider the changing relationship of the word "objective" as it relates to the subjectivity of the researcher.
} 
Deontological or duty based ethics consider the person's motive and intention for action and not the result of that action, so it is also not consequentialist. Deontological ethics requires that a person act according to moral duties and principles, without consideration for the consequences that those actions will produce.

Often times when considering Kant's ethical philosophy, only parts of this larger picture are included in the lessons to students and so the subtlety of the point Kant is trying to make with the various formulations of the categorical imperative can get lost. This is one example of how even the classical ethical concepts that seem simple are actually much more nuanced. The writing of this section is the result of multiple conversation with Dr. Morrison, because I was initially not entirely accurate in my portrayal of this philosophy. Although I never considered myself an expert in this area, I do have more experience studying these philosophies then most STEM students having taken a few different philosophy courses. I bring this up to highlight the complexity of some of these seemingly simple philosophical topics and the time required to accurately interpret them. Consequently, students who only hear about theses ethical theories in a short module would have a hard time understanding them, though no fault of their own. Additionally, the subtle complexity of these ethical theories demonstrates an argument for the inclusion of philosophers in STEM ethics education, to teach engineers and to help other faculty portray philosophical frameworks more accurately in order to employ them more effectively in ethical reasoning around engineering design and technology.

\section{Philosophy of Technology}

Philosophy of Technology 
Philosophy of Technology emerged out of a 20th century branch of philosophy called Phenomenology. Phenomenology calls into question the description of a human being as first and foremost a 'rational man' or 'thinking thing' which was common in the 17 th century, with the enlightenment thinkers. Phenomenology rejects enlightenment mind-body dualism and instead considers human beings as embodied being-in-the-world. Which is to say, that it is impossible to separate a person's 'rational' mind from their physical body and habitual embodied routines within their particular historical and political context. The body a person inhabits and their place in the context of society do impact their actions, and phenomenology doesn't ignore this as previous philosophies have. These bodily experiences are increasingly intertwined with technologies and technological systems. Phenomenological considerations of the human being as embodied within the real world enabled philosophy of technology to began to consider technologies as more than neutral tools.

\section{Technological Artifacts}

In relation to Philosophy of Technology the definition of technology is wider the colloquial use of the term. The actual technological object in the context of Philosophy of Technology is usually referred to as a technological artifact. This is defined in two parts. An artifact is a man-made object. A technological artifact then is an object that is made to serve a purpose, even if as a component to a larger object. So technology does not have to include wires and batteries and screens, rather technology is a broad category including things such as a bow, a spear tip or a set of stairs. By considering technology using this definition, philosophy is seen to be relevant for all engineers, not just software engineers.

\section{Instrumentalism}


Instrumentalism is a philosophical approach which considers an activity, such as science, law or engineering, as purely means to serve a practical purpose. This focus on practicality and purpose eliminates the perceived need for a consideration of the values and ethics. ${ }^{9}$

\section{Technological Utopia}

Technological Utopianism is the belief that technology is usually ethical because it increases what humans are capable of doing. Though these new capabilities could include capabilities to harm this view is that this harm is not the fault of the technologies and instead is the fault of the human users of the technology. There is usually the belief that technology is neutral. Despite criticism of this belief by philosophers there is technological neutrality is still a fairly common belief.

\section{Science and Technology Studies}

The cultural approach comes from a study of the context which the technological object is situated in. One big idea from this approach is that technologies are embedded with scripts, that can influence the way humans see the world, and can influence people to act in a particular way. A commonly cited example here is a set of binoculars, they are a technology that allows a human to see things in the distance that they otherwise cannot. But they do change the way the human is perceiving the world, for example things further away are in much richer detail, but at the cost of a loss of peripheral vision, which means maybe you get to see less of that bird's situation and habitat. This lack of context changes the way an individual perceives the world.

\footnotetext{
${ }^{9}$ When most professional engineers talk about their work they talk about it as being completely logical and objective when in reality there are still decisions being made by engineers that are not completely formulaic. By phrasing it as logical and objective, it eliminates a perceived choice and therefore a perceived need for ethical consideration.
} 
This can be a cyclic process. The values of the creator can influence the type of values that a technology contains within it, and then the values of the technology can mediate the perceptions and actions of the humans who then interact with that technology. For example consider the design of MTU's campus. STEM classes and faculty offices are held in one of the engineering or math buildings located in the center of campus, with a short walk between them. Humanities courses and faculty are housed in Walker, a building that is physically separated from the other buildings by green space. These decisions were probably made to save walking for students and faculty who attend or teach several STEM courses every day, but likely take one humanities class, if they take one at all. The design of the campus is now mediating the perception of students who view the Humanities Department and the Visual and Performing Arts Department as peripheral or "on the margins" of the Engineering Departments on the other side of the campus. . Additionally, the physical separation between the faculty from Humanities and the STEM faculty silently discourages collaboration between faculty in these two areas as it undermines the sorts of collaborations that often fortuitously occur when colleagues work and take breaks in close physical proximity

Similarly technological scripts encourage certain behaviors, or even more subtly allow for the possibility of behaviors that were not available before. For example, a person making a decision about where to go for dinner before a smartphone might have asked a stranger for a recommendation, or maybe looked into the restaurant to see how crowded it was. A person with a smartphone is now a hybrid, person+smartphone, a new agent. This new agent is now more inclined to look up restaurant reviews since it is now within their power to do so. This new agent might also be more likely to leave a review that is much more negative and confrontational, now 
that they have the ability to review online instead of have a confrontation with an individual. This action doesn't take place in a vacuum this review, left in a moment of anger in a restaurant could cost the server their job. So a consideration needs to be made of person + smartphone instead of person and smartphone separately in order to get a more accurate understanding of the entire picture.

\section{The Ethical Cycle}

The Ethical cycle is based partly on an understanding of philosophy of technology. It is primarily used as a teaching tool for Ethics of Technology, though the creators also published a journal article encouraging professionals to use it to work through moral problems in professional practice [34]. The ethical cycle was put forth as a systematic solution to working through messy moral problems. The ethical cycle encourages reworking the problems, it is cyclic and not linear, and each time more insight is gained. The structure also encourages collaboration with others. Both of these actions parallel the engineering design process and the software development process, making it appeal and feel more familiar to students of those disciplines. The ethical cycle emphasizes the complex social, political and technological situation that engineers work in and ultimately are influenced by.

The ethical cycle is explained in detail with a flow chart and more specifics in Chapter 5 of Ethics, Engineering, and Technology by Ibo van de Poel and Lamber Royakkers, but a summary of the process is below. A set of questions written by Alexandra Morrison for the Engineering Ethics course is included in the Appendix and can more clear demonstrate how to apply the ethical cycle. The ethical cycle is a systematic approach to ill structured problems, without sending the message that a particular technique will result in a solution to the problem. 
Most moral dilemmas fall into the ill-structured category because there is no clear definition to the problem statement itself, there is not always a clear goal, and there might be several possible solutions, all equally correct. Crucially though, the blurry definition of the problem lends itself well to the cyclic method of working through it, because as one works through, the problem becomes better defined. By giving some structure to the method of solving a problem, the ethical cycle can limit two common pitfalls students have while working though moral problems, “consist in neglecting certain relevant features of the problem or in just stating an opinion without any justification” [35].

The ethical cycle process starts with formulating the moral question, though due to the ill-structured nature this can be challenging to do as a first step, but part of the ethical cycle means coming back and reconsidering your formulation. The question should be formulated in a way so that the problem is clear, it is clear who has to act, and also the moral part of the problem needs to be articulated. Though it is useful to include who has to act if it is relevant, but in many cases it is not relevant because the moral problem is being looked at in more general terms and there is no one person, or in other cases the situation will be such that there is no one person who has the sole responsibility to act.

The second step is the problem analysis. The problem analysis involved considering the stakeholders and their interests, the relevant moral values, and the relevant facts. One important fact to note is that 'relevant facts' can and should include notes of facts that are disputed, or that are unknown but would be helpful to be known. After the consideration of these three things, it is then useful to go back and reconsider the problem statement to make sure it is as clear as possible and make improvements if necessary. 
The next step is options for actions, this can be a list of possible options or just two options if the problem was phrased as a yes or no. Though the authors warn that this is usually too simplistic of an interpretation for a problem in the real world. This is the step that encourages engineers to use the creative problem solving skills to think of new options that can reduce the negative impacts of the moral problem. Again like before, consider if you have more to add to the problem statement, or if in considering your options you learned something that could be added to the problem analysis step.

Next comes the ethical evaluation step, this where each of the various options for action that were previously listed are evaluated using a variety of ethical frameworks. Some of these include the classical methods mentioned earlier in this report, but others might include intuitive frameworks or a common sense method. In a conversation with Alexandra Morrison one thing we noted as an improvement that we wanted to make to the ethical cycle if we use this framework in the future is to add a more concrete method for students to consider the situation of the moral problem, to determine if there is a way to remove some of the external pressure forcing this situation to become a moral problem. This fits under the creativity of the options section, but possibly finding a way to make this explicit. Additionally Adding more of a focus of Philosophy of Technology would be beneficial as well, considering that this is being taught to engineers and software developers so Philosophy of Technology and Ethics of Technology would be applicable here.

Finally moving on to reflection, after cycling back through the different parts of the cycle at each step. The reflection step is necessary because likely there will be conflicting outcomes from different parts of the analysis, so critically thinking here is required to make a final choice. 
This step involves comparing the different analysis together, and considering the criticisms of each method and the choice as well as the benefits. Another piece to this step can be a collaboration with others. There is no expectation that each individual's outcome from the ethical cycle is the same, the benefit is that each individual came thoughtfully to that conclusion, and has an argument at least partially formed articulate that conclusion. From here collaboration and sharing can take place, and again the decision on which option for action to take can be changed.

The ethical cycle is a useful representation of the process of doing ethics because it has an appreciation for the fact that in some cases a conclusion of some kind is required. So being able to work through steps and get to the end has an appreciation of the fact that sometimes a professional needs to act. But at the same time the ethical cycle cycles back through with the addition of more information from a collaborator, or from more research, or gained through further analysis. This too is representative of how ethics should be done in the professional world. When a new technology becomes available, or new facts are learned about the situation, an ethical reconsideration is necessary to make sure that the current decision is still the best choice, and reconsider if necessary.

It is worth mentioning that the creators of the ethical cycle saw some value in a software implementation of the ethical cycle, and AGORA is mentioned in their book in the chapter about the ethical cycle.

\section{Interview with Mike Kirkpatrick}

Sophia: $\quad$ So to start, I have two sets of questions, I have a set for people who do teach ethics courses and people who don't teach ethics courses, so I am wondering if you could tell me a little about the ethics course you teach, if you teach an ethics course. 
Mike That is complicated. I have not been teaching ethics for a while. I have been mainly teaching the CS courses, data structures, systems, computer organization, we have a weird structure here for systems and concurrent programming. We did create a course in societal ethical issues in computing. I taught it way too long ago. Lets see (...) Fall 2015, so I taught that several semesters ago. I have also co-taught it with a couple other instructors since then. I haven't taught it for a while for a couple of reasons, we've been dealing with the enrollment management issues that everyone has been dealing with, so I've taught other classes. Also I've had a reduced course load we had a baby, well my wife had a baby. Also I have been working with a group on campus for faculty professional methods and development. I have been more involved in educational design. This type of position is normally 3 years long and I am in my second year. I might do it for 4 years. I have to figure that out. But then I would get back into it.

Sophia What is the university goal of that ethics course? I am looking for the more formal goal of the course.

Mike Something the course is trying to accomplish is the learning objectives derived from the ACM curriculum, the ethics \& society objective. And we looked at similar courses from other universities. There is a really good one at BYU. (Brigham Young University). Something I was really pushing for, I am of the view that it is important to bring in multiple perspectives in. There is a place for philosophers and others, but it is important for technologists and computer scientists to have foundational knowledge. It gives them the opportunity to explore ethical reasoning specifically understand the technology issues. For example the electronic voting technologists. There are specific implications there. There are security requirements to consider and there are also limitations of cryptography, situations where you can use it and situations where you can't. An ethics course outside of the [Computer Science ] department doesn't use this example. The hope is to blend the two worlds. Our class is hopefully how to apply those considerations and issues. Even if you are working with an outside group to develop the curriculum, one of my concerns when someone doesn't have the same level of technical depth, they can be really good at ethics but they don't understand the implications of tech. Outside of the CS world, they use the term algorithm very differently than we do, when we say design an algorithm to do $\mathrm{X}$. I am an advocate for technologists to do a better job of building that bruise. I want to improve those skills for technologists for us to work better with other people.

Sophia I guess so you know some more of my background, I actually have and degree in computer science, and then a minor in philosophy. And then I am going back for my masters degree in computer science. Which is kind of 
why I chose to do this project. What would you say that your biggest concern around software engineering ethics in the professional world is?

Mike my biggest concern?

Sophia Let me rephrase that, what would you say the biggest barrier to engineers making ethical decisions is. Does that work?

Mike Yeah. The main barrier for making ethical decisions is that isn't not easy to recognize when you are in an ethical dilemma. The problem is you din't realize that there is an ethical situation at play. Think about the VW emissions scandal. I actually set up this assignment as a trap. When I was teaching one of the other classes. I assigned something early in the semester, it was a gene sequencing assignment, so they had to do some sort of pattern matching in a longer string. Then when we got to the ethics discussion as part of the course, talking about the VW situation, they were all like "Why would they write bad code to bypass the testing?" And I am all "you guys did 6 weeks ago" And they were really surprised. I explained that "I had you write this code and you never asked questions about why you were writing it, or what it was going to be used for". In the VW case, it's really writing a program that given certain inputs returns $T$ or returns $F$. So a manager could have just said to write that. In a larger software program no one has all those details, no one has all the details. Someone working on one component doesn't have enough information to see all the details in a situation. Sometimes you don't even see enough to know to ask the questions. Then on top of that you have the problem of do you have the support necessary to bring up the concern. But I would say the biggest problem is in getting students to ask that question first. One of my pet peeves is the overused words "ethical reasoning" and "critical thinking", these are context specific skills. To use critical thinking you need to be aware of the issues that need to be analyzed first. And that skill of when aware or when to be asking is a context specific skill and so it is really hard to generalize.

Sophia So do you think the course in ethics is helping to address this problem? And if so, how is it doing so?

Mike I think it is a step in the right direction. MY university has a campus wide initiate for ethical reasoning in action. This starts before they even taking the first class, from the day they step on campus. In the week before classes start they have their first lesson in ethics. Then later throughout their education they have workshops. We have a lot of top-down administrative support. There is support for inserting it throughout the curriculum. It is a step in the right direction to have courses, but we need more help to facilitate bringing ethical reasoning skills into more contexts. Its one thing to have a course, but its another to talk about it in data 
structures and computer organization. I think we have to do a better job. The ACM code of ethics, is a start but I think there is more to do.

So how is the class structured. You can talk about either how it was structured when you taught it, how you would structure it now, or a combination of both.

Mike I would probably teach it differently now, knowing what I do now. The way I taught it then was aligned with Michael Quinn's textbook. I have it here somewhere. It is called Ethics in the. Information Age. It is topic focused so we would have two weeks on Intellectual Property, 2 weeks on privacy, and then those would be augmented with papers. We would have interactive lecturing, talking about stuff to open the discussion. Now I would do more peer instruction. I would talk about a topic, then pose a question where they would have to make a choice, to get more of their involvement. This is the dilemma of professors, when we first teach we default to how we were taught. I was taught very lecture based and paper based. One thing I would do differently I would take an assignment from another class and have them create a context around it. So I would have them do more analysis of the context of technical work, including the technical work they have done. One really great resource is by Casey Feasler from University of Colorado Boulder, Have you heard of her? She has this spreadsheet of courses she has found that is really helpful. She also has an assignment about Black Mirror. Have you seen that show? [Sophia shakes head no]. The premise of the show is every episode focuses on some technology, and all the bad stuff that can happen with it. It is interesting to consider all the bad things that can happen from legitimate uses of the technology. For example in one of the episodes someone created robotic bees to replace bees to do the pollination because bees were going extinct. Instead of programming each bee independently, they used AI to get the bees to swarm and be pollinators. But then someone changed the input to swarm to be malicious [Sophia laughs] Yeah it is easy to see how this is going to go. So the hacked bees, someone takes over the botnet, and program the swarm of bees to attack and kill someone. She [Casey Feasler] has actives where she talks about Black Mirror, a technical assignment and how it could legitimately be used for bad things.

Sophia

So when you did the small group discussions, or if you were to do them now, can you talk a little more about what that would look like?

Mike How I would use small discussions now. I would split the class into two, with each half talking different positions. Or I would split the class into multiple groups, and assign each group a different stakeholder and then have them come together and analyze the different positions.

Sophia Do you use engineering codes when teaching these ethics courses? 
Mike Yeah [laughs] I use the ACM code. I'm involved in writing it, but I also use it because I think it does a good job blending ethical frameworks in a readable and readily useable way for technologists. It is nice for the categorical imperative, Utilitarian calculus. Its still high level. To do properly it is difficult. The ACM code puts complicated ideas into language that is easier to readily apply. Take for example the code [the ACM code] talks about moral obligations for system retirement. The language of the code is easier then trying to figure out a universalizible rule for end of life software. A code is good to bridge that gap. It is still important though to use traditional ethical frameworks. One good lesson is why ACM code is written as it is. So go through it and figure out what parts are Rawlsian, what parts are Utilitarian, are there some parts that are very rights based? One thing I like about the ACM code of ethics is that is side steps a pet peeve of mine that comes up when talking about ethics with undergrads, they will ask me "are you a utilitarian? Or are you a social contract theorist?" And its like, "no, everyone is a mis of all of them". So the code does a good idea of blending those lenses, so it has some utilitarianism, and some of the other theories as well.

Sophia So how do you use case studies in the course, or how would you if you were to teach the course now?

Mike Its ongoing, along with the code to develop more case studies and more use for case studies. I always used them in various ways so, small group discussion vs a full group discussion. Or sometime I would take one case and I would write it form multiple perspectives, sort of trying to lead the students into stakeholder analysis. And sometimes I would give one version of the case to one group of students and another version to to another group. The facts are always the same in both versions, but one uses negative language to skew interpretation in one way, using loaded language. I would do this in small groups, so give one small group on version and another small group another version. For example if the case was relating to privacy, I might use language like "dodgy" and "evasive" in one of the versions, to try to indicate that I think the person was acting wrong, and another group gets another version.

Sophia I am not sure if you have ever listened to the Podcast ImaginedLife, but I think you would like it, and it might give you a few more examples for case studies. It is about the life of a public figure before they were famous so it allows you to sympathize more with them. It really humanizes them a bit more I think.

Mike One case I like to use, is the case of Randal Swartz.

Sophia Is that the case of the guy who downloaded the files at MIT, and ended up being charged with Hacking? 
Mike You are thinking of Aaron Swartz. Randal Swartz was prosecuted with a felony. He wouldn't be prosecuted like this today. The laws are written a little differently. To start from one perspective I might talk about how the system administrator sees a weird request, and when they look into it, they find an unauthorized port scan and password crackers. This is worrying because these are the initial steps of breaking into a system. They trace it back and realize that it is coming from one of the contractors, one from Intel. This contractor is running scans on a division that he doesn't work in and isn't authorized to access. The system administrator reported the issue to management, and management reported it to the police, who ended up charging the contractor, Randal Swartz with hacking and corporate espionage, trying to steal corporate secrets. From another perspective, Randal Schwartz used to work for that division, and he still had the old account that was still active on that system. In the new division that he worked in his new job duty was in security. In his new division he found that several of the execs were using weak passwords, and so Randal tried to find out the scope of the problem, were the execs in other divisions using weak passwords as well, did the problem extend to the division he used to work in as well. Although Randal's account was active in the old division, Randal did not have authorization to access that system. Also Randal was a contractor and not a regular employee which changes the permissions of what he can access. Randal was being proactive about his job, and helping to find the depth of the security issue. Eventually Randal was able to get the felony expunged. It helped in his case because he is known world-wide in the tech community and he has written books. He is famous in hacker circles, so the community really rallied behind him to try to show that he was a good guy. But from the System Admins perspective he sees what he thinks and what looks like an attack on the system, so he reports to management. What is he supposed to do? I try to find cases from multiple perspectives and use selective inclusion of facts.

What would you say the big value that case studies bring to the course is?

Mike

They give you an application scenario for applying the code of ethics. And when it doesn't match up with the code you can parse out the details and the nuances. In some cases that have multiple perspective students learn that that is reality. There is a set of facts but that no person is all good, or all bad. It is not a simple binary, not a simple yes or no answer. Many times people disagree, many parties are good, many are bad, and how to respond to the situation is not clear. This is especially important for CS Majors. People in that field get used to binary, either the code works or it doesn't. It is a binary way of thinking. It is difficult. Thinking, is it a privacy violation or not? Same action in different contexts, sometimes it is a violation and sometimes it isn't. Even technology seems to be neutral and binary, but its not. It more nuanced than that. 
Sophia What makes up a good case study?

Mike I like to take a scenario, and ground it in real life. There are certain details you have to change to highlight conflict, but it should be realistic. One on the ACM ethics website is based on. Case where a web hosting provide provided what they advertised as bulletproof web hosting, with zero downtime. They did this through a lot of redundancy, so they wouldn't be able to be taken down with a DDOS attack. This was a popular hosting company with C2 [Command and Control] servers, Botnets, and Malware. You need constant uptime, if you want to spread the virus and infect as many people as possible. If the server is down than you can't spread the virus as quickly. So most of the spam providers around the world were using this platform. But then Macalo, an upstream provider to the web hosting company, severed the service from the internet. Spam around the world dropped by $98 \%$. We effectively did not have spam for a few days, until the spammers moved on and used a different hosting service. I took the case and changed it. In the case study I wrote not only did the provider cut them off but the data was wiped. They took down the bulletproof hosting and wiped out clients data on the service. Even the clients nonmalicious data was wiped, and legitimate users of the hosting service were harmed. So here is tension between stakeholders rights.I am always trying to have some tension between different stakeholders. Favoring one means that you are disfavoring another. Also I like to have principles in conflict. Autonomy vs Discrimination.

Sophia Who would you say that the audience of the case studies that you are writing for the ACM? Is this a resource for academics or is this something you see use in industry for as well.

Mike I am trying to accomplish furthering awareness and understanding of how to use them by the profession. They are useful in a couple of ways, they are written for undergraduate CS majors and professors to bringing case studies into technical courses. For example bringing an Al case study into an Al course. That way it is kind of a "plug and play" to bring the module into the course. There is also a broader push, to work with companies to one in and do trainings for their employees. There is some marketing to be done for the code in this area. The perspective from the tech company is sort of "the code of ethics that ACM is advocating, do we really want to adopt this? What if we do defense contracting, will our employees read a code of ethics that says what our company does and the work they do is wrong and evil. I think the cases help to bring out examples and counter that perception, that it is a black and white issue. For example here is a clause [in the code] on issues that you are concerned about, and here is how it applies with a case study, here are examples of ways to interpret the code and how to think about it. Also we want to stress that the code is an 
aspiration code. The ACM is not going around hunting for violations. Everyone in this case could do better. It is about doing better. [looking at case studies] Some people in this case study could do better, so you can look at the case study and apply some of the principles or improvements to your work.

Sophia How would you say the student reaction to using codes is?

Mike The student engagement is really good. But students in our course could be atypical. Our department is very security focused. James Madison University is located two hours from D.C. So lots of people graduate and end up working for 3 letter agencies, so I think our course is atypical in that way. From what I remember the discussion around case studies was always really good.

Sophia How well would you say that the case studies accurately represent the type of challenges that are faced by professionals?

Mike I think they are intentionally artificial. They are learning devices and learning tools, that say 'here are the relevant facts you need'. But in the field how would you know what facts are relevant? Case studies are encapsulated. In the professional world it is never use one thing, it is a series of interacting things. So case studies are not truly authentic. They are a starting point for discussion, and then the challenge is to use that.

Sophia How would you say the case studies are achieving what you hoped they would achieve in the classroom?

Mike Its getting them to ask more questions. A good case study intentionally hides information. Some things are left unknown, So that the discussion can evolve. A good discussion is powerful, students leave thinking about it. They come back later, 'I just thought of this relevant thing' or 'what if it was like this'. A good case study sticks in the head and gets students to realize that there are always unknowns.

Sophia What is the biggest gap that you wish you could address in student understanding?

Mike The undergraduates still have a sense that these things can be done algorithmically. One big gap is that technology is not neutral. In CS we tend to like objective neutral facts. We can apply an algorithm and make it work. Its about recognizing there is not a solution, Recognizing that the solution is evolving, recognizing the limitations of tech, recognizing the presence of technology itself is an ethical choice its not necessarily neutral. This is an important lesson. People who tend to want to do a CS degree, who want to be CS majors, its wonderful its great, but we tend to be blind 
to the limitations. We think that if something is going to go wrong with my code it will be because I haven't tested it enough' and that our main responsibility is to thoroughly test our code. Just because we can write the code, should we? Solving one problem with technology introduces other problems, and I want students to recognize that.

\section{Interview with Alexandra Morrison I}

Sophia: $\quad$ Ok so what is the university stated goal for the ethics course?

Alex: $\quad$ So it varies. Usually there's an Ethics component that's goal eight. But it would have requirements that would mean we have to do field stuff and field work and as an upper-level course we haven't really figured out how to do that. So as a committee consisting of four philosophers we decided to use it as a goal four, which is creative and critical thinking. In that case it becomes just critical-thinking, which is fine philosophically for me because of the way I approach ethics through Continental philosophy. I think the critical thinking [requirement] is it completely adequate for the class

Sophia: what is your personal goal for the course and how does that differ from the University stated goal?

Alex: I think it dovetails. I think those assessment goals are really kind of clunky and I think how they go about instilling that kind of creative critical thinking in students can change from class to class. So really in this particular class, and I think any ethics class what I want students to learn is to just question their assumptions, their normative assumptions about things. For an engineering ethics class the critical work is more complicated in a sense. It requires that they [students] have a kind of insight into the way ethics is often taught in the context of engineering by engineers who haven't studied ethics. So they actually need to have some historical knowledge about pedagogy, ethical pedagogy, in engineering. And then they have to weigh in on the philosophy of Technology component because $98 \%$ of the students who come into the class think of themselves as active agents and technologies as neutral tools. So if I can shake that up, shake up the assumption, but many students go beyond that. Even students that leave the class with a D, if they get that it's good. And it might take them years of practice to kind of understand why that is a critical thing to keep in mind, because it is very easy to revert back to the idea that technologies are neutral. 
Sophia: What would you consider to be the distinction between this course and the Software Engineering Ethics Course. Do you know how they are split up?

Alex: $\quad$ I don't know what the distinction is.

Sophia: $\quad$ Yours is an HU you right?

Alex: I assume the distinction is that the software course would just focus on case studies that involve computers. You know? Computer stuff, surveillance and those kind of issues. So I think that my course kind of covers or attempts to cover and give the frameworks that are applicable in any engineering setting from civil engineering to mechanical engineering to even forestry. Students have taken the course before and it can act as an introduction to a philosophy of the environment because Heidegger is kind of at the core of that too. The Continental philosophy that they get in this class can kind of prepare them for those kind of glasses too. We don't have a proper philosophy of environment class, but I think that would be really good.

Sophia: Is this required for environmental engineering majors as well? Do you know what majors it's required for?

Alex: $\quad$ This is a totally free elective. This one is not required. A lot of students take it as their HUFA credit but no it is not required

Sophia: What book are you using for the course?

Alex: $\quad$ The one is called ethics engineering and Technology. And I supplemented with Peter Paul Verbeek's book. I also supplemented with a few articles here and there, just so that they can go deeper than the textbook.

Sophia: What would, if you were to pick one biggest concern, what is your biggest concern around engineering ethics in the field? [Alex looks confused] For your standard engineer that goes out into the field, what is your biggest concern with their ethical education?

Alex: $\quad$ That it is non-existent. Really, when I hear a lot of people in the sciences and engineering talking about ethics I don't even recognize it as ethics. I don't recognize a critical component at all. It just seems like cultural norms that you intuitively embrace and that's really as far as it goes. And this is more in engineering, but there is the idea that it is safe if it doesn't mis-function and that's as far as it goes. So there's no real critical element in either of those positions and so for a philosopher it's not really ethical philosophy. 
Sophia: Do you think that what you're doing in this course is helping to address this or do you think it's bigger than the course?

Alex: I think it helps to address it but I think it takes a lot more than course to do that. Ideally it would be woven into the culture, in order to achieve a real robust ethical culture at Tech. This is what I Chuck and I has kind of pitched to the NEH, the National Endowment for Humanities, to get some money to basically to start training first the engineers, the engineering faculty, alerting them to perhaps the inadequate way that ethics gets kind of sideswiped is and isn't really understood. I think that [it would help] if students come to me and they're in my class and they are really excited. I've had many students come to me and say 'I can't believe I almost got out of University and didn't take ethics especially engineering ethics'. But it's hard for me to maintain their interest and their curiosity around it if whenever they go to the engineering professors, who they look up to, and they [the professors] just kind of tell them 'oh you're being distracted by the humanities department again, get back to your real work'. So I think to get them to really start thinking about ethics in engineering design it is key to kind of breakdown the idea of ethics as pertaining to only functionality. [Break down the idea] that if the technology does what it's intended to do and it doesn't hurt anyone [than it is ok]. In order to see how ethics is embedded in the design itself and kind of silently carries values that are normative or those ethical valances in its use, when it's being used by other people. I think that students have to kind of think about ethics from the beginning, when they are sitting down to think about what materials they are going to use. So in a way we need to start to think about how we are going to bring a more critical kind of ethics into the engineering classes themselves. I know that's a really big ask, but I think it could be done. But it would involve first educating the engineering professors and then working together with philosophers and people who have some training in critical ethics, and then we could fashion [the lessons]. You know students are often complaining of how silly the ethical units are in their engineering fundamentals and they say they feel like they're one-off, they're not indepth at all. We could just replace those kind of useless ethical units in say engineering fundamentals with something [more in depth]. That obviously won't do everything, but it's going to at least raise the signal that this [ethics] is a really important thing it's fundamental to what engineers do. It's not something outside of it. And also to keep coming back to building on ethics. That's the thing that Chuck really also agrees with me and is really excited about, is that we need to build these little ethical unit into engineering courses at every level, freshman all the way to senior design and Enterprise. I have made contact with people in engineering fundamentals, and I'm going to be teaching the Enterprise class. The more people I get hooked up with I think this could be something that we could start working on. 
Sophia: $\quad H o w$ much responsibility does an engineer have to consider the ethics of a product they design situated within a larger context?

Alex: I think a philosopher is always going to push them [engineers] to try to take on the impossible. But when you get them [students] thinking about what has classically been called the problem of many hands, being responsible isn't taking the whole thing on their own shoulders, being responsible might mean alerting their colleagues that 'we have to work on this thing together as a group, and we have to try to find an ethical way of doing it' or that 'we have to try to critique what we are in the process of doing to see if we are doing everything correctly'. So maybe part of the ethical moment is to recognize that while you are responsible, you couldn't be responsible for it all, but that doesn't mean that you are dissolved of your responsibilities. It means that you have to alert the other people who are co-responsible to also take on their responsibilities. We live in a culture, not only an engineering culture, but we live in a culture that so atomized and we tend to think of ourselves as these little isolated units. We've got build up our capital, get our resume padded, and all those things. We forget that we are working in this collective here and that there are some things that we do and we can only do them together. The atomization of individual academics is a problem.

Sophia: $\quad$ So back to the implementation of the ethics courses, how is your class currently structured? I am looking for kind of a broad overview, is it discussion-based, is it lecture-based, what happens on a daily basis in your classroom?

Alex: $\quad$ Every class is discussion-based. There is a reading for every class and then I lecture on the key points that I think are the most important and then there's discussion. So it's lecture and discussion every class and it's always focused on the text. I try to break up my lecture. I don't give a big lecture and then discussion but I try to have units of discussions. There are kind of five or four main things that I want to cover [per class so] I'll just cover the first one and then open the discussion. Sometimes that means that I don't necessarily get to all of the points depending on how the discussion goes. But I can easily do a kind of review at the beginning of the next class to remind them that there are some things that we left out and that there is a PowerPoint on those things posted on canvas. There are different things to consider but I think it's more important for them to be talking then for me to cover all the points in the time that I have because they don't get a chance to talk about this kind of stuff. I used to do more online discussion but I fear that it's really hit-or-miss. I get canvas to put them randomly in groups and some of the groups are awesome and they have a critical mass of really smart engaged students in them. Then the ones that don't are really poor and so I've really cut back on that. I only do two of them 
officially a year and then if there's a snow day or something then I have another online discussion. I find that doing online discussions are good for one thing, I can see students who don't tend to speak in class. I can see what they're thinking without them having have to hand in a big project before I know that the student really has no idea what's going on, then I can ask him to come see me. This class is particularly hard because I've never had 80 students. That's a little too big, I think that I'll resist 80 students next time around.

Sophia: How long would you say on average the small group discussion takes? Does it kind of vary widely based on how long people talk?

Alex: I would say it's at least 20 minutes of the class but that 20 minutes broken up between all the little ones. I mean that's a good question.

Sophia: What does this discussion look like, is it led by you or is it something where the students are truly discussing independently?

Alex: It is led by me, at least this time. In a big class like this there are some chatty students in the class who like to talk more than they like to read the text, so I tend to direct it a bit more than I might have otherwise.

Sophia: What kind of interactions are the small groups having with you or each other or is that not really applicable since they are led by you?

Alex: Not really. But on the last snow day I had them read Latour, the piece the humans and nonhumans, and they did discussion groups on it. Because Latour is pretty difficult, or I was assuming it was going to be too difficult for them, I went into each tutorial group, there are 10 of them, and I read through all their comments. I commented on things that were really good just by saying 'yes awesome' or kind of saying 'well it's a little more complicated than that' so I did put comments periodically on their discussion groups. I don't always do that. Sometimes I'Il just make notes of recurring mistakes and then I'll just address that to the whole class next class. Then I will also write down the names of students who have done really well, especially if they are students I don't hear from in class and then I get them to talk in class. It's like breaking the seal, once I get them talking they tend to be more open to talking and if I can tell them 'what you said in your tutorial group yesterday was really smart Jeff' then you know they can tend to be more active in the classroom from then on.

Sophia: What would you consider to be the main value that comes out of those in class discussions?

Alex: $\quad$ To get them thinking about ethics and talking about it in a philosophical and critical way. They're not going to have a lot of opportunities, from what 
I can see, to do that at this institution. If they just listen to me and say 'yeah yeah I get that' but it's only when they can articulate it for themselves and kind of interpret it for themselves and put it in their own words that they can actually own it and they feel like they have a command of it. It's a different way of thinking and its different way of engaging with engineering artifacts and technological systems. They need to be able to articulate it for themselves and sometimes when I'm talking I will explain 'this is Latour's argument, I think this is the argument' and then I'Il stop and I'II say 'now you tell me what you think he said 'and I'II say 'I don't care if you say the same thing I said I just want to hear you say it' and often they will articulate it in a slightly different way that emphasizes something else. It can actually sometimes bring out something new or something that maybe I didn't emphasize and maybe it would be helpful to emphasize. I used to try to cram a lot of stuff into class and now I think it's repetition. I use repetition because [I find] the students repeating it and interpreting it for themselves is actually more important in getting them to understand more stuff, more info. They read the same amount, but the material is more repetitive but when it circles back, like the ethical cycle, when it circles back its richer the next time.

Sophia: Is there something that you wish would happen more in these small discussions that doesn't happen as often as you would like?

Alex: I guess there is a critical mass of the students that seem to just say what they think I want them to say or they just kind of parrot. They're not really taking it up for themselves and they're not really kind of exploring it. To get around it I try to get them to use their own examples. Latour uses these great examples, like the sleeping policeman, and so I was pushing that. Then I put them in their tutorial groups in class and made them kind of come up with their own examples of different kind of technological mediation. That was really helpful because again they get kind of a feel for this way of thinking by coming up with their own examples. But they really need to be pushed to do that because if I just tell them to go and discuss it online and they're tutorial groups they'll just go to the textbook and say what they think is the right answer.

Sophia: How often does putting them in tutorial groups in class happen?

Alex: $\quad$ I've done it maybe three times this semester. So three times in eight weeks and then we meet twice a week so I think it's good. They kind of groan when I do it because they like to sit in their own seats, that they always sit in. When I say 'get in the groups' I think that stuff does happen. While they're talking in their groups I go around and check-in and sometimes I'II have conversations with them if they seem like they're not getting 
anywhere or they have a critical mass of apathetic people in that tutorial group.

Sophia: $\quad$ There is a critical mass of students that say what they think you want to hear, do you mean this in the same way that you say there's a critical mass of apathetic people, so there's a critical mass of people who kind of parrot so that that kind of silences people who have new ideas?

Alex: $\quad$ yes or they just don't want to push it. But I think I have a good enough rapport with students who are really keen that I can kind of use that to kind of break down the groupthink of it or the "groupapathy". They really are resistant, students kind of resist and I think this goes back to the thing: a lot of the students come into the class because they have to take it. It's not required but they do need the class and they kind of resent that they have to be there and being made to think. Really you can kind of feel them rolling their eyes or sometimes you can literally see them rolling their eyes, they just they feel like it's an interruption of their real work, the real work they need to do in their engineering classes. That's the thing that keeps them from opening up to thinking about it [ethics] in a new way and seeing that ethics is actually absolutely critical to what they're doing and they're going to be doing it [ethics] whether they recognize it or not. So I guess that depends, a lot of times, I have to say that in my experience so far, students in mechanical are really bad. Chuck actually went to ME because when we wanted to do the proposal for the National Endowment of the humanities grant we were trying to get people from the engineering faculty on board with the idea that we are trying to have a workshop for the engineering faculty about ethics, and how it's important, it's complicated, and they don't know enough about it, and their students need to know about it so they need to know about it. Chuck went to the chair of the mechanical engineering faculty and he said he couldn't have imagined it would be worse than what that was. It was that so bad. I think it is a culture in that department and in that unit. Whereas I often a lot of students in forestry and biomedical engineering, in CS, in civil engineering, they are really open. They are way more open and more curious. They have a sense that they are not wasting their time, but it's those students who think 'yeah, yeah' those are the ones that make it really difficult, but those are the ones that you really want to reach.

Sophia: I wonder if that has to do with some of the larger demographic differences in that department?

Sophia: What is the student's reaction to this kind of discussion?

Alex: $\quad$ Students who are comfortable and do the readings are okay with it. [students are] more open to online discussions than class discussions. I think that's because they can stop and think about their argument which 
gives them more confidence articulating ideas. Students go to say something and you can tell they're excited but they just can't articulate it. So I try to tease it out of them but they're apprehensive, because that's a moment of exposure, so I try to reduce this for them. Everyone does it [stumbles on words] I do it sometimes too, in the class and when I stumbled over a word I try to highlight it, so that they know it's not just them because really it's not until you say it that you know what you're going to say. Articulation is difficult, most classes don't require that students do this. For an ME this would be a tough course, they're asked to be critical in a new way, they're articulating in their own words to 79 other students. My brother who is a mechanical engineer would have had anxiety attacks before class because he would say that he was a mechanical engineer so we didn't have to deal with this verbal expression.

Sophia: Do you use engineering codes, such as the IEEE Code of Ethics, in this course and how do you use the codes?

Alex: $\quad$ Yes. I use a set of the codes, they are collected in the textbook actually. In an online discussion that happened for the ethical cycle chapter each tutorial group had a different case study and they were supposed to do the ethical cycle and then share their individual ethical cycles with their tutorial groups. Some students actually pulled the codes down that were applicable to their case study.

Interview with Alexandra Morrison II

Sophia: $\quad$ So we got part way through the section on codes and you mentioned that students were pulling codes from the book

Alex: $\quad$ They were actually pulling codes that were related to the particular case but what they mostly did was they were showing how the codes couldn't really go far enough, which was good.

Sophia: $\quad$ Did they demonstrate that to themselves or did what they were doing demonstrate that to you?

Alex: $\quad$ They demonstrated that they were aware of it. This textbook is pretty good because it sets that up right from the get-go, in the first chapter, and then it kind of gives a critique of codes. Saying how they are minimally useful and talking about how in context they're useful, and then it immediately kind of rejects that and points to how they are necessary but insufficient.

Sophia: What would you say the student reaction to the use of codes is, in classroom or in the textbook? 
Alex: I think they find them boring and they kind of turn off. They're just so general and they're mostly negative, prohibitional and they [students] don't respond to that. This actually just came up in a conversation today, because we were talking about collective responsibility and how tricky a case of collective responsibility is. Often countries have legal ways of responding to collective responsibility. In Canada and the UK we have laws called corporate manslaughter, you don't have that here. It's a good thing that we have this on the book because there are many cases where no individual in a corporation could be held personally responsible, but the company can be held responsible as a collective. So that's a good thing, but it's still really difficult to make make it stick right because the distribution of justice or punishment is very difficult. We got into a conversation about this, and one of the examples that came up in class was greenhouse gas emissions and I was asking them 'so if we are all collectively to blame for this' which was what people were saying 'how are we to motivate ourselves and each other in order to respond to this' and I took a quote out of the textbook where talk about motivation, and they use a 'stick' approach [carrot or the stick approach to motivation], deciding you are morally blameworthy and then therefore it's your duty to do something there. [students responded] 'that's never going to work' and so some students were saying we should follow Tesla, because they're trying to change the conversation by not saying 'you should do this' but trying to change the conversation by saying 'this is really cool, you should want to try this'. To make it a desire that's not related to the issue of emissions at all, even though it does address that. So they [students] don't like stick and I guess maybe there's something to that, right? I can think of circumstances in which at least in the cases of passive responsibility where you've caught someone doing something unethical and if you are to harsh on them when you catch them their response could be - the harder you are the more likely the response is going to be negative or evasive. But if you do it in a kind of a gentler way you actually might be able to get positive outcomes in the future. That was a good conversation, and that is something that people have written about codes - that they're too negative and they don't they don't do much to change a culture. So often they are just window dressings and they're not something that would inspire you. You read them and you don't get inspired to be a better person, whereas if you read a really well written essay or you watch a film about someone who is particularly a kind of stand out moral character you're more likely to be inspired then by reading some code.

Sophia: I think a lot of codes come out of disasters so they don't necessarily think of long-term and whether they can change something

Alex: $\quad$ Yeah, they have that framework that legal kind of framework 
Sophia: How did you choose the specific section of the code that you focus on in class because they're pretty long?

Alex: So the students went through and basically just looked at them [the codes] to try to show how they could only get you so far. They were looking for contradictions in the code itself and instances where an application of the code would be so obviously a matter of interpretation. They are looking at case application in relation to a specific case study which parts of the codes would be obviously really difficult to apply or really subjective and therefore not that helpful.

Sophia: Do you use case studies in teaching the course?

Alex: $\quad$ Yes

Sophia: How do you design case studies, if you don't design them how do you select them?

Alex: I have a collection of them that I like. A lot of the ones used in the textbook are really great. For instance today the case study that they used kind of really opened up in a really dramatic way collective responsibility. The case studies in this particular textbook are really well selected to demonstrate the kind of concepts that they are trying to [show]. I usually supplement the case studies because this text book was published in 2012 though the cases are [still relevant]. The case that I was thinking of, the one that we were looking at today, was the citicorp building in New York City and another one was M.S. Herald of Free Enterprise (that was a ferry that sunk and capsized in the English Channel) that [the ferry capsizing] was a long time ago but there's more information all the time, journalists digging up things. For instance, just in 2017 there was kind of a memorial for that particular tragedy and so journalists had written in various European newspapers about the case and revealed new things that have come to light in the years since. So I tried to bring those things in and even further complexity it. In this case I also pointed out today, and I don't always do this but I feel like I have to or I wanted to with this particular class, that the case studies are constructed in such a way that it gives you just enough time to kind of get into the kind of initial description. The [initial description] is very simplistic and black and white and it gives you a really good feeling, like you already solved it and then very quickly - but not too quickly - goes and changes gears and starts making it complex. Then I went and supplemented it with even further facts that I discovered and made it even more complex and more morally ambiguous and I kind of said 'it's very easy to to feel morally righteous when you read about the story that happens right? and you hear that the baseman fell asleep and forgot to shut the door after all the cars were loaded onto the ferry [and respond] like "oh my gosh what an idiot" and you get this feeling of moral righteousness 
like "I wouldn't do something stupid like that". And this case study kind of pulls you into thinking that and giving you that feeling and then takes it away right away, which is really good. I like those kind of case studies. It really depends on how they're written. A couple of weeks ago , when they had an online class, I gave them a case study and then I asked them to do an ethical cycle by themselves, and then I asked them to get together and share their results. But I just gave them shitty ones [case studies] and I asked them how the framing of the case studies could also be part of the critique of the case study. These are case studies that they could go and do research on and reformulate so I purposely gave them crappy ones because case studies are so often presented like 'here's the facts' but how you frame it is really important to how the person will and how subsequent people are going to interpret and I think they [the students] got that from this exercise.

Sophia: What are the typical topics of the case study that you use? Is there a typical topic you always go back to?

Alex: Well this one was a tragedy. They're often disaster cases, but not but the citicorp, that is an averted disaster. A lot of them are disaster cases but I try to draw their attention away from the disaster and get them to look at the culture around the corporation that led to the disaster and led to unethical business practices. Even before the disaster this company was, if not legally culpable, morally culpable. So I think they [students] get that. I'd like to find more [case studies] and maybe get students to contribute more case studies that are less disaster focused and more mundane. That's something that's on going for me, collecting more. Actually their next bit of homework over the break is to go through the ethical cycle. They are going to come up with their own engineering design case studies. There's 80 in my class so some of them are going to come up with some good ones and so maybe I'll have to credit them one day.

Sophia: Do you think that the case studies you use in class typically represent the types of challenges Engineers will actually face in the field?

Alex: $\quad$ No, well I guess it depends on what my class makeup and what they will work on, but no the traditional ones don't. Not like the Challenger and the CityCorp one, although if you point out different individuals in the CityCorp case like obviously they're not Le Messurier, they're not going to be this big structural engineer, but the grad student clearly he had a pretty big role in that whole issue because he's the one that brought it to the big engineers attention. So I think they can relate on that level because I try to emphasize that it was at grad student. And emphasizing a kind of not moral correctness but curiosity and intellectual play. 
Sophia: How would you say the case studies are achieving the goals of the course that you are trying to get them to achieve?

Alex: I don't think the case studies by themselves do much. I think they really need to be used in conjunction with everything else. So they help, they are an imaginative exercise. Instead of just talking about the idea of collective responsibility in the abstract it's good to actually have imaginative scenarios, even if they aren't real real ones, where they [students] can start to think about the complexity of the intersubjective kind of shared responsibility and a communal setting, so they [case studies] stimulate the imagination.

Sophia: How would you say that the students tend to respond to the case studies?

Alex: I'd say that it lets them speak more. It gives them a way to be able to talk, because they're not used to talking about abstract philosophical concepts. So it gives them a way in. And a case study can at least demonstrates or illustrates some of those concepts.

Sophia: What would you consider to be the ethics and philosophy background that most students have coming into the course?

Alex: $\quad$ Nothing.

Sophia: What types of ethics and philosophy topics do you tend to cover in this course?

Alex: What?

Sophia: $\quad$ For you it might be more continental, because you tend to focus on philosophy of technology, so the question here is kind of trying to get at you tend to pick different topics than Linda tends to pick, and I'm wondering how you chose the ones that you chose.

Alex: It's always going away from the black and white. It's always complexifying. So it's always seeing a way in which the morality is not a simple. It's not a simple thing to determine. It's not a simple thing to do and the interplay of political and economic and social and historical forces always has to be thought about.

Sophia: With that in mind, which topics did you select to be in the course? What would the summary of the philosophical background that you tried to give the students be?

Alex: I do cover the classical ethical theories because that's kind of how it's traditionally been taught so it is imperative to understanding the textbook. The textbook critiques the traditional approach and so the students need to 
know the traditional approach. The traditional approach is sometimes salutatory in certain circumstances so we question 'should I use the utilitarian method in this case or should I use something else?'. With virtue ethics there are some really good reasons to think about virtue ethics over decision based approaches, in cultivation of moral character and stuff like that. And then of course because of the typical overemphasis on the human and not on the technological mediation and scripts we get into phenomenology and philosophy of technology and science and technology studies and actor Network Theory. All of those fields in a way are really hard to distinguish from each other because really phenomenology is the basis for all of those.

Sophia: How would you say that you cover these topics is it lecture-based or reading based, discussion-based or all of the above?

Alex: $\quad$ All of the above. I try not to lecture on something that they haven't read about first and then of course we discuss it after, which is why I make them read Latour. They really liked Latour.

Sophia: $\quad H o w$ do you choose which topics to leave out or de-emphasize?

Alex: $\quad$ Usually that's a year-to-year thing and I take out things that don't work. Although I always do try to mitigate that with the idea that I might have just done a bad job this time trying to teach that topic so I have to find a better way of teaching that topic, but sometimes I've tried several times and it just doesn't seem to fly. Sometimes I leave things out because it's just too much detail and it's not really going to add much. Like some things in the textbook get down to the nitty-gritty of fine distinctions of corporate law in Europe, they don't need to know that. It's good to give them a sense of some details in order to raise an an ethical or moral issue but not so much that is just going to bore them and I'm going to lose them. So sometimes if I want them to touch on it I will put it in the PowerPoint. Some things are in there just to flag certain ideas but we didn't really spend any time talking about it. If students use the PowerPoint as refresher for studying for tests or something they'll be able to determine that it's important but it's not as important as the stuff that we spend time on.

Sophia: How do the students tend to respond to these kinds of basic philosophy discussions, when you're trying to give them that basis or that groundwork for philosophy concepts how do the students tend to respond to those?

Alex: $\quad$ They talk more in the case studies, though I'm not sure. A different kind of student talks more, so there were students that talked today when we talk about case studies that never talked before when we talked about philosophy. Something about the case study interested them, but the main talkers tend to talk however I'm teaching, whether it's case studies or 
concepts in philosophy and when I put them in groups they are also the ones talking in their groups.

Sophia: $\quad$ So as far as the outcome of students leaving the course, do you feel that they leave the course with the understanding that you were hoping to give them?

Alex: I think on the whole they do. I think that you might even be able to map it onto grades, if you get a $\mathrm{C}$ or above, you probably got at least the main the main thrust of the course. You know something about technological mediation and the moral agency of technological systems and artifacts, you no longer think that following some set of rules is all it takes [to be moral] as an individual. That would be, what's that percentage then, $75 \%$ of the students get it, because they couldn't get a $C$ without it.

Sophia: $\quad$ What is the biggest gap you wish you could address in student understanding?

Alex: $\quad$ That they could take it back, if I had a sense that this was kind of permeating their whole. If this was getting into their other classes and that these things that they learned in my class were informing the things that they did in their other classes. I have a feeling that with some of them this happens, but I would say it's a small portion of the population.

Sophia: $\quad$ Are you using software in the course?

Alex: $\quad$ Not right now.

Sophia: $\quad$ Do you feel a software program could fill the gaps that you mentioned above?

Alex: I gave them this homework kind of knowing that it was a little bit of a slog for them. If they had a software they could probably do it [easier] and come up with their more of their own case studies, scenarios that are important to them. And that could be the difference. The practice of doing it many times could start to turn it into a habit, a habitual way of thinking and then it could carry over into their engineering and other courses. So they're going to do it now without software and they're going to do it for an extra two points. It's optional because it is a lot of work on top of their regular assignments. Once I made it a regular assignment but I want them to do it again so I'm offering it for two extra points which they're totally happy with. So I'm sure a lot of them will do it but it will be a lot of work and I think the software would make it go a little faster and make it organized. I think it could help to make it into a habit, a habitual systematic way of looking at unsystematic and messy problems. It would be cool at least be able to try it, it would be a good experiment. 
Sophia: How do you use canvas in this course currently?

Alex: I upload all the extra readings on there. I have optional readings that are supplementary, for students who want to go a little deeper in certain things or certain topics. For instance a student wanted to see [more of] Pandora's Hope, because I had them read the Labyrinth chapter from Pandora's Hope so I put more of the book up for them. They do their tutorial discussions [on Canvas]. I organize their readings for them using the calendar on there to remind them so that they keep up on the work, because it really is cumulative and if they get behind it's hard. They do their reading quizzes on there. This extra homework they're going to be submitting on canvas as well. Because of clunky interfacing with the technology in the classroom, I do Powerpoints and then I put them on canvas page and then when I get into the classroom I download them onto the computer because I don't want to have to deal with it. I need an adapter for this which I almost never have in my bag, so that's about it.

Sophia: I think the ones that would be most likely offloaded to another software is tutorial discussions and the readings. I don't think submissions are in the scope of what we were talking about. Can you talk more about how tutorial discussions work for your students?

Alex:: I think it works well. The first tutorial discussion was the one I mentioned before. I gave each tutorial group a different case study. The students went through the ethical cycle for that case study by themselves. Some of them hand wrote it and then they scanned it and put it up on canvas so that their other tutorial members could see it, and some just did a point form outline. Then they talked about it on the discussion board and some of them were amazingly detailed, they imported other outside sources and cited things and downloaded videos and it was pretty detailed. I wonder when your [Sophia Farquhar's] class did that, they weren't as detailed as this class for some reason. I think it's because for your tutorials there were more of them, but they were worth less points. They were two points each and I have these students do less tutorials for higher marks, and so I wonder if that has something to do with it. They only do three of them this semester and then any additional ones that we have to do by accident like if there's a snowstorm or something and I want to stay on schedule with the readings those only become extra points but they aren't officially part of the tutorial discussions.

Sophia: $\quad$ Do you feel that the asynchronous nature of the discussions being on canvas gets in the way of discussion or our students logging back in and adding to it?

Alex: $\quad$ For the keen students they get on there and do it during the class time. I think who it harms is students who are less motivated or I have a couple 
students who seemed to work. If class is canceled it's like they have a job, they are at Walmart working, then they just tend to go on and do something quick one post. I'm not sure how to help them. I don't know if it's the format or they just don't have enough time.

Sophia: I was just asking because I know that was something Professor Ott discussed and that was kind of her experience. Do you think that there is a way that Canvas could be better designed to help with things in the course?

Alex: $\quad$ I'm not sure.

Sophia: Is there anything that's annoying to you after you've been using in the class that you wish it wasn't that way?

Alex: $\quad$ So much of my class is about talking about the material and having discussions that we don't need a lot of visuals and stuff. When I want to use videos and stuff I will embed them into my PowerPoint and then when I download it and that works fine. Then I post PowerPoint on canvas so students can look back at them.

Sophia: $\quad$ So there's nothing about it that kind of bothers you as you use it or nothing that you think could be better?

Alex: I'm sure there is, I just don't tend think about it, I'm kind of set in my ways but I think what would be helpful is to see how other professors use it and kind of get ideas. Something that was a problem was when I was grading the tutorial discussions I would have to go all the way back up to the homepage and then all the way back down to find the button that said switch tutorial group and my wrist would actually get sore. Canvas changed that.

Sophia: $\quad$ Linda Ott found that students would just tend to post and then not come back so it wasn't as much of a discussion as it was a post.

Alex: It depends on the group, really with this group it's much better. It's an actual discussion.

Sophia: How narrow would you say the window for people to comment is? How long do you leave it open?

Alex: $\quad$ This one was pretty narrow, only 48 hours.

Sophia: $\quad$ Do you find that it makes a makes a difference?

Alex: $\quad$ Yes, it can't be too short or too long, 48 Hours seems to be the sweet spot. And I warned them about it many times, I send them an announcement saying 'hey it's coming up get ready' And they had to do something to 
prepare for it, so they had to do that ethical cycle thing. That helped too because they didn't want to do all that work going to the ethical cycle by themselves and they don't get to implement it. The only way they get to implement it is in the group. I didn't actually see that individual work unless they shared it with the group in the discussion group so that probably really helped too.

\section{Interview with Linda Ott}

Sophia: Is the University stated ethics goal of the course is it go for or goal 8?

Linda: $\quad$ you think I actually even know that? (Laughs)

Sophia: $\quad$ or maybe you don't use the goal 4 or 8 ?

Linda: I think I put it on the website but I'm not sure if it's the university or the ABET goals. I have the ABET outcomes on the course website. For ABET there is goal 4 for both software engineering or CS they are slightly different. 4 says to recognize professional responsibilities and make informed judgments in Computing practices based on legal and ethical principles

Sophia: I can just look at it if it's on the course website.

Linda: I don't have goal numbers here. Its says to focus on global literacy, communication and social responsibility.

Sophia: I can just read through those then. what is your goal for the course, obviously it's less formal than the ABET goals but what are you trying to teach in the course?

Linda: To get students to think about the consequences of and the impact of what they do. Or minimally [for students] to be aware that they aren't thinking about it. I can't remember what I asked the class today but it had something to do with the consequences of stuff they develop. Most of the class was interested in whatever they developed being used for good, a few people who were just interested in developing regardless of what it's used for and in some sense some students are like that. But minimally my goal is for them to be aware that they are like that. Maybe that's sitting my standards low, but [I want them] to recognize that what they develop actually gets used and and tell them that what they do may impact how it gets used. Really I want them to think.

Sophia: What would you consider to be the distinction between this course and the ethics course in the philosophy department? 
Linda: $\quad$ Probably the biggest difference or a big difference is that I expect them to have a fair amount of technical knowledge and use that technical knowledge in the considerations so that when they are making evaluations of situations it's coming from a basis of understanding what they can and actually can't do. A realistic understanding of the situation as opposed to sort of a generic, made up understanding of what the issues are.

Sophia: What textbook do you use the course, if use a textbook?

Linda: I don't use a textbook. I used to use one but it was so freaking out of date. I do have them get the writing book but it's not for the ethics part it's just so they have some help writing. The textbook was nice because it gave them a source for the ethics part and it covered a lot of different topics like computer reliability and computer security but the technological part was just very out of date. When I first started teaching the course textbooks could stay relevant for a while but I mean this year textbooks don't talk about the congressional hearings, that people are getting called up to and I think that's what makes the course relevant.

Sophia: What would your biggest concern about software engineering ethics in the field be?

Linda: Do I have to have one?

Sophia: I I can try to phrase it the same way I did for Alex this morning. If you were to say that there was one concern about an engineer leaving college and going into the field and they are being educated in the current standard of Ethics education what would you say a big challenge once they get to the field is?

Linda: I think it's changed some just this past year in my view in a sense that until really recently my concern was that they really didn't take ethics seriously and then they didn't think that they were ethical decisions to be made and their job or that it was going to be very rare other than people telling you to do something illegal or something like that. But that it would be how the software was used and how the software was designed but the impact of their software I don't think it had hit most students. With all the press around the last election and around Facebook and the issues coming out to the news media I'm less concerned about them being completely oblivious that what they do has an ethical or social impact but [concerned with students] still not being prepared to make those decision or doing the thinking. That is a big change that I have seen in the course. I used to have to do a fair amount of time convincing them that this was actually important. I think it was Zuckerburg that was in congress the beginning of last semester so I turned it on and said 'so you do who do you think this course is relevant?'. I am not sure about being equipped to make those 
decisions but without the course they would just be totally unequipped. I'm not sure I'm doing any good but at least it's an attempt.

Sophia: $\quad$ Are we [the computer science department] one of the only departments that require an ethics course or do other departments require it as well?

Linda: $\quad$ We follow $\mathrm{ABET}$ requirements, I'm pretty sure all the engineering departments and programs will have a similar ABET requirement that talks about recognizing professional responsibilities and making informed judgments. I suspect the engineering one [ABET requirement] is pretty similar to other ones, recognizing corporate and professional responsibilities and making informed judgments. They [other engineering departments] might try to put it into other courses I don't know. I can't think of any EE [electrical engineering] courses that are similar.

Sophia: I looked at civil or environmental flow charts, but it looks like it just lets you pick between about 8 courses some of which are ethics and some are general philosophy.

Linda: $\quad$ That may be how they approach it there might just be a list of courses that hit the professional responsibility requirement.

Sophia: How do you think the course is addressing the concern that you mentioned, the students being unequipped to make the ethical decisions?

Linda: Most often I'm not sure. But of all the courses I've ever had the alumni tell me about the one they mention the most often is the ethics course, that it actually has had an impact, so apparently it does. But when I read the papers I'm just never sure.

Sophia: That's really good to hear.

Linda: It's always been a bit surprising but that is one of the courses that most often the alumni tell me about. They say 'remember that time we talked about this and I didn't think it was that relevant but guess what'.

Sophia: How much responsibility would you say an engineer has to consider the ethics of the products they design considering that they are situated in the larger context?

Linda: I would think just to feel good as a human being you considerate it. I don't know if that answers your question but maybe that's just my personality but I find it hard to separate out the ethics. There might be people who say its absolutely necessary to produce war-mongering equipment whatever or defense applications but I can't. It seems like, and that was the article that I was going over today, but for people who don't think like [that war 
mongering technology is essential] that I would think you [the developer] just wouldn't even feel good about how the software you were developing is being used

Sophia: $\quad$ So how is the class currently structured on a day-to-day basis?

Linda: I'm doing things differently this time that I have in the past because it's a larger class. In the past I've typically structured it differently, when I tried to restricted to 30 students or less and then we typically had readings or something and then we would do a lot of class discussion as a class. This semester I'm doing a lot more of having the class just break up informally into small groups and I end up doing discussion that way and then talking about what they come up with [afterwards]. I didn't think very many people would participate if I have a class at 50 and I' $m$ trying to do class discussion that's just a lot of people. I actually think it's working better I actually think students are more engaged in the discussion and they're actually more into it which surprised me. So the focus of the course is broken into three parts over the semester. The first part we talked about the various ethical theories and then we do what we're doing right now which is cases. This semester I'm focusing a lot on current topics for the discussions and then at the end [of the semester] we do presentations. So those will be full length classes talking about a particular aspect about something that impacts society. I think that's probably one thing that I see as a little different from a pure ethics course is I sort of see this as part of it. Part of it is making the ethical decision-making but part of it is just becoming aware of the impact on society and what that means.

Sophia: In both the first second and third sections do you have group discussions in all the classes so even if you are reading articles you always having class discussion?

Linda: Almost everything I'm having in class discussions of one form or another.

Sophia: $\quad$ And after group presentations or no?

Linda: The group presentations? Probably not. I haven't quite figured out how I want to do that. I'm hoping we'll have some class time left for discussion [after the presentations] but that's less in my control once we get into group presentations.

\section{Sophia: Do you have lectures for teaching the ethical theories?}

Linda: Yes.I have a lecture with short little discussions a various questions like I might explain rule utilitarianism and then we had this stupid scenario that we all got bored of but each time we got a new theory we looked at the same scenario to see how it applied. 
Sophia: How long do the group discussions typically last for?

Linda: Today they were a pretty long 15 or 20 minutes and they were doing good stuff so I kind of let them go but typically they go for about 5 minutes and so we might do two or three [per class]. I was planning on doing that, more questions today but we only got through one because the discussion was pretty interesting. What I did today, and what I have been done before, was I had them read the article and then we had I had a list of some of the different ethical questions. For the homework they were just supposed to come up with an ethical question that was raised [in the article]. So then I had a list of six or eight ethical questions that were raised or related to the article and then I gave different parts of the class different theories to work with and then I let them pick the question from the ones that were raised. So we had some sort of different perspectives because of the different ways students were approaching the different questions. We had more questions so we had a lot of interesting discussion today. I didn't expect it, I thought I had to do something different because last class was so boring.

Sophia: What kind of interactions do the small groups have with you or each other once they're small group discussion finishes?

Linda: They're supposed to write something up and submit it on Canvas. Then I just ask the groups what they came up with and then we will talk a little bit [as a class] and get into small groups [again] and they come to different conclusions and look at it a different way and then we can go back and forth as a class. Actually last class everyone looked at utilitarianism and sort of talked about it and the different uses and today we talked about it, we kind of went across the groups to see the differences and then we go on to the next question.

Sophia: What would you say the biggest value that comes out of these discussions is?

Linda: To help them start to consider that they see the different factors than other people and other groups have raised, so that they start to see the complexity of the questions. And they start to get a sense to actually rationally reason about things rather than just kind of go with your gut. And I think sometimes when they see some of the other issues that other [groups] raised it just sort of broaden their perspectives.

Sophia: Is there something that you wish would happen with the small group discussions that doesn't usually is there a way there could be going better?

Linda: Today went good. I wish I could come up with articles that students could get into. I just never know, that's the tricky thing is that I am not very good at judging what they're actually going to find really [interesting and] get into it and talk about it. There definitely seems to be some things that they 
really get into and something's other kind of like ehh. So that's the thing, I wish there was a way to figure out or but I don't know if it's that the articles or if it's that concurrent was due the night before something. I mean last class seems to be deadly so I don't know what was going on then.

Sophia: How do students tend to react to having these types of discussions?

Linda: $\quad$ For the most part students seem to be getting into them. That was really the main thing I was concerned about was that they were going to be nonparticipatory, but they seem to be for the most part getting into it.

Sophia: $\quad$ So then do you use engineering ethics codes like the IEEE or Abet has one?

Linda: $\quad$ so I talked about the ACM code of ethics, is what you are referring to right? So the one I focus on the most is the ACM code of ethics, but I also point out the IEEE software engineering code of ethics which is joint between ACM and IEEE. I think it is the ACM one that we used and then we talked about there being other ones.

Sophia: How do you use them? Is it in a lecture or other method?

Linda: Its more of a lecture. I think I did have one question that I raised to have everyone sort of talk on.

Sophia: How would you say that the student reaction tends to be so these codes?

Linda: $\quad$ Can I say bored? (Laughs) I'm trying to think what's their reaction. I don't see them getting really excited about it, but I guess I don't really care as long as they know they exist. That they can be aware of some of the things. But they get more interested in talking about real stuff you know, like technology and applications, things that they can sort of see and think about.

Sophia: How do you choose which specific sections of the codes to focus on in class because they're pretty big big right?

Linda: So the ACM code you can sort of go over it at a high-level. The end part is more focused on professional management and things that are probably not of immediate concern to them, so I tend to focus on the earlier part of the code. Then I pick one or two things at a higher level and we look up the detailed statements. I think it's the ACM code and it really only has 3 or 4 high level sections.

Sophia: $\quad$ Do you have them apply the codes to something or do you just kind of go over it? 
Linda: This semester we just kind of went over it and then they applied it in the end during class discussions.

Sophia: Do you use case studies to talk about ethics in the course?

Linda: $\quad$ Not specific or formal case studies per se. I typically used news articles as a case study. So not a formal case study but a news article I will use as a case study, maybe as a case and not a case study.

Sophia: $\quad$ So if you are to try to explain utilitarian ethics and you were to apply it to a generic computer science problem to you kind of make something up or?

Linda: $\quad$ So when I was going over the theories I was just kind of making up a scenario. Something that doesn't require a lot of explanation, something that they can sort of easily identify with. Then I use the same sort of scenario when we go through each different kinds of situations, when introducing how rule utilitarian applies or social contract theory or whatever. And then sort of as I'm explaining those differences, then after that this semester I've been focusing on certain current events, and news articles and sort of applying things.

Sophia: So how do you choose news articles?

Linda: (laughs) what I am interested in and what I think they will be interested in. This is sort of again one of those differences between how I used to teach. I tend to choose them fairly spur-of-the-moment in a timely fashion. When I first started teaching this course, in ancient history, there just wasn't that much in the news about these kinds of issues and so I had to have a very different approach and now I will just the glancing through things and sort of just keep a list of some of the things I see and then I just sit down and pick from my list but there's usually just plenty out there nowadays.

Sophia: What are the typical topics of the ones that you choose?

Linda: $\quad$ Tend to choose? I would say I'm sure that varies from semester to semester. I think it pretty much depends on [the semester] like last semester a lot of stuff with privacy was coming up in the news. I want say that's not coming up this semester but there seems to be other things this semester for reasons I am not sure I've had several things related to war and military technology and stuff like that and I don't even think we touched on that at all last semester. So it's partly what's in the news and it's partly what will keep me interested.

Sophia: Do you think that the case studies accurately represent the types of challenges engineers will face in the field? 
Linda: In many cases they won't be aware of it, when they're in the field, you know, they'll be grinding out the code or whatever. I think in terms of them thinking about what they want to do and where they want to do it I think that particularly the current news articles they're looking at are relevant for that making those kind of [job search] decisions which might impact their need to make fewer or more frequent ethical decisions. If you choose the right place to go to work and you're working for a place where they company has a moral compass then it's probably easier not to worry about your own moral compass on a more regular basis. It's probably easier to do that but if you were to go to somewhere that doesn't have a strong moral compas or the company's moral compass doesn't align with yours [then you would have to make more frequent ethical decisions].

Sophia: Do you think the news articles tend to give an accurate amount of context?

Linda: It depends on the article. In some sense its what I want the students to notice is when that happens. Again because they have a technological background I think it is important for them to become smart readers, but also become aware of what others are reading, who might not understand that there's gaps and incorrect impressions coming through.

Sophia: Do you think that the case studies are sort of achieving the goal that you were hoping they would achieve?

Linda: I don't know yet because I am doing it differently this semester. I think it is looking promising but I don't know.

Sophia: How do the students tend to respond to the case studies?

Linda:: It depends if I pick interesting things apparently. Last semester I did get a comment from some of the students that they wished we had had more real situations that they're actually going to potentially encounter. Those are a little harder to come by you know, again because there's such a diversity of situations out there.

Sophia: $\quad$ When you say more like they would actually encounter does that mean the sort of big Facebook disaster is bigger than they would encounter or do you mean that they will be working in a different industry?

Linda: I think it's that kind of thing.

Sophia: $\quad$ The second one?

Linda: No the first one. Where they didn't foresee themselves being in a position where they had any impact on the decisions that would become congressional hearing worthy, but in some sense that's the whole point of 
what I was trying to make them aware of, you know? You never know how your software ends up getting used or a flaw in your software that ends getting you into sort of trouble or whatever.

Sophia: Did you end up choosing any case studies this year that were mundane?

Linda: $\quad$ Not yet, but I still have a few weeks before we have presentations. I think even like today there were some articles about the Hololens. I can see them, and I think they can see themselves, developing software like that, like the type being used on the Hololens. I think that they could have concerns about how that software ultimately ends up being used.

Sophia: What would you consider to be the ethics and philosophy back on that most students have coming into the course?

Linda: Religious training would be what's most apparent to me. Some of them will have taken an ethics course, one of the ethics courses over in humanities. That's probably it.

Sophia: $\quad$ Then how you choose which philosophy and ethics topics to cover in the course, so you chose virtue ethics for example, how do you choose which ones to cover?

Linda: I choose them mostly because that was what was originally in the book that I use years ago. I tended to stick with those probably for no good reason but that I'm comfortable with them yeah that's probably the heart of why.

Sophia: Is there anything else you were kind of half considering including or that you might be interested in going towards in the future?

Linda: Not that I can think of right now, but maybe that's because my brain is kind of turning off I'm enjoying the sun.

Sophia: How do you cover these topics, the base background in ethics and philosophy topics?

Linda: $\quad$ Mostly just boring lecture.

Sophia: Do you have them do any readings?

Linda: Do I tell them there are readings there for them to do? Yes. Do they do them? Certainly not.

Sophia: $\quad$ So the readings are on Canvas?

Linda: Yeah there are links and stuff. I'm pretty sure they don't read them or any of that stuff. They will read the articles though. 
Sophia: How do students tend to respond to these types of lessons?

Linda: I wouldn't say they're very excited about it. Some of them seem to get into it, some of them seem to like these logical ways of approaching these fuzzy hard problems. They like having some kind of a system, being good computer scientists they like having something that looks like steps. I think some of them don't see the relevance until we start looking at real issues. and there might be a way to approach it a little differently but I haven't come up with it.

Sophia: Do you feel that the students are leaving the course kind of with an understanding of ethics?

Linda: A lot of them do. I think they leave with at least some some sense that there are questions that one could be asking and that there are ways to think about them.

Sophia: What is the biggest gap in student understanding that you kind of wish you could address?

Linda: That they just don't know how to apply the theories. Or they find a theory that makes something ethical, when you're usually supposed to look at the question and then apply the theories. They're using it sort of backwards, the way a little kid will decide to ask mom or dad depending on what answer they want. It's amazing how quickly they learn that.

Sophia: $\quad$ Are you using any software outside of canvas in this course?

Linda: No. If there were something that were usable that would be nice, particularly if it would be more usable than Canvas. For some reason I've been making more mistakes this semester on Canvas, forgetting to give them a place to submit stuff, or forgetting on due dates, just really dumb stuff.

Sophia: Do you think a software program could help fill any of these gaps that you notice?

Linda: It could provide some structure that's not there. I mean I'm not quite sure what you're thinking, or what yours could do? I could see, it seems like there should be a way to do something that could provide some support and some structure.

Sophia: When you say support and structure for what exactly are you talking about?

Linda: $\quad$ So I'm sort of envisioning something like a grading program where they develop an argument or something and something says 'uh-uh,'. Maybe that's too strong, but I'm not really sure what exactly I'm thinking of. 
Something that could provide them with a structure for formulating their thinking or help some point out gaps in thinking or gaps and how they're using something. I'm not even quite sure what's feasible to be honest I haven't thought this through.

Sophia: How are you using canvas in this course I know that you agreed on it and sort of puts a references up but you use it for anything else?

Linda: I use it for posting assignments

Sophia: $\quad$ So more like a file transfer?

Linda: $\quad$ yeah

Sophia: Is there a way that Canvas could be better designed to sort of facilitate more discussion?

Linda: When I've been a student in a canvas situation, I haven't found the discussion feature is very useful and part of it's always been the asynchronous. So I'll post something, and then you know someone might not respond for who-knows-how-long by which time I sort of gone off on something else, I am no longer in that context of thinking about that or whatever, so I have to go back and look. I've never found those kinds of discussions very fruitful, so I haven't had much impetus to create them for the students and I'm not sure you could fix canvas to change that.

Sophia: $\quad$ That was my feeling when I had any kind of discussion too. I always felt that the asynchronous part was kind of an issue.

Linda: Yeah because particularly when you happen to be the kind of person that post something first. It diversity training or something that the university had that we had to do and it was only a week long so you would think that the conversations would somehow happen but it didn't until a lot of people just posted stuff at the end. A lot of people were just posting stuff to meet the obligation to post something and so it doesn't strike me as leading to a fruitful insights or discussions and I can't see I don't have an experience with a class where that would be good.

Sophia: $\quad$ Yeah, I mean our goal isn't to fix canvas it's more just to kind of provide a jumping-off point instead of saying 'what do you think this software that's currently an idea should do' it's more to say 'here's one that you're using and say what sucks about and how can it be better'

Linda: $\quad$ And that is sort of an issue. I don't know that there is a way to fix this problem because that's more a nature of people.

Sophia: (Explains Considerlt) 
Linda: I think that is true, most things legitimately have both pros and cons but it is how you weigh it that ultimately determines where you come down on an issue.

Sophia: $\quad$ (Explains differently weighted pro-con colors)

Linda: If you are trying to have a conversation you would have to have other people participate at the same time.

Sophia: $\quad$ What we are trying to do would be less of a conversation because we are trying to make it more timeless. If you are looking at a case study for example how Utilitarianism would view a case study, those things don't expire, they are timeless. And then what sort of happens if you can get saved responses for a particular topic then you can bring them up when they are useful to be able to get the comments right away instead of now where someone might comment something useful but you are already moving on, and so you sort of wish they had commented earlier. After using the software for a few years you could get a pretty good bank of "responses" allowing students to comment with related points right away.

Sophia: $\quad$ we are trying to avoid the trap of the software that we create just becoming marginally better than what is out there. And talking with professor Morrison we are trying to avoid software going on the lines of "there is only one right answer" so we are trying to get software that allows students to check themselves while also reminding students that there is no right answer. We are trying to pull elements from Considerlt. Alexandra Morrison uses the Ethical Cycle to consider the stakeholders. And another thing we want is for students to think about is: what social context is creating this problem? Could the company that you are working for start to break down the social context in order to get around the problem of two bad choices. A guided tour through the ethical cycle. We want students to be able to consider the complexity of the case study, because the news story talks about the on engineer, but the reality is he was probably checked by several different engineers and his manager was probably telling him to do something like that, so what does the environment look like, is this somewhere the engineer felt safe voicing these issues. We are thinking more of a survey style where if the questions make sense, you can use them, and if they are not connected you can click them away. I think one of Alex's big things is that technology isn't a neutral tool and people put their own opinions into it, making choices because of the way the designers were brought up, and so to think that you can just put it into the world and it is going to behave the way it is going to behave because of who interacts with it, isn't entirely accurate. There are things you could do, there are buttons you could gray out or not, there are buttons you could put in the center of the screen and those all have an 
impact on how many times they are clicked, and so we are trying to come up with a way that this could be registered in the software.

\section{Linda: That is something that came up in this semester. How we design the software does influence how it is used.}

Sophia: It makes sense that it would right? Some of the most important people at Apple are a group of like 13 people, people who design how the product feels in your hand and they are up there planning how they want you do interact with the device and then they get artists to design a device that makes you do that.

\section{Linda: It makes you do that}

Sophia: It makes you do that right and then the fonts they use give you a certain feeling and then the colors they choose give you a certain feeling and those people are highly paid because those decisions matter. It changes the way the user interacts with it, so those become ethical and moral decisions. I think part of the problem for me when I took the course, is that these cases don't apply to me. They are these giant bridge disasters, but there are so many ethical decisions that I am making everyday. It is a good example because it is wild and kind of interesting. But it is bad because, I shouldn't be in charge of a bridge (laughs) but also because it is so big. The bulk of my ethical decisions are much smaller. People make tiny ethical decisions every day, should I copy a friends homework, should I look up the answer to a canvas quiz, should I look at code on stack overflow and these questions, these are the kind of ethical questions that parallel what people do at work. Are they using a library that they don't really have a license for? Does the software they are writing have a bug in it but they will fix it in the next release? All of these questions, and the thing is, the pressures are kind of the same, people look at stack overflow because it is due tomorrow, and they will do the same thing at work because it is due tomorrow and I think those almost compare better ot the real world because it is something that you can start looking at in yourself and think oh my god I've done that, and it didn't matter but it could have. And I think that is something I want to put in it. I know there are a lot of things that she wants to put in it, but that is something I really want to put in it.

Linda: You are right. On a daily basis there are those little things that you know also can prepare or not prepare you for when something more challenging comes along, which often does happen at some point, or to be aware to even be looking for it, you know.

Sophia: I think it will start small though. Even if it turns out to be giant. In the paper she [Morrison] wrote there is a quote "by the time the critical decision happens, the decision has already been made" and the decision seems to 
big but it didn't start that way. And it is hard when you read case studies because almost no one knows, unless you were involved in the issue and you are now writing it, which most of the time doesn't happen

Linda: $\quad$ And it's often like you say, you do something because you are a little bit behind and you don't think anything of it and all the sudden the next thing you know you are down this path.

Sophia: A lot of programs are built like you do the first step and then the second and the third you can get yourself into a hole and now it is due tomorrow, and what do you do? You have made all these micro decisions up to the point and now what do you do? I feel like it is super boring to talk about that, but $i$ think that something that everyone in that class somewhere along the spectrum they can say "that describes me" and maybe they haven't copied it, but maybe they have read it and that's against the policy, or they have talked to someone in the class about it.

Sophia: I feel like you would have to write your own, there aren't many case studies that are mundane, they are all the big issues.

Linda: Fortunately there aren't many people who are involved in the big disasters, but that doesn't mean that they haven't faced ethical decisions and sometimes those ethical decisions may have had an impact.

\section{Interview with Marty Wolf}

Sophia: $\quad$ What types of courses do you teach at your University? Is it more ethics or computer scientist or both?

Marty: I'm a computer scientist, and I pretty much teach everything that we offer in our computer science program, from CS1 and CS2 all the way up to theory of computation, web development and mobile applications. We are small program.

Sophia: $\quad$ Do you guys have an engineering ethics course at your University?

Marty: We call it Social, Ethical, and Professional Issues in Computing and it is a required course for all of our computer science majors

Sophia: $\quad$ And do you teach that as well?

Marty: $\quad$ That's my responsibility to teach, at least typically. Some stuff went on this year and I'm not teaching it at all this year.

Sophia: $\quad$ What would you consider the goal of that course to be? 
Marty: $\quad$ The goal of the course is to develop within students the analytical abilities to consider ethical situations that would come up in their professional lives.

Sophia: $\quad$ That sounds pretty similar to a course that we have here. What would be your biggest concern currently about computer science ethics based in the professional environment?

Marty: In terms of my professional environment when students are actually no longer students and are working their jobs, my concern is that they don't feel empowered and as in as a junior person to bring up ethical considerations and ethical concerns that they might have with respect to the projects that they're working on.

Sophia: Do you think that the sociological and professional issues course helps to address that and if so how do you think that's addressing it?

Marty: I actually don't know whether a course can address that. Certainly it's not a goal of the course to teach them how to do that. We certainly talk about that that's something to be cognizant of while they are looking for jobs, and are interviewing for positions to be looking at what sorts of features a company has that would allow them to bring up those sorts of concerns. I advised them in that course that when they're asked at the end of an interview "do you have any questions?" one of the things that they ought to consider asking is "what sorts of mechanisms does the company have for for developers to raise social or concerns about ethical issues for projects that they're working on?"

Sophia: I have a couple questions for how the course is structured what does a typical class look like for the course?

Marty: $\quad$ Typically what I do is I will give students some small assignment, either at the beginning of class or at the end of the previous class, in which they are to read something or consider a case or something like that and then answer three or so questions about that particular thing. My philosophy is that if I do that sort of thing, then at least they can't say to me when they come to class that they don't have anything to say. They should have thought about those questions and they have written three four sentences about them. So when we get to class, depending upon the class size and what particular topic is, I'Il either have a general class discussion or I'II bring them into smaller groups, say three, four, maybe five students, and then give them a project related to the thing that I had assigned or it might just use what they did as the basis for for that assignment. They will do that for a little while and there's small groups and I'll monitor those small groups and then often times there's a concern that one or two or more of the small groups will raise and so I'll call the guys together and we'll focus 
on that particular thing for a little while and then the small groups report out and we'll have some wrap up where we identify the major themes that came out through that exercise. And then we will do that same sort of thing next time.

Sophia: How long would you say that the small-group discussions tend to last?

Marty: $\quad$ So the small groups... it tends to be 10 to 20 minutes depending on the complexity of the issue. Sometimes I'll actually plan it so that individual students will be assigned different areas of expertise. For example "you're supposed to think like a manager", "you're supposed to think like a developer", and then I might arrange the groups and put all of the kids who were supposed to think like developers together and have them share out and say what they could do as developers. Then I'll rearrange the group so that now there's a developer and a manager and a salesperson or whatever all in the same group. Now they have they can take on those different roles among themselves and their groups. So it usually it's about 20 minutes worth of that, and then sprinkled in there is probably another 10 minutes worth of lecture where they've identified issues that they are confused about and so that I lecture on those things. Then probably 10 minutes more of of the groups reporting out and then maybe 10 minutes more discussion on what were the major themes and what were the takeaways for that class.

Sophia: What is the main value that comes out of this small group discussion?

Marty: $\quad$ There are a couple of things. One is some confidence in the ability to talk about these things, the social and ethical concerns that the individuals might have. [Through group discussion] they learn to talk about these things, and they learn the vocabulary that they know, and they learn the vocabulary that their colleagues have, and they begin to also practice those sorts of analytical skills that I'm hoping that they can take away from the course. The second thing that I think they get out of those situations is the ability to consider a diversity of ideas. Different students bring different perspectives, either through who they are as individuals or they bring different perspectives because they've been assigned a different role to play for that particular exercise. They might realize "oh so this is how a manager might think about this problem and here I am a developer thinking about it this way, how can I use my consideration of how a manager might think to better understand this particular issue".

Sophia: Is there something you wish would be happening during these small-group discussions that isn't happening?

Marty: I don't think. I think it's more the other way around, sometimes there are some things that are happening that I wish weren't happening. The bear is 
from time to time there will be groups that get hung up on particular small points and and don't have the wherewithal to move on from that particular small point. So they get tripped up over a small thing rather than take that step back and say "okay what's the bigger problem here? What's the bigger project that we're working on?"

Sophia: $\quad$ Would you say that students are pretty engaged during these discussions?

Marty: $\quad$ Teaching this course is one of the most amazing experiences. I'm always the one at the end of the class time that says "class is over, you can go away now, it's okay, but if you want to stick around we can talk about this thing some more" and it's fairly common that I'll have half a dozen students stay and they will continue to discuss on a particular issue. It seems to me that students are engaged in this and they find it intriguing and interesting and so it's it's a good experience as far as I'm concerned teaching the course.

Sophia: $\quad$ So at our school student engagement is something that can sometimes be an issue for some of that instructors here and I' $m$ wondering, from your perspective, how your school doesn't tend to have this issue? I'm wondering whether you think it's something in a broader university sense? Or something that you're kind of doing early on?

Marty: You're at Michigan Technological University right? So I'm guessing that has a strong engineering focus? Am I right about that?

Sophia: Yeah.

Marty: Bemidji State University, we are about 4,500 students. And arts are part of the university's mission and so students are expected to at least be able to pay lip service to the humanities. So I think that's part of it, who our students are. The other thing that I think is a contributing factor is it is a computer science course is it is Computer Science 4390, I am a Computer Science faculty member, I think that lends legitimacy to the fact that the notion that this is a computer a real computer science course and not something else. Then I think there's something to be said about the nature in general of students that are attracted to the university. The university's mission has, in addition to the commitment to the liberal arts, a commitment to environmental stewardship, and a commitment to community service. Students that come to the university tend to be attracted to those things and so I think in some sense we start with a leg up that way.

Sophia: $\quad$ Yeah I was just wondering if you had a way of getting around it or whether it might just be a population demographics thing? 
Marty: It might be, yeah. And to be fair, there are some students that do see this as a burden that they have to get through. It's not each person that's for sure but there are a fair number of, a high percentage, that actually engage with these topics with some enthusiasm.

Sophia: $\quad$ Then do you use engineering codes in the course.

Marty: $\quad$ Yes, yes I do. I was on the leadership team for the most recent update to the ACM code of ethics so I have a tremendous amount of time invested into the ATM code of ethics and students are subject to my enthusiasm.

Sophia: I figured that might be the case when I saw some of the things that you have written on your website.

Marty: $\quad$ So often what I'll do is, I mentioned my typical classroom setup, so one of the things when we do come to talk about codes of ethics is I give the class a case and then I divide the class up into three groups and give them each a different code of ethics and then when they go home I have them think about the case with respect to their code of ethics. Then when they come to class I'll put them into groups go three where they each come at it with a different code of ethics and then they have some conversation about similarities and differences among the three codes of ethics that they've looked at.

Sophia: $\quad$ What would you say that the student reaction to using the codes is?

Marty: I think It's not too much different than anything else that I teach in the course. So in the course we cover things like utilitarianism, deontology, social justice theory, virtue ethics, and then the codes of Ethics too. I asked my students to use those things as analytical tools. Tools that they can dissect and think about and take the dives into issues that they might face. And I think, if I'm reading my students correctly, that's how they come away from the codes because it's just another tool in the toolbox to help them think through potential situations.

Sophia: $\quad$ Do you give lectures on the codes and if you do how do you pick and choose which section to lecture about or focus on?

Marty: $\quad$ Yes I do. The picking and choosing tends to come from points of confusion. I mentioned the typical class, where I'll stop and a lecture on a thing that seems to be coming out of the various small group activities, and so it'll be dynamic and depends on the particular set of students and the particular things that they seem to be missing or struggling with.

Sophia: $\quad$ Some students that I was talking to at Michigan Tech complain of how the codes are difficult to apply in practice because it's hard to know which 
section to prioritize or sometimes have trouble interpreting them and I was wondering, do you think this tends to be a misunderstanding of the students reading the code? or do you think there might be trying to use the code in a way that wasn't intended? or are they may be struggling with it being too high level and they're trying to apply it and really detailed way? What are your thoughts in this area.

Marty: $\quad$ So I think that complaint is actually fair and I'm suspicious that too many people think that doing ethics or doing this sort of ethical and social analysis is supposed to be straightforward. Most of the time, it's been my experience that doing ethics is hard. It's really hard work, it takes deep thought, it takes conversation with people from different backgrounds and different perspectives, it takes considering the various positions of a wide variety of stakeholders in order to deeply understand the situation. And the complaint is a fair one. The answer is I think you need to practice. You have to have conversations with colleagues and friends. You don't get good add it without practicing, without doing it. It's hard. The other thing that is present, certainly in the ACM code of ethics, is ultimately we say that the public good is the paramount consideration. So certainly we ask that the code be used and considered in its entirety and we understand that various principles in the code may come into contact with one another and part of doing ethics is parsing out the real conflict and figuring out and identifying ways to understand that conflict so that that thing can be addressed and then the other thing. In the code of ethics we call for doing all of this transparently, being clear with those around you what your concerns are, what your potential solutions are, and what the trade-offs of those solutions are. So it's not easy.

Sophia: How do you design the case studies that you used to aid in the teaching of the course?

Marty: Most typically I don't design them, I use the case studies found in the books that I use or I have found some on the internet.

Sophia: $\quad$ What do you think makes up a good case study?

Marty: So actually at $\operatorname{SIGCSE}^{10}$ I mentioned this when I presentations on this topic. It depends on who your audience is. So professors tend to like case studies with lots of detail, lots of nuance. Students tend to do better with case studies that are much thinner. They have fewer details and they do better with a case study if the details are added slowly as they are thinking about

${ }^{10}$ Wolf is referring to the SIGCSE Technical Symposium, a conference focused on improving computing education. SIGCSE stands for the Special Interest Group on Computer Science Education. 
it; They get to some sort of decision point and they need more information and that's when the details need to be added. So that's one feature that I consider. Another feature of case studies is people seem to gravitate towards case studies with a protagonist of some point of some sort, that sort of can be taken to task. Then another feature of a good case study is one that stops at in its description at some tense point in the story. So a good case study is like a good novel I guess or a good short story.

Sophia: Do you think that a case study that has the sort of strong individual protagonist with one major decision point, like what you mentioned before as things people respond to, accurately represents the kind of challenges faced by engineers in the field?

Marty: $\quad$ Probably not. My guess is in most professional settings things are murkier. So you have a sense that something untoward is going on but you don't have all the details and and you're not quite sure who is doing what. The objective is different. The reason that I use a case study in the class is to give students the opportunity to practice using be analytical skills that I want them to have and be good at. So that is different I think, then once you have the skills under your belt you can use them in a real life situation. This goes back to the point that I made before about the sort of case studies that I find interesting as a professor or as a scholar are the ones with the murkier details, that may matter or may not, and nuances that are unclear. I think that part of the reason that those are the sorts of case studies that are attractive to me, and attract a lot of professors and scholars, is because we can then use those analytical skills that we've developed. So it's the case that students are in a different place in their intellectual development as students than they are as actual practicing professionals.

Sophia: $\quad$ What would you say you consider to be the ethics and philosophy background that most students have coming into the course?

Marty: $\quad$ My assumption is that they don't have any. Occasionally I do have students who are either philosophy minors or have taken our Universities Ethics course and they are always stronger contributors to the class, especially early on, and I guess I'll try to leverage their expertise when it's time to putting small groups together and things like that. But my general assumption is that nope we have to start with the basics.

Sophia: You mentioned that you have a University Ethic's course. What would you consider to be the main distinction between that course and your course?

Marty: I don't know a lot about that course, but I think one of the main distinctions is: in our course we address professionalism and in the University Ethics course, to the best of my knowledge, that's not an issue 
that's addressed. So the whole aspect of codes of ethics, of what sort of special responsibilities you have as a computer scientist to society, that someone else in a different profession, a different job, might not have those sorts of responsibilities. There's also a strong thread through the course that says that says this is your job and you need to incorporate this into what you do professionally.

Sophia: How do you choose which philosophy and ethics topics to cover in the course? You have listed some of the ones that you do cover, but how do you choose which ones to cover?

Marty: $\quad$ Personal preference. It's also the case that I either tend to use Herman Tavani's book or Michael Quinn's book ${ }^{11}$ and those are ethical theories that are used by those two. After that both those books tend to go into other topics like privacy and network security and those sorts of things.

Sophia: How do you cover those topics, do the students do readings about those philosophy topics or is it covered mostly in lectures?

Marty: $\quad$ They do the readings in the textbook and then we do exercises as I described earlier in class to practice those ideas as analytical skills. So there might be a case study and "now you are a deontologist how would you approach this case?" and then when I put them in small groups I listen for linguistic cues that they are using deontological language, about rules and not violating the rules, and then if they start to slip into conversation about outcomes then it's like "oh no hold on a little bit there's a distinction that you need to be aware of".

Sophia: $\quad$ Do you find students respond to these lessons about as well as the other types of lessons?

Marty: It really depends on the class. Sometimes I'll get classes that just absolutely love class debate. They just want to debate about things. Then there are other classes where students just want to be in the small groups. They're not comfortable once the group gets beyond four or five students. But in those small groups they are talking to each other and they're having a lot of conversation. I tried to be responsive to that so that I can keep students engaged. I guess it depends.

Sophia: $\quad$ Do you feel that students tend to leave the course with the understanding and analytical skills and ethical reasoning that you're trying to give them and then what would your one biggest gap in student understanding be?

${ }^{11}$ Wolf is referring to Herman T. Tavani's Computing Ethics Textbook, the most recent edition is Ethics and Technology: Controversies, Questions, and Strategies for Ethical Computing, 5th Edition. The other book is Michael Quinn's Ethics for the Information Age. 
Marty: $\quad$ When students leave the course they have the knowledge of those analytical skills but they lack the comfort that comes with expertise. They still just struggle through using the techniques. I think this manifests itself as a lack of self-confidence as they leave the course, and with that lack of self-confidence, unless they end up in a professional environment that invites them to participate in those same sorts of conversation, what I'm worried about is that they're not confident enough to bring up ethical issues ethical concerns on their own and as they identify them in their professional career.

Sophia: $\quad$ Do you use any software in the course?

Marty: No

Sophia: Do you do any online discussions or is everything in person?

Marty: $\quad$ Everything is in person except for the final exam but that's not really the right term. The final evaluator piece is always a debate and so I'Il divide the class into the number of teams and identify a particular issue. So then the teams end up putting together an argument either for or against the particular position. Then their responsibility is to research the thing and research the issue and develop arguments for and consider counterarguments against so that they're ready to take those ideas on. So in that sense yes, I'm sure some discussion does happen offline because those teams get together outside of class and put together their their components of this final debate.

Sophia: Do you think any kind of software program would help with any part of the course?

Marty: I don't know and it probably would depend on what that piece of software did. I know a colleague of mine has in the past used a piece of software to essentially walk students through the process of getting to a decision point, and then they make a decision, it's some sort of role-playing type software. I've just not really found a need for that or a desire for that sort of stuff.

Sophia: $\quad$ So that is all the questions that I had. Ss there any other big topics about engineering ethics or trying to better understand teaching ethics to Computer Science majors that I didn't cover?

Marty: $\quad$ No. Well, yes actually. I have lots of ideas. One of the big things that we were actually addressing at SIGCSE was the notion that we need to have ethical considerations built into the curriculum really throughout it. Having this one off course at the end, especially having the one-off prize at the end not taught by computer scientist, sends a message that ethics is something that you do at the end or something that you get someone else 
to do and so I think that that's a problematic message. What we are trying to do at SIGCSE was to help folks develop assignments for their "technical courses", CS1, CS2, Algorithms, that allow them to embed ethical considerations into the assignments. We gave some strategies and techniques for developing that sort of assignment. There are a number of projects and things that are going on out there that are nudging computer science in that particular direction. They're developing the code of ethics, one of the things that we did realize and something that is sort of embodied in the following saying: "it used to be that we did computer science for computer science's sake; now we do computer science for society's sake" and so we have sort of gone from a discipline that used to be focused inside to a discipline that's now focused externally. It's tough enough to understand the technology but to understand society and human beings and individuals that's complicated. Really this needs to be an integrated effort up and down the Computer Sciences and further on. 